University of Tennessee Health Science Center

UTHSC Digital Commons

\title{
Psychometric Evaluation of the Nursing Child Assessment Teaching (NCAT) Scale in Two Samples of Mothers and Children
}

\author{
Samantha H. Ransone \\ University of Tennessee Health Science Center
}

Follow this and additional works at: https://dc.uthsc.edu/dissertations

Part of the Maternal and Child Health Commons, and the Maternal, Child Health and Neonatal Nursing Commons

\section{Recommended Citation}

Ransone, Samantha H. (http://orcid.org/0000-0001-5106-7588), "Psychometric Evaluation of the Nursing Child Assessment Teaching (NCAT) Scale in Two Samples of Mothers and Children" (2017). Theses and Dissertations (ETD). Paper 438. http://dx.doi.org/10.21007/etd.cghs.2017.0430.

This Dissertation is brought to you for free and open access by the College of Graduate Health Sciences at UTHSC Digital Commons. It has been accepted for inclusion in Theses and Dissertations (ETD) by an authorized administrator of UTHSC Digital Commons. For more information, please contact jwelch30@uthsc.edu. 


\title{
Psychometric Evaluation of the Nursing Child Assessment Teaching (NCAT) Scale in Two Samples of Mothers and Children
}

\begin{abstract}
The mother-child relationship (MCR) has received an increasing amount of attention over the last several decades regarding its effect on long-term child development. Because the quality and quantity of interactions in the MCR have been established as important predictors of the child's development, early identification of areas in the relationship requiring support and intervention is essential for promoting positive child outcomes. Observational assessment of the mother and child is considered best practice in evaluating maternal-child interaction (MCl). The Nursing Child Assessment Teaching (NCAT) scale is an instrument that has been used to quantify the quality of interaction in the MCR during the first 36-months of a child's life. While studies have shown the NCAT scale as both a reliable and valid instrument, limited evidence exists confirming theoretical congruence between the scale and the Barnard Model it is based on. These analyses were conducted using data from two large, demographically different samples, the Nursing Child Assessment Satellite Training (NCAST) database and the Conditions Affecting Neurocognitive Development and Learning in Early Childhood database. Item response theory, confirmatory factor analysis, and multiple indicators multiple causes modeling were used to examine the psychometric properties of the NCAT scale and describe the interactions between mothers and children from these samples. Results of analyses offer support for the Barnard Model and the potential for instrument abbreviation, which may provide researchers and practitioners a more concise, reliable way of measuring $\mathrm{MCl}$. In addition, the predictive validity of both the full NCAT scale and resulting abbreviated NCAT scale (NCAT-AB) was established by obtaining Pearson correlations and associated probabilities for $\mathrm{MCl}$ at 12-months, measured by the NCAT and NCAT-AB, and child cognitive and language development at 36-months, as measured by the Bayley Scales of Infant and Toddler Development, Third Edition. This study provided critical appraisal of the NCAT scale, supported the continued use of the NCAT scale in evaluating $\mathrm{MCl}$, and contributed to the growing body of literature surrounding the importance of the MCR on early child development.
\end{abstract}

\section{Document Type \\ Dissertation}

\section{Degree Name}

Doctor of Philosophy (PhD)

\section{Program}

Nursing Science

\section{Research Advisor}

J. Carolyn Graff, Ph.D.

\section{Keywords}

mother-child interaction, NCAT, nursing child assessment teaching scale, other-child relationship, parentchild interaction, psychometric evaluation

\section{Subject Categories}

Maternal and Child Health | Maternal, Child Health and Neonatal Nursing | Medicine and Health Sciences | Nursing 
Psychometric Evaluation of the Nursing Child Assessment Teaching (NCAT) Scale in Two Samples of Mothers and Children

\author{
A Dissertation \\ Presented for \\ The Graduate Studies Council \\ The University of Tennessee \\ Health Science Center \\ In Partial Fulfillment \\ Of the Requirements for the Degree \\ Doctor of Philosophy \\ From The University of Tennessee
}

By

Samantha H. Ransone

May 2017 
Copyright (C) 2017 by Samantha H. Ransone. All rights reserved. 


\section{DEDICATION}

I dedicate this work to my best friend and husband, Alex. I am thankful for your love, support, and willingness to play golf every weekend so I could take the time to write. I am also grateful to my parents and sister for continuously supporting my overachieving tendencies; I think it finally paid off. And I am grateful to my friends who have laughed with me, cried with me, and given of themselves to help me succeed. 


\section{ACKNOWLEDGEMENTS}

I would like to thank the mothers and children who participated, and are continuing to participate, in the Conditions Affecting Neurocognitive Development and Learning in Early Childhood (CANDLE) Study. You will never know the extent of your contributions to the expanding field of early child development. I would also like to thank the CANDLE team of investigators for their big picture thinking in development of the CANDLE Study and particularly for their collaboration during my doctoral research.

I would also like to thank Dr. Monica Oxford for providing me with incredible insight into the Nursing Child Assessment Teaching Scale instrument, for pushing me to think deeper, and for supporting my research so enthusiastically. I would like to thank Dr. Andrew Bush for equipping me with new knowledge, expanding my horizons, teaching me so patiently, being my statistics "wizard", and making me laugh. I do not know what I would have done without you these last three years. I would also like to thank Dr. Mona Wicks for her critical, yet nurturing spirit when reviewing, editing, and giving me feedback on my work. Your encouragement and probing always came at the right time and in the right order. I would also like to thank Dr. Kristen Archbold for her support of my work and pushing me to consider the next steps of my research career.

Lastly, I would like to thank Dr. Carolyn Graff, my dissertation committee chairperson, for gently guiding my thoughts in new directions, always being a listening ear, and helping me grow both personally and professionally. Your supportive nudging has introduced me to a world of research I never would have thought about entering on my own. And, most importantly, I have learned from and enjoyed the iterative process of it all! 


\begin{abstract}
The mother-child relationship (MCR) has received an increasing amount of attention over the last several decades regarding its effect on long-term child development. Because the quality and quantity of interactions in the MCR have been established as important predictors of the child's development, early identification of areas in the relationship requiring support and intervention is essential for promoting positive child outcomes. Observational assessment of the mother and child is considered best practice in evaluating maternal-child interaction (MCI). The Nursing Child Assessment Teaching (NCAT) scale is an instrument that has been used to quantify the quality of interaction in the MCR during the first 36-months of a child's life. While studies have shown the NCAT scale as both a reliable and valid instrument, limited evidence exists confirming theoretical congruence between the scale and the Barnard Model it is based on. These analyses were conducted using data from two large, demographically different samples, the Nursing Child Assessment Satellite Training (NCAST) database and the Conditions Affecting Neurocognitive Development and Learning in Early Childhood database. Item response theory, confirmatory factor analysis, and multiple indicators multiple causes modeling were used to examine the psychometric properties of the NCAT scale and describe the interactions between mothers and children from these samples. Results of analyses offer support for the Barnard Model and the potential for instrument abbreviation, which may provide researchers and practitioners a more concise, reliable way of measuring MCI. In addition, the predictive validity of both the full NCAT scale and resulting abbreviated NCAT scale (NCAT-AB) was established by obtaining Pearson correlations and associated probabilities for MCI at 12-months, measured by the NCAT and NCAT-AB, and child cognitive and language development at 36-months, as measured by the Bayley Scales of Infant and Toddler Development, Third Edition. This study provided critical appraisal of the NCAT scale, supported the continued use of the NCAT scale in evaluating MCI, and contributed to the growing body of literature surrounding the importance of the MCR on early child development.
\end{abstract}




\section{TABLE OF CONTENTS}

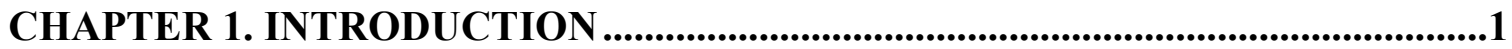

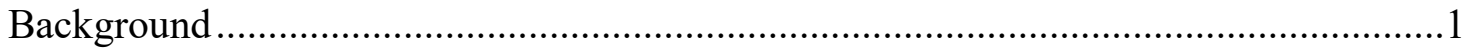

Conceptual Foundations and Framework .................................................................2

The Nursing Child Assessment Teaching Scale ...........................................................

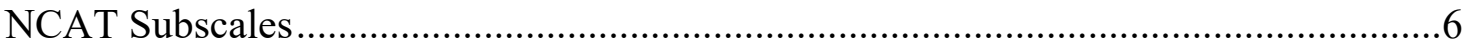

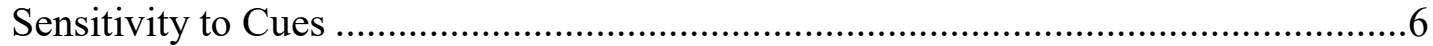

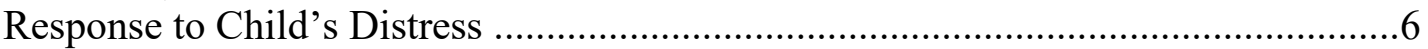

Social Emotional and Cognitive Growth Fostering ................................................ 7

Clarity of Cues and Responsiveness to Caregiver ................................................... 7

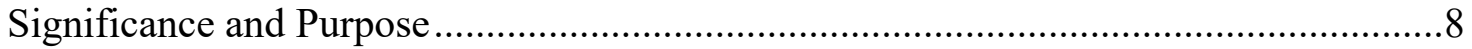

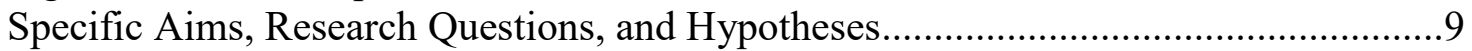

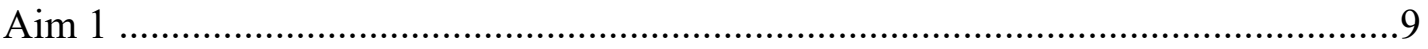

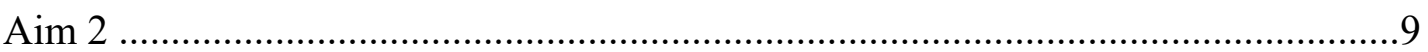

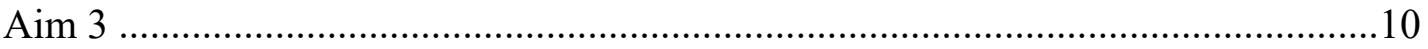

General Description of Populations under Study ….......................................... 11

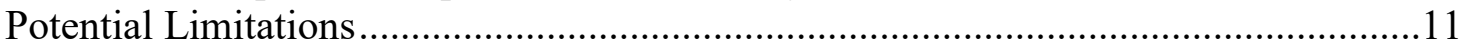

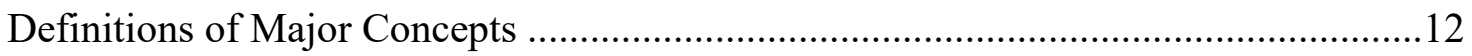

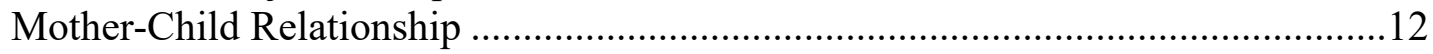

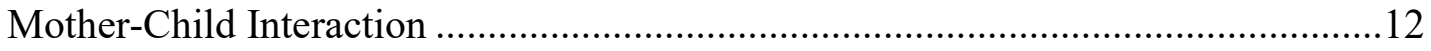

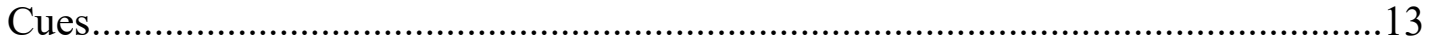

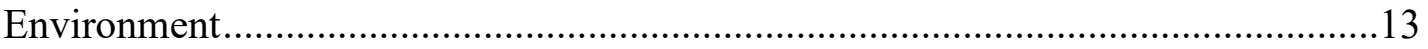

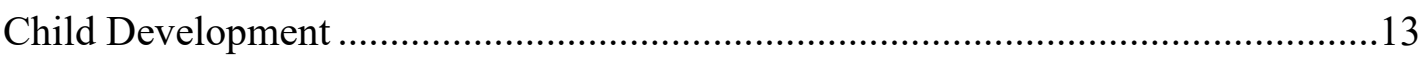

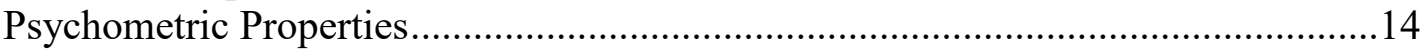

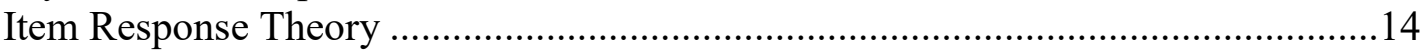

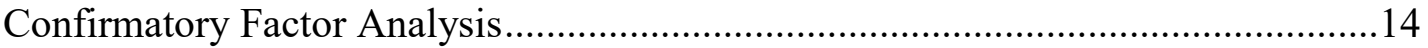

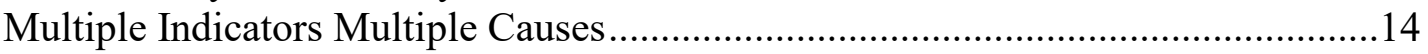

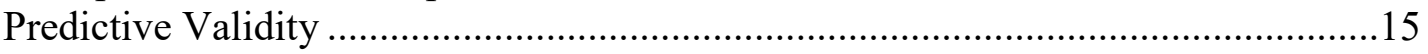

\section{CHAPTER 2. PSYCHOMETRIC EVALUATION OF THE NURSING CHILD} ASSESSMENT TEACHING SCALE USING THE NURSING CHILD ASSESSMENT SATELLITE TRAINING DATABASE ....................................16

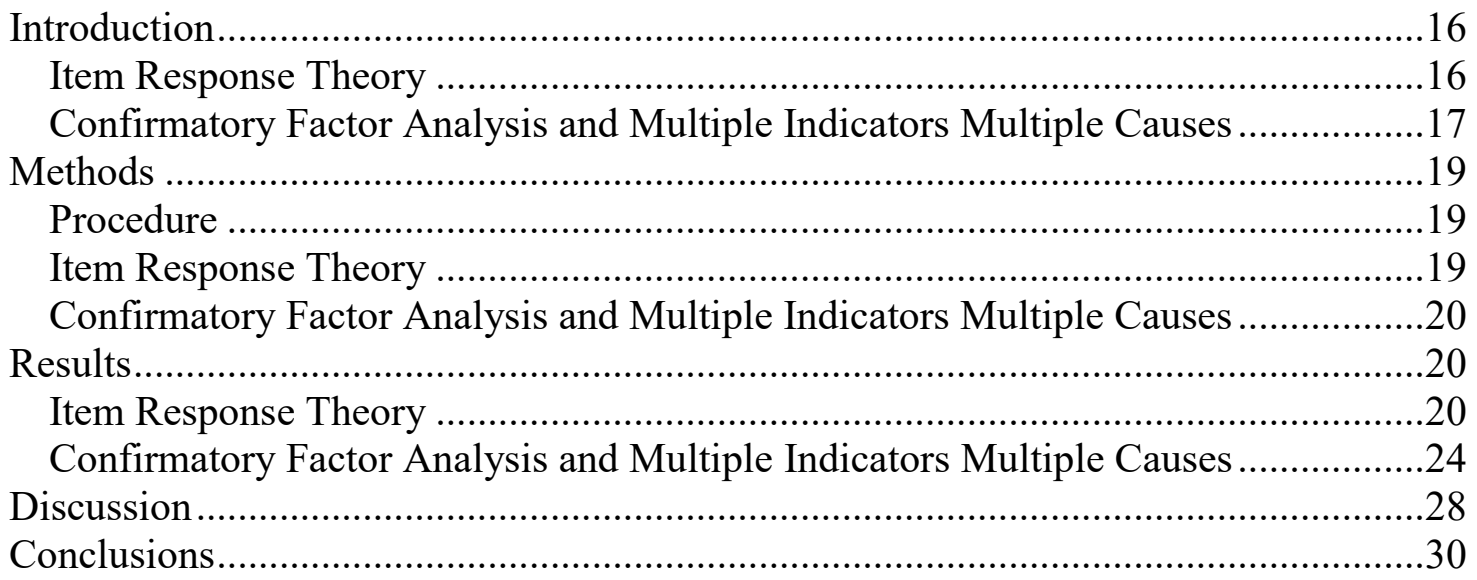




\section{CHAPTER 3. PSYCHOMETRIC EVALUATION OF THE NURSING CHILD ASSESSMENT TEACHING SCALE IN A COMMUNITY BASED SAMPLE OF MOTHERS AND CHILDREN FROM THE CONDITIONS AFFECTING NEUROCOGNITIVE DEVELOPMENT AND LEARNING IN EARLY

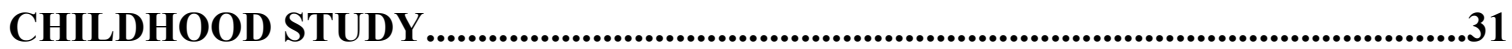

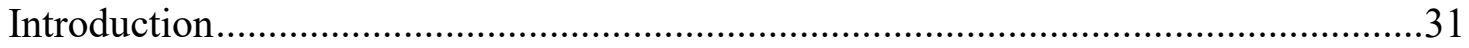

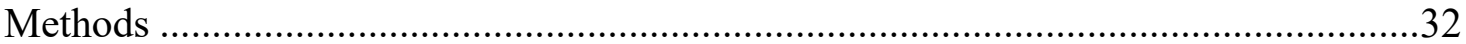

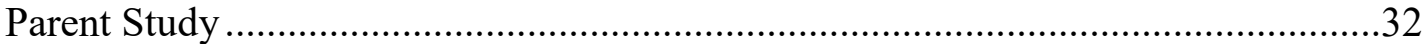

The Nursing Child Assessment Teaching Scale Instrument ...................................33

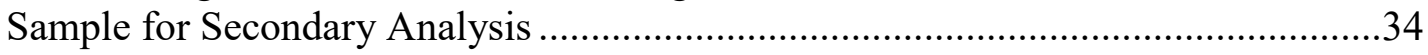

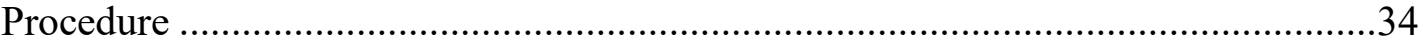

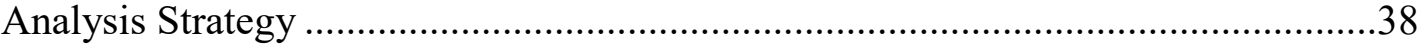

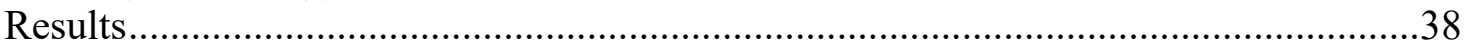

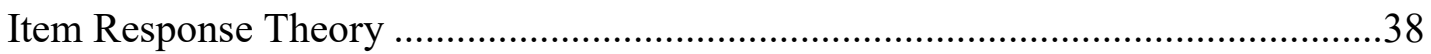

Confirmatory Factor Analysis and Multiple Indicators Multiple Causes ..................39

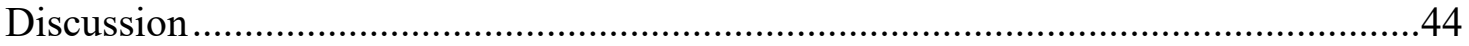

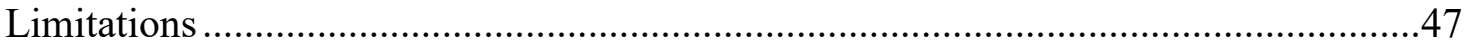

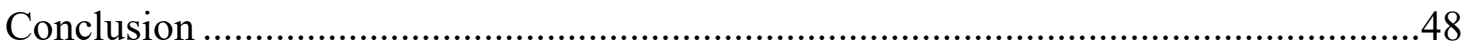

CHAPTER 4. PREDICTIVE VALIDITY OF THE NURSING CHILD

ASSESSMENT TEACHING SCALE IN A COMMUNITY BASED SAMPLE OF MOTHERS AND CHILDREN FROM THE CONDITIONS AFFECTING NEUROCOGNITIVE DEVELOPMENT AND LEARNING IN EARLY

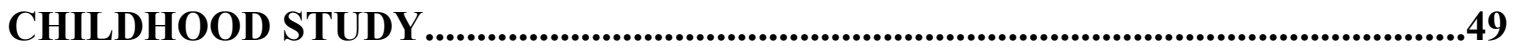

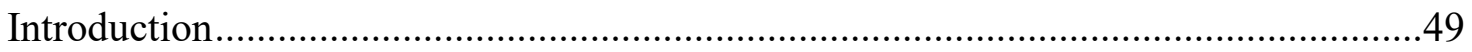

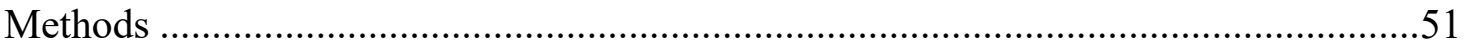

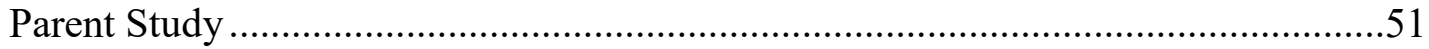

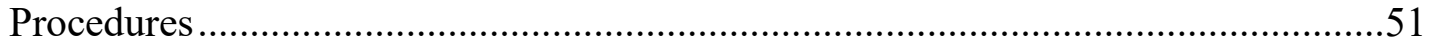

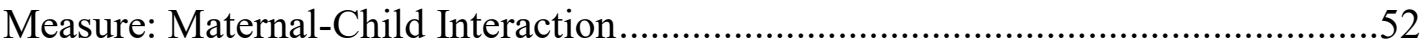

Measure: Child Cognitive and Language Development ..........................................52

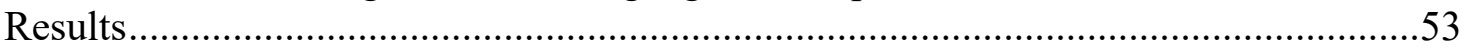

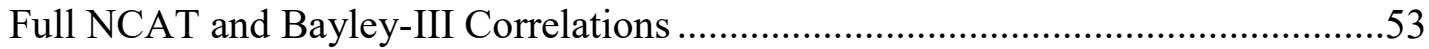

Associations of Scores Within the Full NCAT Scale ............................................53

Associations of Scores Within the Bayley-III.....................................................53

Associations Between Full NCAT Scale Scores and Bayley-III Scores ...................56

NCAT-AB Scale and Bayley-III Correlations ......................................................56

Associations of Scores Within the NCAT-AB Scale .............................................56

Associations Between Abbreviated NCAT Scale Scores and Bayley-III Scores ......58

Comparison of Associations from the Full and NCAT-AB Scale ...........................58

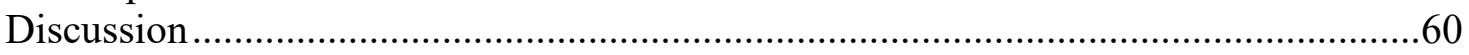

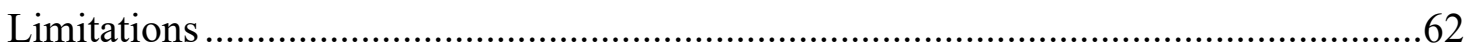

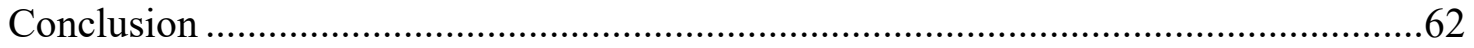




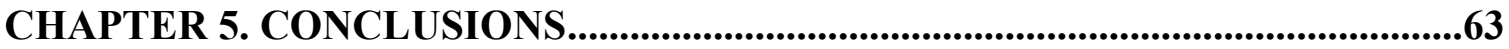

Overall Summary of Findings................................................................................63

Psychometric Evaluation of the Nursing Child Assessment Teaching Scale in

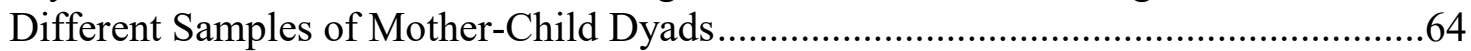

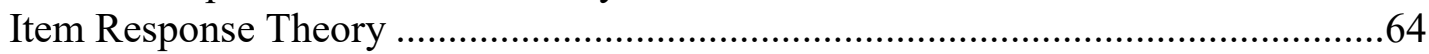

Confirmatory Factor Analysis and Multiple Indicators Multiple Causes

Modeling

The Predictive Validity of the Full and Abbreviated Versions of the Nursing Child

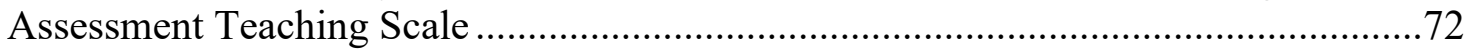

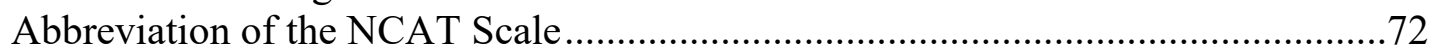

Reliability and Validation of the NCAT Scale ………...........................................73

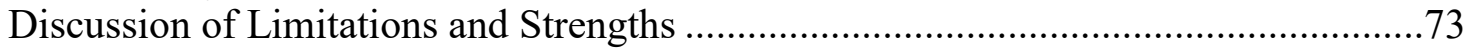

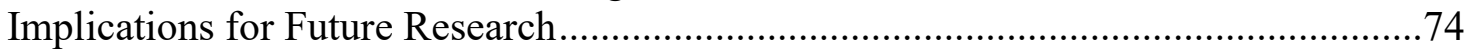

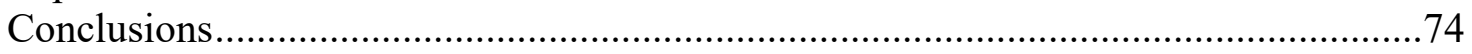

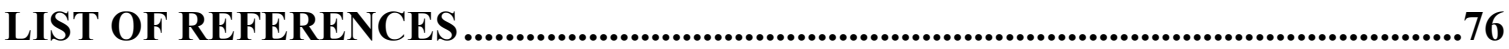

APPENDIX A. TWO-PARAMETER ITEM RESPONSE THEORY

DIFFICULTY AND DISCRIMINATION BY SUBSCALE FOR THE NURSING

CHILD ASSESSMENT SATELLITE TRAINING DATABASE ..................................86

APPENDIX B. REMOVED NURSING CHILD ASSESSMENT TEACHING SCALE ITEMS BY SUBSCALE FROM ANALYSIS WITH THE NURSING

CHILD ASSESSMENT SATELLITE TRAINING DATABASE

APPENDIX C. TWO-PARAMETER ITEM RESPONSE THEORY

DIFFICULTY AND DISCRIMINATION BY SUBSCALE FOR THE NURSING

CHILD ASSESSMENT SATELLITE TRAINING DATABASE .

APPENDIX D. TWO-PARAMETER ITEM RESPONSE THEORY

DIFFICULTY AND DISCRIMINATION BY SUBSCALE FOR THE NURSING

CHILD ASSESSMENT SATELLITE TRAINING DATABASE

VITA 


\section{LIST OF TABLES}

Table 2-1. Demographic Characteristics of the NCAST Database for Secondary Analysis

Table 2-2. Item Discriminations by Category and Subscale Factor for the NCAST

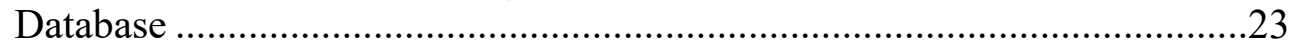

Table 2-3. CFA Factor Loadings of the NCAT Scale for the NCAST Database...........25

Table 2-4. MIMIC Models for Significant Demographic Predictors in the NCAST Database

Table 2-5. Model Fit Without Item Association for the NCAST Database ...................29

Table 2-6. Final Model Fit with Item Association for the NCAST Database................29

Table 3-1. Examples of NCAT Items Observations by Subscale .....................................35

Table 3-2. Demographic Characteristics of the CANDLE Database for Secondary Analysis

Table 3-3. Item Discriminations by Category and Subscale Factor for the CANDLE Database

Table 3-4. CFA Factor Loadings of the NCAT Scale for the CANDLE Database .......41

Table 3-5. MIMIC Models for Significant Predictors in the CANDLE Database..........43

Table 3-6. Model Fit Without Item Association for the CANDLE Database .................45

Table 3-7. Final Model Fit with Item Association for the CANDLE Database..............45

Table 3-8. Cronbach's Alphas $(\alpha)$ for the NCAT-AB Scale Scores before and after Item Reversal in the CANDLE Database.

Table 4-1. Pearson Correlations Within and Between Full NCAT Scale Scores at 12-Months and Bayley-III Scores at 36-Months Using the CANDLE Database

Table 4-2. Correlations Between Scores Within the Bayley-III Instrument 55

Table 4-3. Pearson Correlations Within and Between NCAT-AB Scale Scores at 12-Months and Bayley-III Scores at 36-Months Using the CANDLE Database

Table 4-4. Full NCAT Scale Total and NCAT-AB Scale Total Correlations with Other Scale Totals and Subscale Scores 
Table 5-1. Removed Items by Subscale from the NCAT Scale for Low Variability in the NCAST and CANDLE Databases.

Table 5-2. Negatively Correlated Items by Subscale Reverse Coded for Analyses in the NCAST and CANDLE Databases.

Table 5-3. Shared Demographic Predictors by Subscale Between the NCAST and CANDLE Databases from MIMIC Modeling.

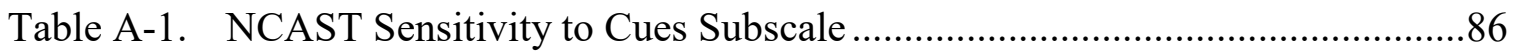

Table A-2. NCAST Response to Distress Subscale ..................................................86

Table A-3. NCAST Social Emotional Growth Fostering Subscale .............................87

Table A-4. NCAST Cognitive Growth Fostering Subscale ......................................87

Table A-5. NCAST Clarity of Cues Subscale ......................................................... 88

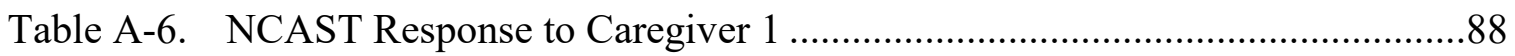

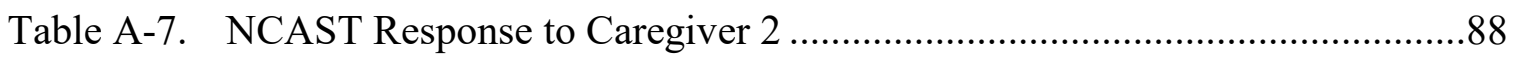

Table C-1. CANDLE Sensitivity to Cues Subscale ...................................................90

Table C-2. CANDLE Response to Distress Subscale ............................................90

Table C-3. CANDLE Social Emotional Growth Fostering Subscale ..........................91

Table C-4. CANDLE Cognitive Growth Fostering Subscale ....................................91

Table C-5. CANDLE Clarity of Cues Subscale....................................................92

Table C-6. CANDLE Response to Caregiver 1 ......................................................92

Table C-7. CANDLE Response to Caregiver 2 ....................................................... 92 


\section{LIST OF FIGURES}

Figure 1-1. The Child Health Assessment Model ..........................................................4

Figure 1-2. The Barnard Model ….............................................................................

Figure 2-1. Item Characteristic Curve for the Social Emotional Growth Fostering (SEGF) Subscale ......................................................................21 


\section{LIST OF ABBREVIATIONS}

$\begin{array}{ll}\text { CANDLE } & \begin{array}{l}\text { Conditions Affecting Neurocognitive Development and Learning } \\ \text { in Early Childhood } \\ \text { CC }\end{array} \\ \text { Clarity of Cues } \\ \text { CFA } & \text { Confirmatory Factor Analysis } \\ \text { CG } & \text { Comparative Fit Index } \\ \text { CGF } & \text { Caregiver } \\ \text { IRT } & \text { Cognitive Growth Fostering } \\ \text { MCI } & \text { Item Response Theory } \\ \text { MCR } & \text { Maternal-Child Interaction } \\ \text { MIMIC } & \text { Mother-Child Relationship } \\ \text { NCAST } & \text { Multiple Indicators Multiple Causes } \\ \text { NCAT Scale } & \text { Nursing Child Assessment Satellite Training } \\ \text { NCAT-AB Scale } & \text { Nursing Child Assessment Teaching Scale } \\ \text { RC } & \text { Abbreviated Nursing Child Assessment Teaching Scale } \\ \text { RD } & \text { Response to Caregiver } \\ \text { RMSEA } & \text { Response to Distress } \\ \text { SC } & \text { Root Mean Square Error of Approximation } \\ \text { SEGF } & \text { Sensitivity to Cues } \\ \text { SES } & \text { Social-Emotional Growth Fostering } \\ \text { TLI } & \text { Socio-Economic Status }\end{array}$




\section{CHAPTER 1. INTRODUCTION}

\section{Background}

The mother-child relationship (MCR) has received an increasing amount of attention over the last several decades, specifically regarding its influence on long-term, comprehensive development of the child. Widely recognized as one of the most important relationships a person experiences in life, the MCR provides a complex context for understanding the developing child. From the beginning of research and clinical work surrounding the MCR, there has been a persistent debate about the effects of nature and nurture. Researchers and clinicians across various disciplines such as psychology, medicine, and nursing have come to realize the combined effect both nature and nurture have on the developing brain and have emphatically proclaimed the first three years of a child's life as the most crucial time period for cognitive and social-emotional development (Bornstein \& Tamis-LeMonda, 2010; National Scientific Council on the Developing Child, 2007; Brain Development, 2016). This proclamation is based largely on the expanding knowledge of the science on brain development.

Beginning in pregnancy, the physical, emotional, mental health and health habits of the mother along with the stress of the mother's environment directly impact the developing brain of the unborn child (Goswami, 2014; Lester, 2010; Monk, Spicer, \& Champagne, 2012; Salisbury, Yanni, Lagasse, \& Lester, 2005). Factors like maternal depression, drug and alcohol abuse, and poor nutrition are thought to reprogram the brain of the fetus by altering biologic set points (Lester, 2010; National Scientific Council on the Developing Child, 2010). This alteration is considered an adaptive and protective strategy. Through a process labeled fetal programming, the brain of the unborn child begins to learn and adapt to the environmental stressors within the womb as preparation for the postnatal world (Lester, 2010).

Postpartum, it is through the context of the MCR that newborn babies and infants begin to understand and interact with the world around them. From basic needs like nursing and temperature regulation in the neonatal period to more complex needs for affective touch and play during infancy, the MCR experiences certain required changes to meet commonly identified developmental milestones. By age three, a child's brain is $80 \%$ of the volume and contains twice as many synapses as exist in adulthood (Klass, Needlman, \& Zuckerman, 2003). Synapses form neural circuits that are particularly plastic during early childhood. Through a "blooming and pruning" process, neural circuits used more frequently take root and become hard wired into the brain, while circuits used infrequently become inactive and are pruned (Huttenlocher, 2002). "The brain itself is literally molded by experience: every sight, sound, and thought leaves an imprint on specific neural circuits, modifying the way future sights, sounds, and thoughts will be registered" (Eliot, 1999, p.3).

Because the plasticity and wiring of the developing brain is influenced so heavily by early experiences, understanding the environment in which interactions between the 
mother and child take place is essential to understanding the blooming and pruning process (Luby et al., 2013). In the literature, socio-economic status (SES), culture, race, and ethnicity are frequently used to describe environmental factors affecting development. From this perspective, SES is identified as a combination of maternal education level, household income, and maternal occupation, while culture is identified as the familial and communal support systems available to the mother and child (Hackman \& Farah, 2009; Lupien, King, Meaney, \& McEwen, 2000). The effects of SES on the MCR and subsequent child developmental outcomes have been discussed extensively and identified as common predictors of child cognition, social-emotional development, and educational achievement (Elliott, Demianczuk, \& Robertson, 2014; Hair, Hanson, Wolfe, \& Pollak, 2015; Oberklaid, Baird, Blair, Melhuish, \& Hall, 2013). Similarly, familial and communal resources and resource utilization have been acknowledged as directly impacting the quality of parenting and the cognitive and socialemotional development of the child (Bronfenbrenner \& Morris, 2006; Lugo-Gil \& TamisLeMonda, 2008; Tronick, 2007).

\section{Conceptual Foundations and Framework}

In the presence of an unsupportive environment, the mother and child can experience strain that may manifest itself in the MCR and that can negatively affect the child's overall development (Brooks-Gunn \& Duncan, 1997; Horodynski \& Gibbons, 2004; Schiffman, Omar, \& McKelvey, 2003). Many theoretical and conceptual frameworks have contributed to the global understanding of how the child develops in the context of the MCR. From the classical work of psychologists like Jean Piaget, to the more recent work of Bronfenbrenner and Sameroff, the quality and quantity of interactions in the MCR have been established as key indicators of the child's future development and as the buffering system for how the environment affects the child (Ainsworth, 1985; Bronfenbrenner, 1986; Bronfenbrenner \& Morris, 2006; Goswami, 2014; Sameroff, 2010; Sparrow, 2013).

Interactions between the mother and child foster varying levels of information exchange through observed, perceived, and communicated processes with both verbal and non-verbal goal directed behaviors (Pridham, Lutz, Anderson, Riesch, \& Becker, 2010; Tronick, 2007). These interactions increase in complexity over time and are both a learned and natural part of the MCR. The exchange, or communication, of information through interaction in the MCR contributes to the mother and child's individual and dyadic states which provides meaning making opportunities for both the mother and child (Beeghly \& Tronick, 2011; Tronick, 1998). These meaning making opportunities determine the trajectory of the MCR by requiring continuous mutual adaptation between the mother and child. In this sense, the mother and child actively learn how to engage and interact with one another in ways that promote bonding in their relationship.

Because it can be adapted to the natural environment of the mother and child, observational assessment is considered best practice for evaluating the complexities of maternal-child interaction (MCI) (Brazelton, 1973; Lavelli \& Fogel, 2013; Lester, 2010; 
Pridham et al., 2010; Tronick, 2001). While its roots stem from the field of psychology, observational assessment has overlapped into other disciplines and is commonly used to assess the health and well-being of children. To standardize and infer meaning from the observation of mothers and their children, Kathryn Barnard, a nurse with expertise and extensive training in psychology, worked with a team of researchers, clinicians, and caregivers to develop a theoretical framework and instrument for the assessment of MCI. The Child Health Assessment Model (Figure 1-1) emerged in 1979 from the work of Barnard and her colleagues on the Nursing Child Assessment Project (NCAP). Through their work, the Nursing Child Assessment Teaching and Feeding (NCAT and NCAF) scales were created and have since provided a consistent way of evaluating and describing the day-to-day interactions between the mother and child (Oxford \& Findlay, 2013).

Recognizing the interaction among the environment, mother, and child as the overlapping and most influential component of a child's development, Barnard and the NCAP team furthered their thinking and developed a second model called the parentchild interaction model (Oxford \& Findlay, 2013). The parent-child interaction model, more commonly referred to as the Barnard model, uses the developmental concepts of contingency, positioning, verbalness, sensitivity, affect, and engagement/disengagement to characterize the mother and child as living in constant communication with one another and as having certain individual responsibilities that enable their interactions (Figure 1-2). The environment, mother, child, or any combination of the three can interrupt the adaptive processes of interaction, represented by the "break (//) in the arrow" (Oxford \& Findlay, 2013, p. 12). Because each MCR is unique in its communication and adaptation patterns, the development of the child can be understood best when personal and biological characteristics of the mother and child are considered in conjunction with their interactive abilities and environment (Bornstein \& Tamis-LeMonda, 2010; Oxford \& Findlay, 2013; Tronick, 2007; Wachs \& Bates, 2010).

\section{The Nursing Child Assessment Teaching Scale}

As the basis for the NCAT scale, Barnard's model quantifies the overall quality of interaction in the MCR during the first 36 months of a child's life (Oxford \& Findlay, 2013). Empirical evidence for use of the NCAT scale in assessment of MCI during this first 36-months is extensive. The scale has been used in both community and clinically based samples, ethnically diverse populations, and numerous intervention studies to identify and describe parenting characteristics and interactive behaviors of mothers and children as well as child developmental outcomes (Banerjee \& Tamis-LeMonda, 2007; Drummond, Letourneau, Neufeld, Stewart, \& Weir, 2008; Elliott et al., 2014; Pridham et al., 2010; White-Traut et al., 2013).

Evaluation of interaction quality using the NCAT scale is conducted through standardized observation of the mother and child as the mother teaches the child an unfamiliar, developmentally challenging task. The NCAT scale contains 73 yes/no items 


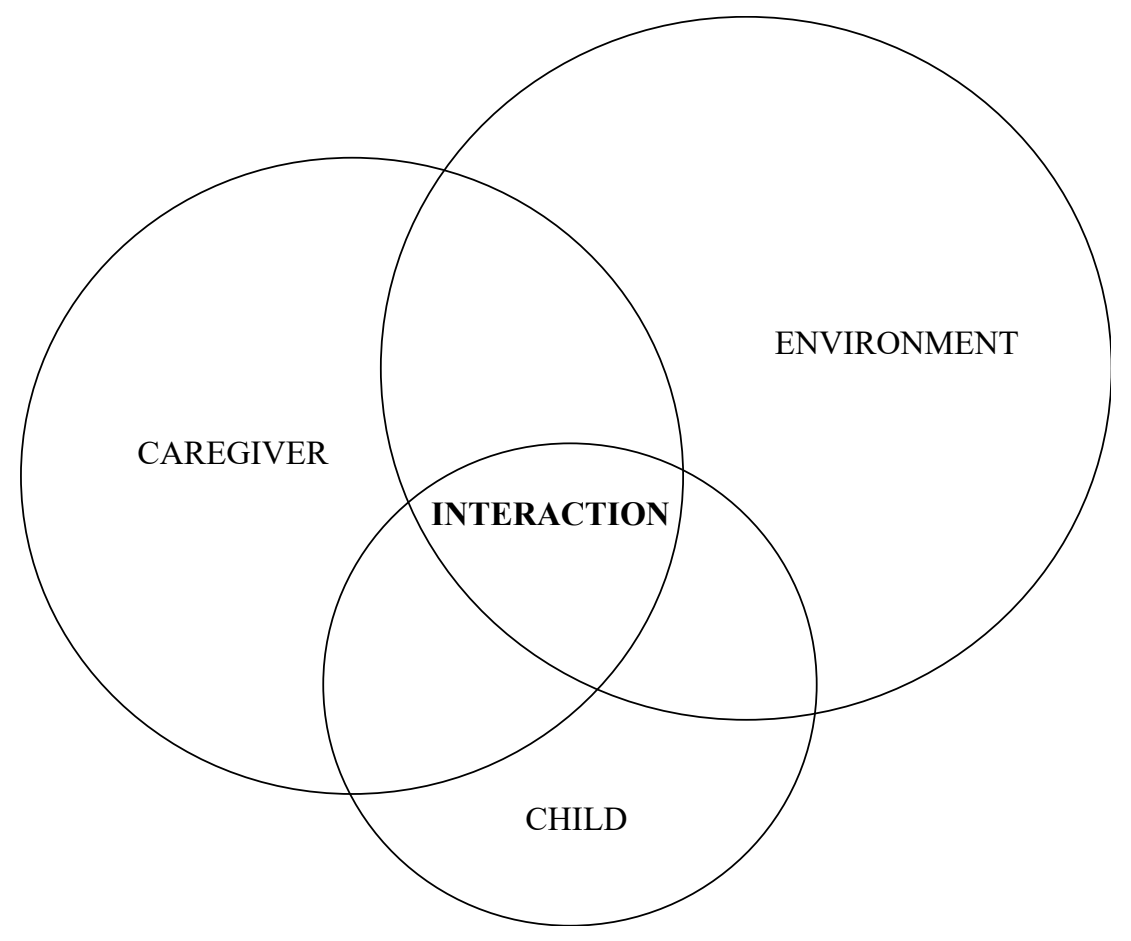

Figure 1-1. The Child Health Assessment Model

Adapted with permission from the NCAST programs. Oxford, M. L., \& Findlay, D. M. (2013). NCAST caregiver/parent-child interaction teaching manual. University of Washington, School of Nursing, Seattle: NCAST Programs. 


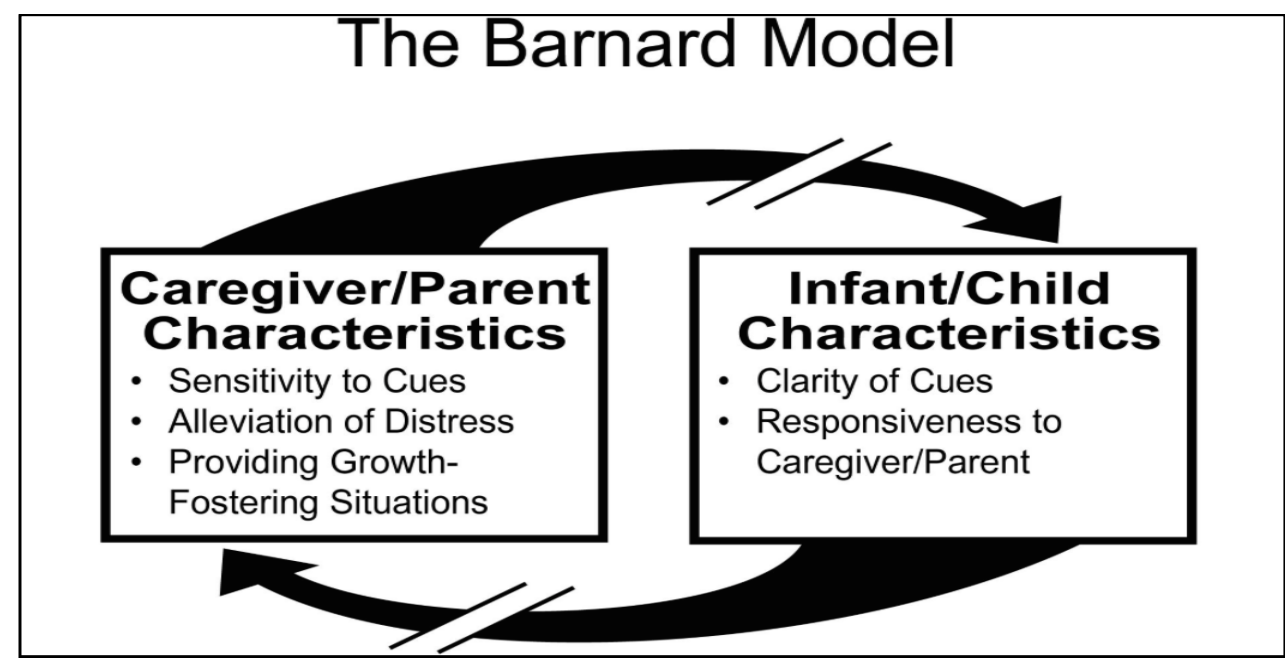

Figure 1-2. The Barnard Model

Reprinted with permission from the NCAST programs. Oxford, M. L., \& Findlay, D. M. (2013). NCAST caregiver/parent-child interaction teaching manual. University of Washington, School of Nursing, Seattle: NCAST Programs. 
categorized into six subscales and is completed by a certified observer. Depending on the method of data collection, the observation of the mother and child may be coded in realtime or from a video recording. The instrument's subscales assess specific mother and child characteristics consistently shown in the literature to influence the MCI and are divided into four mother and two child subscales. In addition, the instrument contains 32 embedded contingency items evaluating the reciprocal and adaptive behaviors of the mother and child as a dyad.

\section{NCAT Subscales}

The 73 binary items creating the NCAT scale act as empirical indicators for the attributes of MCI measured by their associated subscale. Each subscale has both conceptual and developmental importance in identifying the characteristics of the mother and child that are essential to effective interaction. Mother subscales include sensitivity to cues (SC), response to child's distress (RD), social-emotional growth fostering (SEGF), and cognitive growth fostering (CGF). Child subscales include clarity of cues (CC) and responsiveness to caregiver (RC). Cues are an important part of each subscale and can be defined broadly as the communication signals between the mother and child. Cues are exchanged both naturally and intentionally between the mother and child and consist of goal directed, non-verbal and verbal behaviors such as facial expressions and changes in body posture, talking, laughing, or crying.

\section{Sensitivity to Cues}

Items in the SC subscale assess the mother's ability to perceive and accurately interpret her infant's communication signals and respond accordingly. When a mother is sensitive to her child's cues, she is keenly aware of her child's emotional state, level of interest in activity, and developmental capabilities (Eliot, 1999). Maternal sensitivity has been discussed in the literature as essential in developing secure attachment (Ainsworth, 1985; Page et al., 2010), promoting healthy mutual and self-adaptation strategies (Beeghly \& Tronick, 2011; Kochanska, 2002; Moore et al., 2009), and providing appropriate cognitive and social emotional growth stimulation (Page et al., 2010; Shin, Park, Ryu, \& Seomun, 2008). Increased maternal sensitivity is not only a positive predictor of the child's social-emotional competence, but also later cognition and academic achievement (Bornstein \& Tamis-LeMonda, 2010; Page et al., 2010; Raby, Roisman, Fraley, \& Simpson, 2015). In addition, the sensitivity a mother displays towards her child directly influences her responsivity, or how she responds to the needs of her child.

\section{Response to Child's Distress}

The ability of the mother to respond or alleviate her child's distress, as assessed by the RD subscale, requires the mother to know appropriate timing of soothing 
interventions and the types of interventions that work with her child. Responsiveness of the mother indicates to the child she or he is supported and safe (Kochanska, 2002). While some cues of distress are obvious, such as back arching and saying "no", others require more attentiveness and sensitivity from the mother, such as increased feet movement and facial grimacing (Oxford \& Findlay, 2013). In the literature, responsiveness of the mother is often seen in conjunction with discussion of infant temperament (Coffman, Levitt, \& Guacci-Franco, Nathalie, 1995; Kochanska \& Kim, 2013; Lester, 2010; Nuttall, Valentino, \& Borkowski, 2012) and cues of distress are considered signals of interaction disengagement (Barnard, 2010; Oxford \& Findlay, 2013; Tronick, 2010).

While the RD subscale specifically looks at the mother's response to her child's distress, maternal response to lack of distress can be equally as important from a development standpoint. Children are active learners who require encouragement, or positive regard, from their mothers (Lugo-Gil \& Tamis-LeMonda, 2008). Warm maternal response through both verbal and non-verbal communication enhances the child's social competence (Goswami, 2014). In addition, knowledge of normal developmental trajectory can help mothers increase their responsiveness and support their child's development (Murray, 2014).

\section{Social Emotional and Cognitive Growth Fostering}

While the SC and RD subscales are related to the mother's ability to interpret and respond to her child's cues, the SEGF and CGF subscales assess the ability of the mother to engage the child in activity that stimulates cognitive and social-emotional growth using age appropriate language and motivators (Oxford \& Findlay, 2013). The mother has the responsibility of initiating and teaching her child a developmentally appropriate, yet challenging task. Therefore, the mother must know how to engage her child in addition to knowing her child's current developmental state and next developmental milestone (Huang, O’Brien Caughy, Genevro, \& Miller, 2005; Iruka, Durden, \& Kennel, 2015). In the literature, the mother's education level has been directly linked to her ability to provide growth stimulating activities and a language-rich environment (Lanza, Rhoades, Greenberg, Cox, \& Family Life Project Key, 2011; Mazzeschi, Pazzagli, Radi, Raspa, \& Buratta, 2015; Noble et al., 2015; Rhoades, Greenberg, Lanza, \& Blair, 2011). The ability of the mother to remain encouraging while teaching her child new tasks has also been shown to be an important indicator of the child's brain development and continued learning (Banerjee \& Tamis-LeMonda, 2007; Luby et al., 2013).

\section{Clarity of Cues and Responsiveness to Caregiver}

Moving from assessment of the mother, the $\mathrm{CC}$ subscale evaluates the ability of the child to provide clear communication signals, while the $\mathrm{RC}$ subscale assesses the child's ability to read and respond to the mother. Confusing or vague cues exhibited by the child or mother can inhibit the "serve and return" interactions necessary for the 
child's growth and adaptation (National Scientific Council on the Developing Child, 2004). As the child develops she or he becomes more engaged and responsive to the mother's attempts at interaction and cues become more organized and intentional. The clarity of the child's cues and responsiveness of the child promote effective "serve and return" interactions, adaptation, and synchrony between the mother and child (Oxford \& Findlay, 2013; Van Puyvelde et al., 2013).

\section{Significance and Purpose}

The NCAT subscales embedded in the Barnard model work hand-in-hand to provide a comprehensive picture of MCI by emphasizing the constantly evolving and adaptive nature of the MCR. Because the foundation of the child's future development is laid through the moment-to-moment interactions occurring in the MCR during the child's first three years of life, early identification of areas in the MCR requiring support and intervention is essential in promoting positive child outcomes. While studies conducted using the NCAT scale have shown the instrument to be both reliable and valid in the assessment of MCI quality and in the prediction of child developmental outcomes, formal psychometric evaluations of the scale supporting its use in diverse samples of mothers and children have been limited in the literature.

To report valid findings from data collected using an observational instrument, such as the NCAT scale, there should be critical appraisal of the instrument in regular increments (Lynn, 2015; Polit \& Beck, 2012). Additionally, because people are continuously changing and instruments used for observational assessment are often not limited to one demographic sample, appraisal should extend to diverse samples to test their validity. Therefore, the purpose of this research was to formally investigate the psychometric properties of the NCAT scale using mothers and children from two large, demographically different, databases. To promote the generalizability of study results the same methods of analyses were employed for both databases.

While the interactions between the mother and child are the primary focus of the NCAT scale, this study considers the influence of demographics on that interaction and identifies core characteristics of mothers and children that not only influence MCI, but also the child's later developmental outcomes. Therefore, the Child Health Assessment Model provides the overall conceptual framework for this research. Three studies were generated from this work. The specific aims, research questions, and hypotheses for each study are identified in the following section. 


\section{Specific Aims, Research Questions, and Hypotheses}

\section{Aim 1 \\ To examine and report the structural and psychometric properties of the Nursing Child Assessment Teaching scale using a sample of mothers and children from the national Nursing Child Assessment Satellite Training database.}

Using analysis methods of item response theory (IRT), confirmatory factor analysis (CFA), and multiple indicators multiple causes (MIMIC) modeling, the investigator sought to address the following questions:

1) What are the psychometric properties of the NCAT scale in this sample of mothers and children from the NCAST database?

2) How are the demographic characteristics of mothers and children from the NCAST database associated with the observed interactions measured by the NCAT scale?

Hypotheses for Aim 1 are:

1) The psychometric properties of the NCAT scale will be supported in the sample of mothers and children from the NCAST database.

2) The association between demographic characteristics of mothers and children from the NCAST database and observed interactions measured by the NCAT scale will vary in strength.

$\operatorname{Aim} 2$

To examine the psychometric properties of the NCAT scale using a community-based sample of mothers and children from the Conditions Affecting Neurocognitive Development and Learning in Early Childhood (CANDLE) database.

Using analysis methods of IRT, CFA, and MIMIC modeling, the investigator sought to address the following questions:

1) What are the psychometric properties of the NCAT scale in this sample of mothers and children from the CANDLE database?

2) How are the demographic characteristics of mothers and children from the CANDLE database associated with the observed interactions measured by the NCAT scale? 
Hypotheses for Aim 2 are:

1) The psychometric properties of the NCAT scale will be supported in the sample of mothers and children from the CANDLE database.

2) The association between demographic characteristics of mothers and children from the CANDLE database and observed interactions measured by the NCAT scale will vary in strength.

3) The influence of demographic characteristics on observed interactions between mothers and children from the CANDLE database will be different than those reported in the NCAST database.

\section{$\operatorname{Aim} 3$}

\section{To determine the predictive validity of the NCAT scale using a community- based sample of mothers and children from the CANDLE database.}

Determining the predictive validity of the NCAT scale using the sample of mothers and children from the CANDLE database addresses the following questions:

1) What are the associations of scores within the NCAT scale at 12-months?

2) What are the associations of scores within the Bayley Scales of Infant and Toddler Development, Third Edition (Bayley-III) at 36-months?

3) What are the associations between the NCAT scores at 12-months and the BayleyIII Cognitive Scale scores at 36-months?

4) What are the associations between the NCAT scores at 12-months and the BayleyIII Language Scale scores at 36-months?

5) What are the associations between the NCAT scores at 12-months and the BayleyIII Receptive Communication subtest scores at 36-months?

6) What are the associations between the NCAT scores at 12-months and the BayleyIII Expressive Communication subtest scores at 36-months?

Hypotheses for Aim 3 are:

1) The association of scores within the NCAT scale at 12-months will support the reliability of the scale.

2) The association of scores within the Bayley-III at 36-months will support the reliability of the instrument.

3) Higher NCAT scale scores at 12-months will be associated with higher Bayley-III Cognitive Scale scores at 36-months.

4) Higher NCAT scale scores at 12-months will be associated with higher Bayley-III Language Scale scores at 36-months.

5) Higher NCAT scale scores at 12-months will be associated with higher Bayley-III Receptive Communication subtest scale scores at 36-months.

6) Higher NCAT scale scores at 12-months will be associated with higher Bayley-III Expressive Communication subtest scale scores at 36-months. 


\section{General Description of Populations under Study}

Detailed descriptions of the national NCAST database and the community-based CANDLE database are presented in Chapters 2 and 3. Briefly, the NCAST database is the national database that includes data collected using the NCAT scale. The NCAST database contains nearly 2,100 reported observations of mothers and children from across the United States and combines both community- and clinically-based assessments of interaction (Oxford \& Findlay, 2013). For this current study, 1,887 mother-child dyads from the NCAST database were used for secondary analyses.

Contrasting the NCAST database, the CANDLE database contains a communitybased sample of mothers and children. Mothers and children in the CANDLE database were originally enrolled in a longitudinal study designed to investigate the internal and external effects of maternal prenatal activities along with child development, experiences, genetic makeup, and environmental exposures on brain development during the child's first three years of life (The Department of Preventive Medicine UTHSC, 2014). The CANDLE study is based in Shelby County, Tennessee and uses 54 different instruments to collect data from the mother and child at pre-determined time points over a child's first several years of life. The NCAT scale was one of the data collection tools used in the CANDLE study. For this current study, data from 1,121 mother-child dyads enrolled in CANDLE were used for secondary analyses.

\section{Potential Limitations}

A primary potential limitation associated with this research is the use of secondary data. While analysis of existing data has its benefits, two of the most prominent limitations of secondary analysis are the issues of missing data and the lack of control the researcher has over the data previously collected (Coyer \& Gallo, 2005; Greenhoot \& Dowsett, 2012). In the CANDLE database, observations using the NCAT scale are missing in some cases due to lack of follow-up and incomplete data collection. Missing NCAT scale data from the CANDLE database is discussed in Chapter 3.

A second potential limitation is that observations of interactions between the mothers and children were conducted and scored by an observer in real time rather than scored based on video record, which is the preferred method of data collection for the NCAT scale. Although observation has become a best practice standard for assessing interaction between the mother and child, use of the NCAT scale for data collection in the CANDLE study was conducted in a clinic setting rather than a natural environment. This has the potential to skew results because mothers may feel they are performing when being observed and attempt to alter their behaviors.

A third potential limitation of this research is that mothers who were enrolled in the parent CANDLE study were done so via convenience sampling to mirror the

demographics of the county in which these mothers reside (The Department of Preventive Medicine UTHSC, 2014). Because data for the national NCAST database are collected 
through observations sent to the University of Washington from community- and clinically-based settings across the United States, this could also be considered convenience sampling. Convenience sampling can lead to the over or under representation of certain groups within the sample (Polit \& Beck, 2012). In addition, demographic characteristics used for analyses in these studies were chosen based on similar available variables between the NCAST and CANDLE databases. Other factors that may influence the MCR and MCI, such as home environment or other caregiving relationships outside of marriage, were excluded from secondary analysis.

\section{Definitions of Major Concepts}

The following concepts and general definitions of variables used in this study are defined based on Kathryn Barnard's work (Barnard et al., 1985), the NCAT scale manual (Oxford \& Findlay, 2013), and existing literature from the field of child developmental psychology. Primary child psychology resources include the work of Ainsworth, Brazelton, Tronick, and Bronfenbrenner. Theoretical and operational definitions of major concepts discussed in this current research are provided.

\section{Mother-Child Relationship}

As the most commonly described dyadic caregiving unit in early child development literature, the mother-child relationship (MCR) is considered the most important influential connection with another human being a child will have in their life (Ainsworth, 1985; Tronick, 2010). This relationship is a complex system and unique in all cases. Some MCRs are biological, while others are adoptive and can be relative caregivers rather than biologic mothers. In this study, the MCR is assumed to be the primary caregiving relationship. For the purposes of this research, the MCR is described using the dyads of mothers and children from the NCAST and CANDLE databases and is operationalized by the results from MIMIC models which consider the demographic influences of each respective sample on the interactive processes and the relationship as a whole.

\section{Mother-Child Interaction}

Interactions occur between the mother and child as they engage one another to exchange information through joint action patterns. These joint action patterns are the observed, perceived, and communicated processes with both verbal and non-verbal goal directed behaviors (Pridham, Lutz, Anderson, Riesch, \& Becker, 2010; Tronick, 2007; Zaidman-Zait, Marshall, Young, \& Hertzman, 2014). In this research, MCI is operationalized by totaling each item in the NCAT scale, as the characteristics of the mothers and children from each database are assessed, to yield the total instrument score. 


\section{Cues}

Both non-verbal and verbal communication signals exist in the MCR. These communication signals are called cues and are an essential component of interaction. There are different types of cues, but for this study, the majority can be summarized in two broad categories of engagement and disengagement. Engagement cues are expressed through active attention between the mother and child during an interaction and include things like eye-to-eye contact, smiling at or in response to each other, and verbalizing at or in response to each other (Goswami, 2014; Oxford \& Findlay, 2013). Disengagement cues are expressed as a disconnect, or break, in the interaction and include things like turning the head or body away from each other, back arching, and cries of distress (Oxford \& Findlay, 2013). For this research, cues are operationalized in each NCAT subscale through the interactive behaviors of the mother and child.

\section{Environment}

In research surrounding development in early childhood, environment is considered in many different ways, but often refers to the child's physical, social, and economic surroundings (Bronfenbrenner, 1986; Bronfenbrenner \& Morris, 2006). Interactions between the mother and child occur in the context of environment and are therefore influenced by the environment (Barnard et al., 1985). For this research, environment is discussed broadly and its influence is operationalized through the association between demographic characteristics of each sample and NCAT subscale totals presented by multiple indicators multiple causes analyses.

\section{Child Development}

Child development can be broadly defined as the growth and change in a child over time as she or he accomplishes and surpasses identified milestones for overall maturation. Typically, child development is considered through the evaluation and discussion of physical, emotional, cognitive, and social outcomes (Bronfenbrenner \& Morris, 2006; Shonkoff, Richter, van der Gaag, \& Bhutta, 2012). This research specifically considers the child's cognitive and language development. Cognitive development refers to the child's ability to internally process information and environmental stimuli, learn numerical and alphabetical concepts, and problem solve (Bayley, 2006). Language development refers to the child's overall communicative ability and can be categorized into receptive and expressive communication. Receptive communication focuses on the child's ability to comprehend and respond appropriately to the environment and her or his mother while expressive communication focuses on outward gestures and age appropriate vocalization (Bayley, 2006; Cates et al., 2012; Eliot, 1999). For this research, the child's cognitive and language development are measured by the scores from the Bayley-III Cognitive scale, Language scale, Receptive Communication subtest, and Expressive Communication subtest (Bayley, 2006). 


\section{Psychometric Properties}

Polit and Beck (2012) define psychometrics as "the theory underlying principles of measurement and the application of the theory in the development of measuring tools" ( $p$ 739). The psychometric properties of a scale are determined and displayed by the statistical correlations existing among sets of variables identified in a hypothesized model or theory (Brown, 2015; Kline, 2012). These statistical correlations provide reliability and validity measurements for the scale which determine the overall quality of the scale (Polit \& Beck, 2012). For this research, the psychometric properties of the NCAT scale are determined through IRT and structural equation modeling approaches of CFA and MIMIC.

\section{Item Response Theory}

IRT is used to create a scale that can measure a variable of interest that is often unobservable, but instinctively implicit (Baker, 2001; Cook, 2013). These measurement models graphically display the relationship between items in the scale and the traits of the participants to the probability of response in a particular way (Brown, 2015). IRT takes into account the participant response to items in a scale. For this research, IRT is used to describe the observed rates of endorsement on items in the NCAT scale in the NCAST and CANDLE samples.

\section{Confirmatory Factor Analysis}

CFA is a hypothesis driven type of structural equation modeling that deals specifically with the relationship between an observed measure and a factor. In psychometric evaluation, CFA is a measurement model used to examine the structure of the scale or instrument under investigation by explaining the correlations among scale items (Brown, 2015). For this research, CFA is used to explain the correlations between NCAT scale items and their respective subscale factors.

\section{Multiple Indicators Multiple Causes}

MIMIC modeling provides the structural component of structural equation modeling by evaluating the relationship between identified covariates and the factor (Brown, 2015). For this research, MIMIC structural models are used to augment the CFA measurement models to identify the influence of demographics on the NCAT scale factors. 


\section{Predictive Validity}

The validity of a scale provides statistical support for continuing to use the scale and can be categorized in several ways. Predictive validity falls into the category of criterion-related validity where the primary focus is whether the scale is a useful measure of future outcomes (Polit \& Beck, 2012). For this research, the predictive validity of the NCAT scale is explored in relation to the child's future cognitive and language

development as identified by the Bayley-III Cognitive scale, Language scale, Receptive Communication subtest, and Expressive Communication subtest (Bayley, 2006). 


\title{
CHAPTER 2. PSYCHOMETRIC EVALUATION OF THE NURSING CHILD ASSESSMENT TEACHING SCALE USING THE NURSING CHILD ASSESSMENT SATELLITE TRAINING DATABASE
}

\begin{abstract}
Introduction
The initial development of an instrument used to collect data in practice and research typically begins with a concept of interest and a realization that no other existing instrument is adequate for measuring that concept. As the knowledge related to the investigated concept grows, new questions can emerge requiring the instrument to be critically appraised and thoughtfully revised to ensure the items in the instrument are continuing to accurately measure what they were originally intended to measure (Lynn, 2015; Polit \& Beck, 2012). Repeated examination of the psychometric properties of an instrument can provide rationale for the continued use of the instrument in practice and research through determination of reliability and validity in a given sample of participants (Pett, Lackey, \& Sullivan, 2003). It can also provide opportunities for instrument modification. The use of item response theory (IRT) and structural equation modeling approaches of confirmatory factor analysis (CFA) and multiple indicators multiple causes modeling (MIMIC) are commonly used in instrument evaluation. These analysis approaches determine the psychometric properties of an instrument by testing an underlying theory, or set of concepts and provide quantitative measures and visual models of how well an identified theory fits with the sample under investigation (Brown, 2015; Lei \& Wu, 2007).
\end{abstract}

\section{Item Response Theory}

IRT uses measurement models to assess and graphically display the relationship between the properties of items in an instrument and the characteristics, or latent traits, of the participants evaluated by the instrument. The main purpose of IRT is to create a scale that can measure an underlying variable of interest which is often unobservable, but instinctively understood (Baker, 2001; Cook, 2013). IRT models account for actual participant responses to items and estimate the likelihood of different responses by participants with varying levels of the measured trait. The relationship between traits of the participants and the items in an instrument are depicted graphically through item characteristic curves (ICC). These curves display a nonlinear regression of a response probability given a specific participant characteristic (Brown, 2015).

Three types of IRT models exist and include one parameter (1PL), two parameter (2PL), and three parameter (3PL) logistic models. Using 1PL-IRT, the participant trait is considered along with the difficulty of the item in the instrument. The item difficulty is represented by beta (b) and "conveys the level of the latent trait where there is a $50 \%$ chance of a positive response on the item" (Brown, 2015 p. 363). Items which are considered easy have lower $b$ values and curves closer to the horizontal axis when looking at the ICC. 
In a 2PL-IRT model, discriminatory ability of the items is considered in addition to the difficulty of the items. The discrimination shows how well items differentiate between the traits of the participants based on responses to the items. In other words, "the probability of a positive response depends on the discriminating power of the item" (Brown, 2015, p. 364). An increase in the discriminating power is represented by an increase in the slope (a) of the ICC. Item discriminatory ability is typically classified as very low, low, moderate, high, or very high (Brown, 2015). Going one step further, the 3PL-IRT logistic model includes a guessing parameter and is used primarily in aptitude testing, rather than observational assessment. In 3PL-IRT, the value of the guessing parameter displays how likely a participant is to obtain the correct answer by guessing and it assumes that "if an item can be correctly answered by guessing, the probability of a positive response is greater than zero even for persons with low levels of the latent trait" (Brown, 2015 p. 364).

Several assumptions are made about the participants in the sample and the instrument under investigation when using IRT. First, it is assumed each participant possesses some degree of the underlying ability being evaluated. Second, it is assumed that participants are responding to the same items in the instrument, that these items are independent of one another, and that the item parameter estimates are the actual values of the item parameters (Baker, 2001; Cook, 2013). Third, it is assumed that the ability of each participant is independent of all other participants in the sample.

\section{Confirmatory Factor Analysis and Multiple Indicators Multiple Causes}

CFA and MIMIC allow hypothesized causal processes, represented by regression weights, to be modeled. This modeling allows structural theory testing given a certain underlying phenomenon (Kline, 2012). Two types of factor analysis, exploratory and confirmatory, are used to determine the nature and number of latent, unobserved factors in an instrument based on the correlational associations among the instrument items (Brown, 2015). The key difference between exploratory factor analysis (EFA) and confirmatory factor analysis is that CFA is hypothesis driven. While EFA is used to determine the number of factors in a model, CFA is used to verify the number of prespecified factors in the model are appropriate and support what the instrument is attempting to measure in a given sample of study participants (Brown, 2015).

Factor analysis is commonly used to support the reliability and validity of an instrument during its initial development and any subsequent revisions. Factor analysis with binary outcomes is equivalent to the 2PL-IRT model previously discussed and discrimination in IRT is synonymous with factor loadings in CFA (Brown, 2015). The factors in a model are the unobservable categories of behavior established by the persons developing the instrument and the instrument items are the quantitative measures observed in a group of participants.

Correlations between the items in the subscales and the subscale factors, called factor loadings, are the regression slopes that allow hypothesized causal relationships in 
the model to be numerically estimated (Brown, 2015; Lei \& Wu, 2007). The estimated model explains the variance and covariance between the items in the instrument (Hooper, Coughlan, \& Mullen, 2008). MIMIC modeling is used to augment CFA measurement models by structurally linking specified predictors to identified factors. Interpretation of results from CFA and MIMIC should not be considered at the level of the item, but rather the level of the factor and goodness-of-fit indices should be used to determine how well the model fits with the sample (Brown, 2015; Hooper et al., 2008; Kline, 2012).

CFA and MIMIC models make several assumptions about the data. First, the assumption is made that a cause and effect relationship exists where the direction of cause is correctly specified by the model. Therefore, CFA and MIMIC models require "a strong empirical or conceptual foundation to guide the specification and evaluation of the factor model" (Brown, 2015, p. 12). Second, the assumption is made that the association between the observed trait and the factor holds when controlling for other variables that may also affect the factor. In addition, the relationship among the variables are allowed to intercorrelate freely (Kline, 2012).

Using IRT, CFA, and MIMIC modeling, this study examined the psychometric properties of a commonly used observational instrument called the Nursing Child Assessment Teaching (NCAT) scale. The original Nursing Child Assessment Feeding (NCAF) and Teaching (NCAT) scales were developed in 1972 with the intent to observe and score day-to-day interactions between mothers and their children on a 7-point scale. The scores were then totaled and clustered together to represent the different aspects of the observed interaction (Oxford \& Findlay, 2013). Methods used to determine the reliability and validity of the instrument were largely based on a pilot study conducted using the instrument with 193 mother-child dyads. Results supported the use of the NCAF and NCAT scales and their ability to assess the interactive patterns in the maternal-child relationship (Barnard \& Eyres, 1979). However, use of the instrument, particularly in scoring the interaction, was found to be a bit cumbersome in the pilot study so in 1979 the NCAF and NCAT scales were revised by Kathryn Barnard (Oxford \& Findlay, 2013). Revisions made by Barnard were conceptually driven and since its revision in 1979, the NCAT scale has remained virtually unchanged.

As the use of the NCAT scale spread, the Nursing Child Assessment Satellite Training (NCAST) database was developed to ensure its reliability and validity. The NCAST database is described in the most recent NCAT training manual and contains nearly 2,100 mother-child observations from across the United States combining both community- and clinically-based samples (Oxford \& Findlay, 2013). Demographic characteristics of mothers from the database include mostly Caucasian (54\%) married (77.2\%) women with a minimum high school education (80\%) who average 25.7 years of age at the birth of their child. Reported child demographics show $52 \%$ of the children in the database to be male and the average child age to be 15.5 months. Using this sample of mothers and children, the NCAT manual provides a detailed report of the reliability and validity of the instrument along with how the instrument has been used in research and clinical practice since its development by Barnard (Oxford \& Findlay, 2013). 
Contributions to the NCAST database continue to be made as certified observers from assorted disciplines use the NCAT scale in research and daily practice. Although empirical evidence for the use of the NCAT scale continues to grow, updated reports formally evaluating the psychometric properties of the scale are limited in the literature. To address this gap, a sample of 1,887 mother-child dyads from the NCAST database were used to formally examine the NCAT scale. By employing IRT, CFA, and MIMIC analyses, this study sought to address the following questions: 1) What are the psychometric properties of the NCAT scale in this sample of mothers and children from the NCAST database? 2) How are the demographic characteristics of mothers and children from the NCAST database associated with the observed interactions measured by the NCAT scale?

Hypotheses for this study were that: 1) the psychometric properties of the NCAT scale would be supported in the sample of mothers and children from the NCAST database, and 2) the association between demographic characteristics of mothers and children from the NCAST database and observed interactions measured by the NCAT scale would vary in strength.

\section{Methods}

\section{Procedure}

All IRT, CFA, and MIMIC modeling for secondary analyses were conducted using $\mathrm{R}$ version 3.1.3 (R Core Team, 2015). R packages used included psych (Revelle, 2015), ltm (Rizopoulos, 2006), lavaan (Rosseel, 2012), semTools (SemTools Contributors, 2015), Amelia (Honaker, King, \& Blackwell, 2011), and car (Fox \& Weisberg, 2011). Specifically, the Amelia R package (Honaker, King, \& Blackwell, 2011) was used to address issues related to missing data by evoking multiple imputation using twenty imputed data sets. NCAT scale items on which mothers and/or their children from the NCAST database scored a "yes" greater than $97 \%$ of the time were excluded from analyses due to minimal response variability. Removal of these items left 62 of the 73 original items for secondary analysis.

\section{Item Response Theory}

In the NCAT scale, the assessed latent traits of the mother and child participants are the instrument's six conceptually derived subscales (Sensitivity to Cues, Response to Distress, Cognitive Growth Fostering, Social Emotional Growth Fostering, Clarity of Cues, Response to Caregiver). Each of the 62 items remaining in the NCAT scale was evaluated using 2-PL IRT. The 3PL-IRT model was not used for analysis because the data were collected using observational assessment and did not require a guessing parameter. 
To provide a visual example of 2-PL IRT modeling, Figure 2-1 displays the ICC for the NCAT subscale Social Emotional Growth Fostering (SEGF) where mothers from the NCAST database are the participants and the trait being observed is the mother's ability to instruct her child in a developmentally challenging activity that promotes the child's the social emotional growth. In the SEGF subscale, item 33 (t33 displayed in red) is the least difficult item and discriminates minimally between the ability of mothers in the sample. This is apparent by the items' probability and slope of the curve. In contrast, item 26 (t26 displayed in blue) is the most difficult item with moderate discriminating ability. Items $25,27,28$, and 29 ( 25 , green, $\mathrm{t} 27$ teal, $\mathrm{t} 28$ magenta, $\mathrm{t} 29$ yellow) have the highest discriminatory abilities.

\section{Confirmatory Factor Analysis and Multiple Indicators Multiple Causes}

In the CFA and MIMIC analyses using the NCAST database, NCAT item associations were allowed within subscale factors and model fit was evaluated using three goodness-of-fit indices. The subscale factors were the six conceptually derived mother and child subscales previously mentioned. Guidelines for interpreting goodness-of-fit suggest that indices from different "fit" categories be used to comprehensively consider the model (Brown, 2015). Therefore, root mean square error of approximation (RMSEA) $<0.05$ was used to evaluate model parsimony based on the sample and the comparative fit index (CFI) $>0.90$ and Tucker-Lewis index (TLI) $>0.90$ were used to evaluate model fit between the baseline Barnard model and the investigator specified abbreviated model with removed items. RMSEA was from the category of parsimony correction while the CFI and TLI were from the category of comparative fit. MIMIC modeling was used to augment the CFA using demographic predictors of the sample. Demographic predictors were chosen based on availability from the NCAST database and included maternal parity, age at child's birth, education, race, marital status, and child age and sex and (Table 2-1).

\section{Results}

\section{Item Response Theory}

Table 2-2 presents a summary of item discrimination categories by subscale factor for the NCAT items. Items in the Response to Distress (RD) subscale exhibited strong associations with the underlying latent factor as evidenced by the presence of very high discriminations on all items. Discrimination estimates were obtained for each item during analysis and are presented in Appendix A. In addition, Appendix B contains the NCAT items removed for low variability and high item associations. Due to high item associations identified in the RD and Response to Caregiver (RC) subscales, item 17 from the $\mathrm{RD}$ subscale was removed and the $\mathrm{RC}$ subscale was partitioned into two smaller more homogeneous scales named Response to Caregiver 1 (RC1) and Response to 


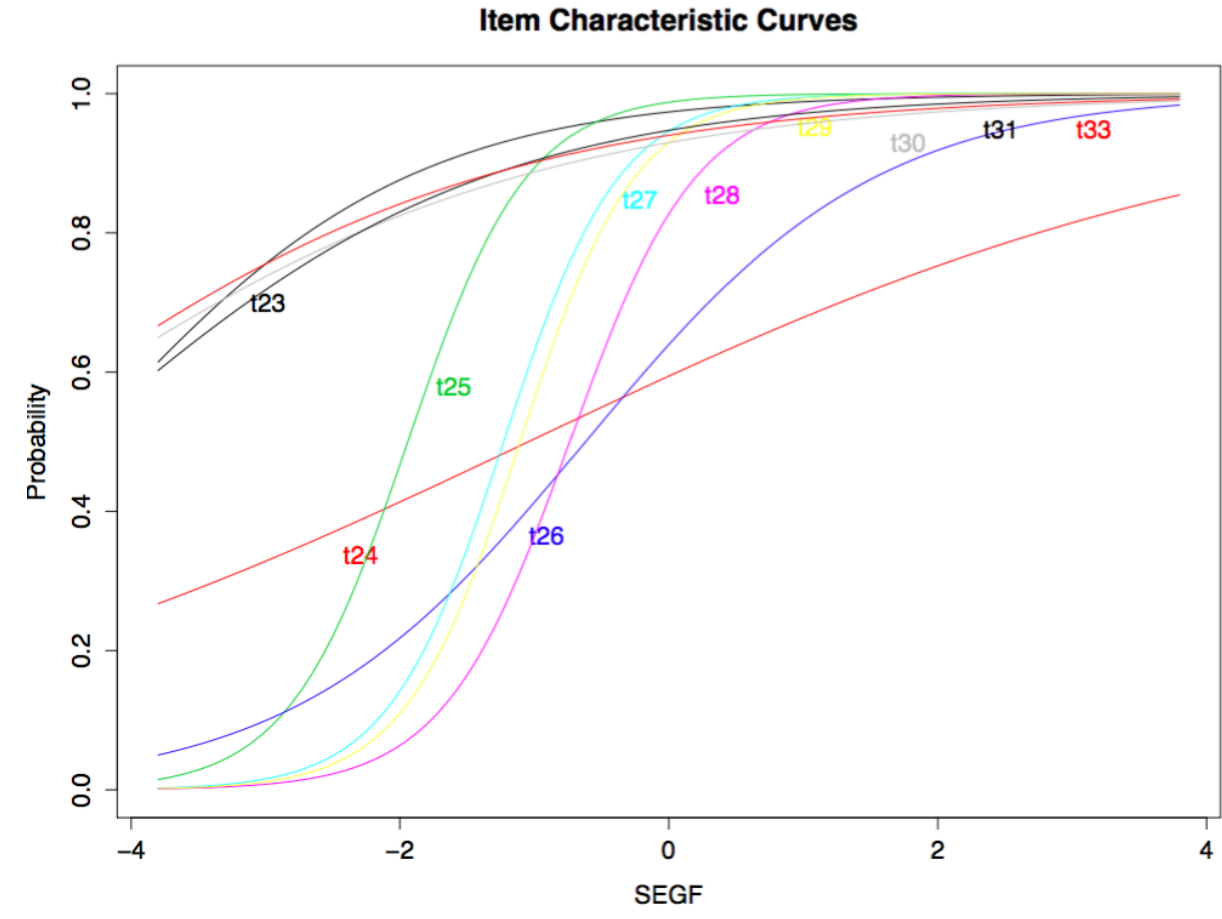

Figure 2-1. Item Characteristic Curve for the Social Emotional Growth Fostering (SEGF) Subscale 
Table 2-1. Demographic Characteristics of the NCAST Database for Secondary Analysis

\begin{tabular}{lcc}
\hline Variable & Value & Missing (\%) \\
\hline Maternal & $\mathrm{n}=1,887$ & \\
Age, yr, M(SD) & $26(5.55)$ & \\
Education, yr, M(SD) & $13(2.70)$ & \\
Marital status, n (\%) & $1,873(99.2)$ & \\
Married & $1,521(81.2)$ & \\
Not married & $352(18.8)$ & 10 cases $(0.74)$ \\
Parity, $\mathrm{n}(\%)$ & $1,877(99.5)$ & \\
Mother has only 1 child & $895(47.4)$ & \\
Mother has more than 1 child & $982(52.0)$ & \\
Race, $\mathrm{n}(\%)$ & $1887(100)$ & \\
Caucasian & $1,107(58.7)$ & \\
Black & $497(26.3)$ & \\
Other & $283(15)$ & \\
& & \\
Child & $\mathrm{n}=1,887$ & \\
Age, mo, M(SD) & $15(9.74)$ & \\
Gender, $\mathrm{n}(\%)$ & $1,887(100)$ & \\
Male & $984(52.1)$ & \\
Female & $903(47.8)$ & \\
\hline
\end{tabular}


Table 2-2. Item Discriminations by Category and Subscale Factor for the NCAST Database

\begin{tabular}{lccccc}
\hline Factor & $\begin{array}{c}\text { Very } \\
\text { Low }\end{array}$ & Low & Moderate & High & $\begin{array}{c}\text { Very } \\
\text { High }\end{array}$ \\
\hline Sensitivity to Cues & 0 & 3 & 4 & 0 & 2 \\
Response to Distress & 0 & 0 & 0 & 0 & 8 \\
$\begin{array}{l}\text { Social-Emotional Growth } \\
\text { Fostering }\end{array}$ & 0 & 2 & 4 & 0 & 4 \\
Cognitive Growth & 1 & 2 & 5 & 2 & 6 \\
Fostering & 1 & 1 & 1 & & \\
Clarity of Cues & 0 & 0 & 0 & 1 & 2 \\
Response to Caregiver 1 & 0 & 0 & 1 & 1 & 4 \\
Response to Caregiver 2 & & & & & \\
\hline
\end{tabular}


Caregiver 2 (RC2). After partitioning, RC1 contained items $61-67$ and $\mathrm{RC} 2$ contained items $68-73$. In addition, items 58, 59, and 60 in the Clarity of Cues (CC) subscale were negatively correlated with the total $\mathrm{CC}$ subscale score and were reversed for further analyses. Removal of item 17 and reversal of items $58-60$, left 62 total items and seven subscale factors for structural equation modeling.

\section{Confirmatory Factor Analysis and Multiple Indicators Multiple Causes}

Factor loadings from the CFA for NCAT scale items and their respective subscale factors are presented in Table 2-3. The factor loadings describe the strength of the relationship between the item and the factor. Items with correlations closest to 1.0 represent strong loadings on the factor, while items with correlations $<0.40$ are typically considered weak and may be removed from the instrument (Brown, 2015; Pett, Lackey, $\&$ Sullivan, 2003). Full understanding of the clinical utility of the item, despite its loading value, should be considered carefully before removing an item.

MIMIC models displayed significant demographic predictors $(\mathrm{p}<0.05)$ and underlying subscale factor linkage patterns which varied by subscale (Table 2-4). The factor $R_{2}$ represented the proportion of variance in each respective subscale explained by the demographic predictors of the sample and the beta weights $(\beta)$ were the standardized regression coefficients for each predictor. In comparing the $\beta$ 's for predictors in each subscale, when Caucasian race was present it was consistently the best predictor of the subscale factor followed closely by mothers who had greater than a high school education. When the mother's age at the child's birth and the child's age at the time of observation were predictors of a subscale, they consistently displayed the weakest values. Maternal ability to respond sensitively to her child's cues as assessed by the SC subscale was greater when mothers were Caucasian, had higher than a high school education, were older when their child was born, and when their child was older. Maternal ability to calm or alleviate the distress of her child as assessed by the RD subscale was greater when mothers were married and older when their child was born. Maternal ability to provide social-emotional growth fostering through affect and physical touch as assessed by the SEGF subscale was greater when mothers were Caucasian, had higher than a high school education, and were older when their child was born. Maternal ability to provide cognitive growth fostering activities for her child as assessed by the CGF subscale was greater when the mothers were Caucasian, had higher than a high school education, were African American, older when their child was born, and when the child was older. Child ability to provide clear cues for her or his mother as assessed by the CC subscale was greater when the child was older and child responsiveness to her or his mother's attempts at interaction as assessed by the RC1 subscale was greater when the mother was Caucasian, had higher than a high school education, were married, older when their child was born, and when the child was older. Child responsiveness to her or his mother's attempts at interaction as assessed by RC2 was greater when the child was female. Parity of the mother (the child's birth order) was not a predictor of mother or child subscale factors. 
Table 2-3. CFA Factor Loadings of the NCAT Scale for the NCAST Database

\begin{tabular}{|c|c|c|}
\hline Factor & Item & Item Correlation \\
\hline \multirow[t]{9}{*}{ Sensitivity to Cues } & 3 & 0.682 \\
\hline & 4 & 0.734 \\
\hline & 5 & 0.435 \\
\hline & 6 & 0.355 \\
\hline & 7 & 0.618 \\
\hline & 8 & 0.606 \\
\hline & 9 & 0.344 \\
\hline & 10 & 0.342 \\
\hline & 11 & 0.425 \\
\hline \multirow[t]{8}{*}{ Response to Distress } & 12 & 0.754 \\
\hline & 13 & 0.972 \\
\hline & 14 & 0.865 \\
\hline & 15 & 0.682 \\
\hline & 16 & 0.888 \\
\hline & 18 & 0.647 \\
\hline & 20 & 0.723 \\
\hline & 22 & 0.674 \\
\hline \multirow[t]{10}{*}{ Social-Emotional Growth Fostering } & 23 & 0.346 \\
\hline & 24 & 0.284 \\
\hline & 25 & 0.803 \\
\hline & 26 & 0.549 \\
\hline & 27 & 0.887 \\
\hline & 28 & 0.629 \\
\hline & 29 & 0.650 \\
\hline & 30 & 0.303 \\
\hline & 31 & 0.263 \\
\hline & 33 & 0.214 \\
\hline \multirow[t]{7}{*}{ Cognitive Growth Fostering } & 34 & 0.023 \\
\hline & 36 & 0.537 \\
\hline & 37 & 0.433 \\
\hline & 38 & 0.698 \\
\hline & 39 & 0.730 \\
\hline & 40 & 0.731 \\
\hline & 41 & 0.677 \\
\hline
\end{tabular}


Table 2-3. (Continued)

\begin{tabular}{lcc}
\hline Factor & Item & Item Correlation \\
\hline & 42 & 0.640 \\
43 & 0.399 \\
44 & 0.583 \\
45 & 0.613 \\
46 & 0.601 \\
47 & 0.629 \\
48 & 0.864 \\
Clarity of Cues & 49 & 0.343 \\
& 50 & 0.210 \\
& 54 & 0.384 \\
Response to Caregiver 1 & 55 & 0.069 \\
& 57 & 0.078 \\
& $58 \mathrm{R}$ & 0.693 \\
$59 \mathrm{R}$ & 0.844 \\
& $60 \mathrm{R}$ & 0.899 \\
61 & 0.553 \\
& 62 & 0.686 \\
& 63 & 0.715 \\
& 64 & 0.608 \\
& 65 & 0.622 \\
& 66 & 0.986 \\
& 67 & 0.963 \\
& 68 & 0.679 \\
& 69 & 0.856 \\
& 70 & 0.834 \\
& 71 & 0.780 \\
& 72 & 0.643 \\
& 73 & 0.618 \\
\hline
\end{tabular}

NOTE. $\mathrm{R}=$ reverse coded items; $\mathrm{CFA}=$ confirmatory factor analysis; item correlations $<0.40$ represent weak loadings on the factor; item correlations closer to 1.0 represent strong loadings on the factor 
Table 2-4. MIMIC Models for Significant Demographic Predictors in the NCAST Database

\begin{tabular}{|c|c|c|c|c|c|}
\hline Factor & Factor $R^{2}$ & Predictor & $\beta$ & $\mathbf{S E}$ & P-Value \\
\hline \multirow{4}{*}{$\begin{array}{l}\text { Sensitivity to } \\
\text { Cues }\end{array}$} & 0.264 & Caucasian & 0.384 & 0.106 & $<0.001$ \\
\hline & & $\begin{array}{c}\text { High school } \\
\text { education }\end{array}$ & 0.376 & 0.113 & 0.001 \\
\hline & & $\begin{array}{l}\text { Mother's age at } \\
\text { child's birth }\end{array}$ & 0.056 & 0.008 & $<0.001$ \\
\hline & & Child age & 0.031 & 0.004 & $<0.001$ \\
\hline \multirow{2}{*}{$\begin{array}{l}\text { Response to } \\
\text { Distress }\end{array}$} & 0.038 & Married & 0.216 & 0.095 & 0.023 \\
\hline & & $\begin{array}{l}\text { Mother's age at } \\
\text { child's birth }\end{array}$ & 0.021 & 0.007 & 0.003 \\
\hline \multirow{3}{*}{$\begin{array}{l}\text { Social-Emotional } \\
\text { Growth Fostering }\end{array}$} & 0.159 & Caucasian & 0.407 & 0.094 & $<0.001$ \\
\hline & & $\begin{array}{l}>\text { High school } \\
\text { education }\end{array}$ & 0.380 & 0.100 & $<0.001$ \\
\hline & & $\begin{array}{l}\text { Mother's age at } \\
\text { child's birth }\end{array}$ & 0.049 & 0.007 & $<0.001$ \\
\hline \multirow{5}{*}{$\begin{array}{l}\text { Cognitive Growth } \\
\text { Fostering }\end{array}$} & 0.283 & Caucasian & 0.458 & 0.084 & $<0.001$ \\
\hline & & $\begin{array}{l}>\text { High school } \\
\text { education }\end{array}$ & 0.384 & 0.091 & $<0.001$ \\
\hline & & African American & 0.253 & 0.095 & 0.008 \\
\hline & & $\begin{array}{l}\text { Mother's age at } \\
\text { child's birth }\end{array}$ & 0.045 & 0.006 & $<0.001$ \\
\hline & & Child age & 0.043 & 0.003 & $<0.001$ \\
\hline Clarity of Cues & 0.032 & Child age & 0.018 & 0.003 & $<0.001$ \\
\hline \multirow{5}{*}{$\begin{array}{l}\text { Response to } \\
\text { Caregiver } 1\end{array}$} & 0.125 & Caucasian & 0.290 & 0.084 & 0.001 \\
\hline & & $\begin{array}{l}>\text { High school } \\
\text { education }\end{array}$ & 0.281 & 0.091 & 0.001 \\
\hline & & Married & 0.164 & 0.084 & 0.050 \\
\hline & & $\begin{array}{l}\text { Mother's age at } \\
\text { child's birth }\end{array}$ & 0.025 & 0.003 & $<0.001$ \\
\hline & & Child age & 0.023 & 0.003 & $<0.001$ \\
\hline $\begin{array}{l}\text { Response to } \\
\text { Caregiver } 2\end{array}$ & 0.009 & Child sex & 0.064 & 0.056 & 0.025 \\
\hline
\end{tabular}

NOTE. MIMIC $=$ multiple indicators multiple causes; $\beta=$ beta weights; $\mathrm{SE}=$ standard error 
Using goodness-of-fit indices RMSEA, CFI and TLI required model respecification due to poor model fit in the SEGF, CGF, CC and RC subscales (Table 2-5). Poor model fit reflected RMSEA values $>0.05$ and CFI and TLI values $<0.90$ (Brown, 2015; Hooper, Coughlan, \& Mullen, 2008). To improve model fit, a modification index $>10$ was used to allow item associations within each respective subscale. Respecification of the model meant that item associations were allowed one-byone when conducting analysis until the RMSEA, CFI, and TLI values indicated a goodfitting model. Item association varied by subscale factor, but following model respecification, RMSEA, CFI, and TLI displayed both a parsimonious and good-fitting model (Table 2-6). For model fit, RC is displayed as one subscale because RC1 and RC2 were modeled simultaneously during MIMIC analyses.

\section{Discussion}

Formal appraisal of an instrument's psychometric properties requires large and diverse samples to promote generalizability of both the theory or concept under scrutiny and the instrument used to assess that theory or concept (Brown, 2015; Hooper et al., 2008). Hypotheses and assumptions from analyses with IRT, CFA, and MIMIC were met by this study. Conclusions were that while the CFA and MIMIC modeling supported Barnard's conceptual model, they also revealed an opportunity to potentially modify the instrument.

The first potential modification came with the removal of low variability items. Prior to beginning IRT, CFA, and MIMIC analyses these items were carefully considered by the research team. While some of the items could indicate interactive issues in the mother-child relationship, such as the possibility of a mother yelling or slapping her child (Appendix B items 19, 21, 32), other items were almost always innate to the mother, such as positioning her child for safety and within reach of the task materials (Appendix

B items 1 and 2). After reviewing and discussing each items' clinical utility in context of the subscale and NCAT scale the items that were removed were not felt to alter the meaning of the subscale, scale, or assessment of the mother and child.

The second potential modification presented itself when high item associations and negatively correlated items were identified in the Response to Distress, Response to Caregiver, and Clarity of Cues subscales. The RC subscale contains items where there is opportunity for assessing cues of engagement and disengagement. Cues of engagement and disengagement are a necessary part of the MCR from a clinical perspective. From an empirical standpoint, however, evaluating these cues while they are in the same subscale can be difficult because of how they are scored. Even though cues of disengagement are positive communication signals in the MCR, they can display negative correlations because they are actions such as frowning and pushing away. By removing one item from the RD subscale, partitioning the RC subscale into two scales, and reversing the negatively correlated items in the $\mathrm{CC}$ subscale, the research team again felt that the clinical utility of the instrument was unchanged and supported empirical assessment of 
Table 2-5. Model Fit Without Item Association for the NCAST Database

\begin{tabular}{lccc}
\hline Factor & RMSEA & CFI & TLI \\
\hline Sensitivity to Cues & 0.022 & 0.915 & 0.900 \\
Response to Distress & 0.029 & 0.975 & 0.970 \\
Social-Emotional Growth Fostering & 0.051 & 0.762 & 0.722 \\
Cognitive Growth Fostering & 0.061 & 0.838 & 0.821 \\
Clarity of Cues & 0.057 & 0.860 & 0.921 \\
Response to Caregiver & 0.082 & 0.945 & 0.935 \\
\hline
\end{tabular}

NOTE. RMSEA = root mean square error of approximation; CFI = comparative fit index; $\mathrm{TLI}=$ Tucker-Lewis index

Table 2-6. Final Model Fit with Item Association for the NCAST Database

\begin{tabular}{lccc}
\hline Factor & RMSEA & CFI & TLI \\
\hline Sensitivity to Cues-R & 0.021 & 0.916 & 0.923 \\
Response to Distress-R & 0.020 & 0.989 & 0.986 \\
Social-Emotional Growth Fostering-R & 0.031 & 0.914 & 0.895 \\
Cognitive Growth Fostering - R & 0.030 & 0.964 & 0.957 \\
Clarity of Cues-R & 0.044 & 0.921 & 0.891 \\
Response to Caregiver-R & 0.031 & 0.993 & 0.991 \\
\hline
\end{tabular}

NOTE. $\mathrm{R}=$ respecified for model fit; RMSEA $=$ root mean square error of approximation; $\mathrm{CFI}=$ comparative fit index; TLI $=$ Tucker-Lewis index 
interaction. The resulting abbreviated NCAT scale (NCAT-AB) displayed good model fit with the NCAST sample of mothers and children. The final NCAT scale resulting from these analyses consisted of 62 items and 7 subscales.

\section{Conclusions}

Instrument development and modification is a lengthy process that should seek to consider both the statistical and clinical implications of the instrument. Without employing statistical methods for instrument evaluation the instrument lacks reliability and validity, and without considering the clinical use of the instrument accurate inferences about the sample under investigation cannot be made (Brown, 2015; Lynn, 2015). While the NCAT scale is a well-established instrument for assessing the interactions between mothers and their children, it has not been supported with routine critical appraisal in the literature. This study provided critical appraisal supporting the NCAT scale by formally examining its psychometric properties. The significant demographic predictors and underlying subscale factor linkage patterns determined from these analyses indicate that if analyses were conducted in a similar fashion using a large sample of mothers and children with varying demographic characteristics, it could further benefit those who use the NCAT scale in their practice and research. 


\section{CHAPTER 3. PSYCHOMETRIC EVALUATION OF THE NURSING CHILD ASSESSMENT TEACHING SCALE IN A COMMUNITY BASED SAMPLE OF MOTHERS AND CHILDREN FROM THE CONDITIONS AFFECTING NEUROCOGNITIVE DEVELOPMENT AND LEARNING IN EARLY CHILDHOOD STUDY}

\section{Introduction}

The first three years of a child's life are arguably the most critical time period during development (National Scientific Council on the Developing Child, 2014; Shonkoff, Richter, van der Gaag, \& Bhutta, 2012). By age three, a child's brain is $80 \%$ of the volume and contains twice as many synapses as exists in adulthood (Klass, Needlman, \& Zuckerman, 2003). Synapses form neural circuits which are particularly plastic during early childhood. Through a "blooming and pruning" process, circuits used more frequently take root and bloom while circuits used infrequently become inactive and are pruned (Huttenlocher, 2002).

Essential to this blooming and pruning process is the mother-child relationship (MCR). It is through the interactive processes embedded in the MCR that children begin to understand the world around them, process new information, problem solve, and develop social relationships (Banerjee \& Tamis-LeMonda, 2007; Barnard, 2010; ElseQuest, Clark, \& Tresch Owen, 2011; Tronick, 2010). The interactions occurring between the mother and child increase in complexity over time, building on the child's developing cognitive and social-emotional frameworks. Unsupportive environments can place a strain on the MCR and its interactive processes. Without appropriate resource availability and utilization, this prolonged strain can negatively affect and even be toxic to the child's overall development (Brooks-Gunn \& Duncan, 1997; Horodynski \& Gibbons, 2004; Schiffman, Omar, \& McKelvey, 2003). Because the quality and quantity of interactions in the MCR are important predictors of the child's future development, early identification of areas in the MCR requiring support and potential intervention is essential for promoting positive child developmental outcomes.

Observational assessment is considered by many to be best practice for evaluating maternal-child interaction (MCI) (Lavelli \& Fogel, 2013; Lester, 2010; Pridham, Lutz, Anderson, Riesch, \& Becker, 2010; Tronick, 2001). Although its roots are in the field of psychology, observational assessment is often used by nurses. Using the developmental concepts of contingency, positioning, verbalness, sensitivity, affect, and engagement/disengagement, Kathryn Barnard, a nurse with expertise and extensive training in psychology, developed a theoretical model of MCI. The Barnard Model characterizes the mother and child as living in constant communication with one another and as having certain individual responsibilities that enable their interactions. Barnard's model provides the basis for the Nursing Child Assessment Teaching (NCAT) scale, which is used to quantify the overall quality of interaction in the MCR during the first 36 months of a child's life (Oxford \& Findlay, 2013). 
Extensive use of the NCAT scale contributed to the development of the Nursing Child Assessment Satellite Training (NCAST) database. Described in the most recent NCAT training manual, the database contains approximately 2100 mother-child observations from across the United States and combines both community and clinically based samples. Mostly Caucasian (54\%) and married (77.2\%) women with a minimum high school education ( $80 \%$ ) who average 25.7 years of age at the birth of their child comprise the NCAST database. Data from children in the NCAST database average 15.5 months of age and 52\% are male. This NCAST sample of mother-child dyads has been used to establish the internal consistency reliability and validity of the NCAT scale (Oxford \& Findlay, 2013).

Empirical evidence supporting the use of the NCAT scale in the assessment of MCI is extensive. The instrument is used in both community- and clinically-based samples, ethnically diverse populations, and many intervention studies to describe parenting characteristics and behaviors as well as child developmental outcomes (Banerjee \& Tamis-LeMonda, 2007; Drummond, Letourneau, Neufeld, Stewart, \& Weir, 2008; Oxford \& Findlay, 2013; Pridham et al., 2010; White-Traut et al., 2013). While these studies have shown the NCAT scale as both a reliable and valid instrument, limited evidence exists confirming theoretical congruence between the Barnard Model and the NCAT scale. Theoretical congruence of the model and the NCAT scale across varying demographic samples is important in supporting the reliability and validity of the instrument. Therefore, the purpose of this study was to examine the psychometric properties of the NCAT scale using a community-based sample of mothers and children from the Conditions Affecting Neurocognitive Development and Learning in Early Childhood (CANDLE) study. The research questions for this study were: 1) what are the psychometric properties of the NCAT scale in this sample of mothers and children from the CANDLE database, and 2) how are the demographic characteristics of mothers and children from the CANDLE database associated with the observed interactions measured by the NCAT scale?

Hypotheses for this study were that: 1) the psychometric properties of the NCAT scale would be supported in the sample of mothers and children from the CANDLE database, 2) the association between demographic characteristics of mothers and children from the CANDLE database and observed interactions measured by the NCAT scale would vary in strength, and 3) the influence of demographic characteristics on observed interactions between mothers and children from the CANDLE database would be different than those reported in the NCAST database.

\section{Methods}

\section{Parent Study}

The current study was a secondary analysis of data from the Conditions Affecting Neurocognitive Development and Learning in Early Childhood (CANDLE) study. The 
CANDLE study is a descriptive, longitudinal study designed to investigate the effects of maternal prenatal activities along with the child's development, experiences, genetic makeup, and environmental exposures on brain development during the first three years of life (The Department of Preventive Medicine UTHSC, 2014). The overall aim of CANDLE is to improve the health and well-being of children living in Shelby County, Tennessee, where $30 \%$ of children live in poverty and half of this $30 \%$ live in extreme poverty (U.S. Census, 2011). The convenience sample of 1,503 mothers who were enrolled in the CANDLE study during their second trimester of pregnancy is a representative demographic sample of Shelby County where $52 \%$ of the population are Black, $71.5 \%$ have at least a high school education, $61 \%$ are single mothers, and $77 \%$ are between the ages of 20-35 (U.S. Census, 2011). Similarly, $66 \%$ of mothers enrolled in the CANDLE study are Black, $31 \%$ are Caucasian, $88 \%$ have at least a high school education, $63 \%$ are single mothers, and $82 \%$ are between the ages of $20-35$ (The Department of Preventive Medicine UTHSC, 2014). The mothers and children enrolled in the CANDLE study have been systematically followed since 2006 using clinic visits, home visits, and phone calls (Palmer et al., 2013; Völgyi et al., 2013). Data collection using 54 questionnaires as well as biological measures from the mother and child continues.

The NCAT scale is one of the instruments used in CANDLE to evaluate the interactions between mothers and children in the sample. Appropriate use of the NCAT scale requires a certified observer to evaluate the interaction between the mother and child as the mother teaches the child an unfamiliar, developmentally challenging task. Interaction evaluation can occur through real-time or video recorded observation. For the CANDLE study, cognitive examiners were trained and certified as reliable NCAT observers to the standard of the NCAST program, maintaining $>85 \%$ correctness in their submitted coding assessments. Observations were conducted in real-time with the mother, child, and cognitive examiner in the same room and occurred when the child reached 12-months, 24-months and 36-months of age, coinciding with CANDLE study clinic visits one, two, and three.

\section{The Nursing Child Assessment Teaching Scale Instrument}

The NCAT scale contains 73 yes/no items categorized into 6 subscales. These subscales assess specific mother and child characteristics consistently shown to influence MCI and include four mother and two child subscales. Mother subscales include sensitivity to cues (SC), response to child's distress (RD), social-emotional growth fostering (SEGF), and cognitive growth fostering (CGF); the child subscales include clarity of cues (CC) and responsiveness to the caregiver (RC). In addition, the instrument contains 32 embedded contingency items evaluating the reciprocal behaviors of the mother and child as a dyad. These items display the subtle and obvious reactions of the mother to the child and vice versa as they exchange cues during their interaction. The cues assessed by the NCAT scale are the communication signals between the motherchild dyad and consist of both non-verbal and verbal behaviors such as facial 
expressions; changes in body posture; and talking, laughing, and crying (Oxford \& Findlay, 2013).

Each subscale in the NCAT scale evaluates a unique aspect of the MCR. Table 3-1 contains examples of NCAT scale items from each subscale and Figure 1-2 displays the Barnard model on which these subscales are based. The environment, mother, child, or any combination of the three can interrupt the adaptive processes of interaction represented by the Barnard model (Oxford \& Findlay, 2013). Specifically, the SC and RD subscales assess the mother's ability to perceive and accurately interpret her infant's communication signals and respond accordingly with appropriate interventions while the SEGF and CGF subscales assess the ability of the mother to engage the child in activity using age-appropriate language and motivators. The $\mathrm{CC}$ and $\mathrm{RC}$ subscales assess the ability of the child to provide the mother with clear communication signals while also reading and responding to the mother's attempts at interaction.

Scoring of the NCAT scale occurs in a stepwise fashion. First, the 73 items in the subscales are added based on "yes" observations. The four mother subscales are combined to provide a mother total score, and the two child subscales are combined to provide a child total score. A score of 50 is possible for the mother, and a score of 23 is possible for the child, yielding a total scale score up to 73 . The 32 contingency items embedded in the mother and child subscales are scored in the same manner. A score of 20 is possible for the mother, and a score of 12 is possible for the child, yielding a contingency mother and child total score up to 32. More "yes" observations yield higher mother, child, and total scores, indicating positive interactive ability.

\section{Sample for Secondary Analysis}

To provide a baseline assessment of MCI in mother-child dyads enrolled in the CANDLE study, data from the sample of 1132 dyads who completed their first clinic visit were requested and obtained from the primary CANDLE investigators. Participant attrition between enrollment and the first clinic visit was multifactorial and included fetal demise, post-consent ineligibility, and pre-delivery withdrawal from the study (Palmer et al., 2013). Of the 1132 remaining dyads, 7 did not have existing NCAT scale data and 4 children were assessed by the CANDLE study team without their birth mothers which excluded them from this analysis. In addition, NCAT scale items on which mothers and/or their children scored a "yes" greater than $97 \%$ of the time were excluded due to minimal response variability, leaving 62 of the 73 original items and 1121 dyads for secondary analysis.

\section{Procedure}

The Barnard Model of caregiver-child interaction was examined using item response theory (IRT) and structural equation modeling methods of confirmatory factor 
Table 3-1. Examples of NCAT Items Observations by Subscale

\begin{tabular}{lcl}
\hline Subscale & Item & \multicolumn{1}{c}{ Observation } \\
\hline Sensitivity to Cues & 4 & $\begin{array}{l}\text { Caregiver gives instruction only when child is attentive } \\
\text { (90\% of the time) }\end{array}$ \\
$\begin{array}{l}\text { Response to Distress } \\
\text { Caregiver changes voice volume to softer or higher pitch, } \\
\text { does not yell. } \\
\text { Caregiver makes cheerleading type statements to the } \\
\text { child during the teaching interaction. }\end{array}$ \\
$\begin{array}{l}\text { Social-Emotional } \\
\text { Growth Fostering }\end{array}$ & 29 & $\begin{array}{l}\text { Caregiver uses explanatory verbal style more than } \\
\text { imperative style in teaching the child. }\end{array}$ \\
$\begin{array}{l}\text { Cognitive Growth } \\
\text { Fostering }\end{array}$ & 40 & $\begin{array}{l}\text { Child smiles or laughs during the episode. } \\
\text { Clarity of Cues }\end{array}$ \\
$\begin{array}{l}\text { Response to } \\
\text { Caregiver }\end{array}$ & 57 & $\begin{array}{l}\text { Child shows subtle and/or potent disengagement cues } \\
\text { within five seconds after caregiver changes facial } \\
\text { expression or body movement. }\end{array}$ \\
\hline
\end{tabular}

NOTE. The Nursing Child Assessment Teaching Scale Instrument. Oxford, M. L., \& Findlay, D. M. (2013). NCAST caregiver/parent-child interaction teaching manual. University of Washington, School of Nursing, Seattle: NCAST Programs. 
analysis (CFA) and multiple indicators multiple causes (MIMIC) modeling. Analyses were conducted in $\mathrm{R}$ version 3.1.3 (R Core Team, 2015). R packages used included pysch (Revelle, 2015), ltm (Rizopoulos, 2006), lavaan (Rosseel, 2012), semTools (SemTools Contributors, 2015), Amelia (Honaker, King, \& Blackwell, 2011), and car (Fox \& Weisberg, 2011).

Each of the 62 retained NCAT scale items were evaluated for difficulty and discriminatory capability using two-parameter (2-PL) IRT. Such 2-PL IRT models show how the participant responses to instrument items relate to the properties of the item as well as the latent traits of the individual (Baker, 2001; Brown, 2015). Identifying item ability to discriminate allowed assessment of the sensitivity of the items in the scale. Latent traits of mothers included the overall ability of the mothers to be sensitive to their child's cues, to respond to their child's distress, and to provide social emotional and cognitive growth-fostering situations for their child. Latent traits of children included the ability of the child to provide his or her mother with clear cues and respond to her as developmentally appropriate.

CFA and MIMIC modeling allow hypothesized causal processes and relationships among variables to be visually illustrated while testing an underlying theoretical or conceptual model. For this secondary analysis, descriptive statistics, reliabilities, and factor loadings were obtained using CFA. These CFA measurement models were then augmented to form MIMIC models linking manifest demographic predictors to the six NCAT subscale factors. Demographic predictors included maternal parity, age at child's birth, education, race, marital status, income and insurance status, and child age and sex. Maternal parity, age at child's birth, education, race, marital status and child age and sex were chosen based on the demographic predictors provided in the NCAST database and NCAT manual. Income and insurance were added at the request of the primary CANDLE investigators to allow more accurate inferences to be made regarding the influences of socioeconomic status (SES) on interaction in the MCR. Addition of these variables was necessary because of the relationship between SES and the MCR discussed in literature on early child development (Brooks-Gunn \& Duncan, 1997; Hackman \& Farah, 2009; Patterson \& Vakili, 2014). SES is defined as the combination of education, income, and occupation and has been commonly identified as a predictor of child cognition, language development, and educational achievement (Hair, Hanson, Wolfe, \& Pollak, 2015; Rhoades et al., 2011).

Data were missing from demographic predictors and NCAT scale items in 177 dyads from the CANDLE database (Table 3-2). Only four NCAT scale items (item numbers 5, 35, 39, and 42) had complete responses. Incomplete responses to items were likely due to the live observation methods used in data collection. To address issues related to missing demographic and NCAT scale data, multiple imputation with 20 imputed data sets was employed using the Amelia R package (Honaker, King, \& Blackwell, 2011). Use of multiple imputation was chosen over other approaches that address missing data because it produces unbiased parameter estimates allowing for more accurate inferential conclusions (Schlomer, Bauman, \& Card, 2010). 
Table 3-2. Demographic Characteristics of the CANDLE Database for Secondary Analysis

\begin{tabular}{|c|c|c|c|}
\hline Variable & n (\%) & Mean (SD) & Missing (\%) \\
\hline \multicolumn{4}{|l|}{ Maternal $(n=1,121)$} \\
\hline Age & & $27.40(5.5)$ & \\
\hline$\leq 18$ years & $63(5.6)$ & & \\
\hline $19-25$ years & $431(38.4)$ & & \\
\hline $26-35$ years & $561(50.0)$ & & \\
\hline$>35$ years & $66(5.9)$ & & \\
\hline Education & & & 1 case $(0.1)$ \\
\hline$<$ High School & $107(9.6)$ & & \\
\hline High School or GED & $502(44.8)$ & & \\
\hline Technical School & $105(9.4)$ & & \\
\hline College & $253(22.6)$ & & \\
\hline Graduate/Professional degree & $153(13.7)$ & & \\
\hline Marital status & & & 2 cases $(0.1)$ \\
\hline Married & $476(42.5)$ & & \\
\hline Never married & $416(37.2)$ & & \\
\hline Living with partner & $195(17.4)$ & & \\
\hline Divorced & $20(1.7)$ & & \\
\hline Separated & $12(1.1)$ & & \\
\hline Parity & & & 41 cases $(3.6)$ \\
\hline Mother has only 1 child & $458(40.8)$ & & \\
\hline Mother has more than 1 child & $622(55.5)$ & & \\
\hline Race & & & 2 cases $(0.1)$ \\
\hline Caucasian & $400(35.7)$ & & \\
\hline Black & $700(62.6)$ & & \\
\hline Asian & $11(0.9)$ & & \\
\hline Other & $8(0.7)$ & & \\
\hline Income & & & 69 cases $(6.2)$ \\
\hline$\leq \$ 25,000$ & $422(37.6)$ & & \\
\hline$>\$ 25,000$ & $630(56.2)$ & & \\
\hline \multicolumn{4}{|l|}{ Insurance } \\
\hline Medicaid & $611(54.5)$ & & \\
\hline Other types & $510(45.5)$ & & \\
\hline \multicolumn{4}{|l|}{ Child $(n=1,121)$} \\
\hline Age & & $13(0.13)$ & \\
\hline$<12$ months & $252(22.5)$ & & \\
\hline 12 months & $461(41.1)$ & & \\
\hline$>12$ months & $408(36.4)$ & & \\
\hline \multicolumn{4}{|l|}{ Sex } \\
\hline Male & $563(50.2)$ & & \\
\hline Female & $558(49.8)$ & & \\
\hline
\end{tabular}




\section{Analysis Strategy}

In the CFA and MIMIC analyses, NCAT scale item associations were allowed within subscale factors. Model fit was evaluated using three goodness-of-fit indices. Root mean square error of approximation (RMSEA) $<0.05$ was used to evaluate model parsimony based on the sample, while the comparative fit index (CFI) $>0.90$ and TuckerLewis index (TLI) $>0.90$ were used to evaluate model fit between the baseline Barnard model and the investigator specified abbreviated model (Brown, 2015). Model $\chi^{2}$ were obtained but were not considered informative due to the large sample size (Hooper, Coughlan, \& Mullen, 2008). In addition, Cronbach's alpha coefficient estimates were calculated for the Mother Total score, Child Total score, and NCAT Scale Total score as a measure of internal consistency reliability.

\section{Results}

\section{Item Response Theory}

NCAT subscale items' difficulties and discriminations were examined by 2-PL IRT, and the item discriminations classified as very low, low, moderate, high, or very high (Appendix C; Brown, 2015). Reasonable discrimination estimates were produced by five of the six subscales, but examination of the Response to Caregiver (RC) subscale uncovered several negative item discriminations. While in other subscales the easiest items had low discriminatory strength, in the RC subscale the easiest items had very high discriminatory strength. Instead of reverse coding items with negative discrimination for further analyses, the original RC subscale was partitioned into 2 smaller more homogeneous scales named Response to Caregiver 1 (RC1) and Response to Caregiver 2 (RC2) with items $61-67$ going to RC1 and items $68-73$ to RC2.

Items in the RC subscale are contingency items and each, except for one, require an action from both the mother and child to be given a "yes" score. The similarity in NCAT item task-action response between some items resulted in some items in the RC1 subscale being very highly correlated $(>0.90)$ and led to a nonpositive item correlation matrix. Consequently, items 63, 65, and 66 were removed from the $\mathrm{RC} 1$ subscale. Additional high item correlations $(>0.85)$ were identified in the Cognitive Growth Fostering (CGF) subscale. Therefore, items 42 and 45 were also removed before further analyses. The choice of which items to retain after identifying these collinearity issues was based on the discriminating strength of the subscale items. Items which were stronger discriminators were left in the RC1 and CGF subscales.

In addition, items $68-72$ in RC2 subscale and items $58-60$ in the Clarity of Cues (CC) subscale were negatively correlated with each respective total scale score and were reverse coded. By reversing the negatively correlated items to positive correlations, the clinical utility of the items was unchanged. As with analyses conducted using the NCAST database in Chapter 2, items removed before analysis for low observational 
response variability and during analyses for collinearity issues are presented by subscale in Appendix D for the CANDLE database. Removal of items and splitting of the RC subscale left 57 total items and 7 subscale factors.

Final IRT, CFA and MIMIC analyses were conducted using the resultant abbreviated version of the NCAT scale (NCAT-AB). Overall, the abbreviated subscales lacking seven mother items, nine child items, and four embedded contingency items had reasonable values for item characteristics. Table 3-3 presents a summary of item discrimination categories by subscale factor for the 57 retained NCAT items. Items in the Response to Distress (RD) subscale exhibited strong associations with the underlying latent factor, as evidenced by the presence of only moderate to very high discriminations, whereas items in the Sensitivity to Cues (SC) subscale appeared weakest in the study sample.

\section{Confirmatory Factor Analysis and Multiple Indicators Multiple Causes}

Correlations, or factor loadings, for the 57 retained NCAT scale items and their respective subscales are displayed in Table 3-4. Items with weak correlation $(<0.40)$ were identified and considered in each subscale (Brown, 2015; Pett, Lackey, \& Sullivan, 2003). These items were left in the NCAT-AB scale due to clinical relevance and are presented in the Discussion that follows.

Augmenting the CFA, structural MIMIC models displayed significant demographic predictors $(\mathrm{p}<0.05)$ and underlying subscale factor linkage patterns which varied by subscale (Table 3-5). Maternal ability to respond sensitively to her child's cues as assessed by the SC subscale was greater when the child was older and when mothers were Caucasian and married. Maternal ability to calm or alleviate the distress of her child as assessed by the RD subscale was greater when mothers had higher than a high school education, had higher levels of income, and were older when their child was born. Maternal ability to provide social-emotional growth fostering through affect and physical touch as assessed by the SEGF subscale was greater when mothers had higher levels of income, were married, Caucasian, had higher than a high school education, and were older when their child was born. Maternal ability to provide cognitive growth fostering through appropriate developmental activities as assessed by the CGF subscale was greater when mothers had higher levels of income, were Caucasian, and married. Child ability to provide clear cues for his or her mother, as indicated by the CC subscale, was greater when the child's mother had a higher level of income and child responsiveness to his or her mother's attempts at interaction, as indicated by the RC2 subscale, was greater when the child was older. Parity of the mother, child sex, and insurance status were not predictors of caregiver or child subscale factors.

In the final MIMIC model, NCAT scale items were reversed and removed as previously mentioned. Using goodness-of-fit indices, CFI and TLI required model 
Table 3-3. Item Discriminations by Category and Subscale Factor for the CANDLE Database

\begin{tabular}{lccccc}
\hline Factor & $\begin{array}{c}\text { Very } \\
\text { Low }\end{array}$ & Low & Moderate & High & $\begin{array}{c}\text { Very } \\
\text { High }\end{array}$ \\
\hline $\begin{array}{l}\text { Sensitivity to Cues } \\
\text { Response to Distress }\end{array}$ & 0 & 4 & 3 & 1 & 1 \\
$\begin{array}{l}\text { Social-Emotional } \\
\text { Growth Fostering }\end{array}$ & 0 & 0 & 3 & 2 & 5 \\
$\begin{array}{l}\text { Cognitive Growth } \\
\text { Fostering }\end{array}$ & 1 & 2 & 8 & 1 & 2 \\
$\begin{array}{l}\text { Clarity of Cues } \\
\text { Response to }\end{array}$ & 0 & 1 & 0 & 0 & 3 \\
$\begin{array}{l}\text { Caregiver 1 } \\
\text { Response to }\end{array}$ & 0 & 0 & 2 & 0 & 2 \\
Caregiver 2 & 0 & 0 & 2 & 0 & 4 \\
\hline
\end{tabular}


Table 3-4. CFA Factor Loadings of the NCAT Scale for the CANDLE Database

\begin{tabular}{|c|c|c|}
\hline Factor & Item & Item Correlation \\
\hline \multirow[t]{9}{*}{ Sensitivity to Cues } & 3 & 0.732 \\
\hline & 4 & 0.806 \\
\hline & 5 & 0.595 \\
\hline & 6 & 0.194 \\
\hline & 7 & 0.517 \\
\hline & 8 & 0.341 \\
\hline & 9 & 0.249 \\
\hline & 10 & 0.190 \\
\hline & 11 & 0.161 \\
\hline \multirow[t]{10}{*}{ Response to Distress } & 12 & 0.407 \\
\hline & 13 & 0.936 \\
\hline & 14 & 0.860 \\
\hline & 15 & 0.304 \\
\hline & 16 & 0.747 \\
\hline & 17 & 0.487 \\
\hline & 18 & 0.917 \\
\hline & 19 & 0.663 \\
\hline & 20 & 0.646 \\
\hline & 22 & 0.541 \\
\hline \multirow[t]{9}{*}{ Social-Emotional Growth Fostering } & 24 & 0.203 \\
\hline & 25 & 0.872 \\
\hline & 26 & 0.601 \\
\hline & 27 & 0.830 \\
\hline & 28 & 0.620 \\
\hline & 29 & 0.395 \\
\hline & 30 & 0.247 \\
\hline & 31 & 0.299 \\
\hline & 33 & 0.341 \\
\hline \multirow[t]{5}{*}{ Cognitive Growth Fostering } & 34 & 0.176 \\
\hline & 35 & 0.429 \\
\hline & 36 & 0.351 \\
\hline & 37 & 0.296 \\
\hline & 38 & 0.749 \\
\hline
\end{tabular}


Table 3-4. (Continued)

\begin{tabular}{lcc}
\hline Factor & Item & Item Correlation \\
\hline & 39 & 0.612 \\
40 & 0.594 \\
41 & 0.480 \\
43 & 0.347 \\
44 & 0.588 \\
& 46 & 0.451 \\
& 47 & 0.843 \\
& 48 & 0.511 \\
Clarity of Cues & 49 & 0.367 \\
& 50 & 0.056 \\
Response to Caregiver 1 & 57 & 0.255 \\
& $58 \mathrm{R}$ & 0.787 \\
& $59 \mathrm{R}$ & 0.948 \\
$60 \mathrm{R}$ & 0.859 \\
Response to Caregiver 2 & 61 & 0.926 \\
& 62 & 0.813 \\
& 64 & 0.260 \\
& 67 & 0.553 \\
& $68 \mathrm{R}$ & 0.598 \\
& $69 \mathrm{R}$ & 0.413 \\
& $70 \mathrm{R}$ & 0.456 \\
& $71 \mathrm{R}$ & 0.934 \\
$72 \mathrm{R}$ & 0.912 \\
& 73 & 0.225 \\
\hline
\end{tabular}

NOTE. $\mathrm{R}=$ reverse coded items; $\mathrm{CFA}=$ confirmatory factor analysis; item correlations $<0.40$ represent weak loadings on the factor; item correlations closer to 1.0 represent strong loadings on the factor 
Table 3-5. MIMIC Models for Significant Predictors in the CANDLE Database

\begin{tabular}{|c|c|c|c|c|c|}
\hline Factor & Factor $\mathbf{R}^{2}$ & Predictor & $\beta$ & SE & P-Value \\
\hline \multirow{3}{*}{$\begin{array}{l}\text { Sensitivity to } \\
\text { Cues }\end{array}$} & \multirow[t]{3}{*}{0.195} & Child age & 0.852 & 0.359 & 0.018 \\
\hline & & Caucasian & 0.458 & 0.124 & 0.000 \\
\hline & & Married & 0.344 & 0.140 & 0.014 \\
\hline \multirow[t]{3}{*}{$\begin{array}{l}\text { Response to } \\
\text { Distress }\end{array}$} & \multirow[t]{3}{*}{0.174} & $\begin{array}{c}>\text { High school } \\
\text { education }\end{array}$ & 0.444 & 0.131 & 0.002 \\
\hline & & Income & 0.261 & 0.110 & 0.018 \\
\hline & & $\begin{array}{l}\text { Mother's age at } \\
\text { child's birth }\end{array}$ & 0.036 & 0.009 & 0.003 \\
\hline \multirow{5}{*}{$\begin{array}{l}\text { Social-Emotional } \\
\text { Growth Fostering }\end{array}$} & \multirow[t]{5}{*}{0.225} & Income & 0.423 & 0.121 & 0.000 \\
\hline & & Married & 0.375 & 0.132 & 0.005 \\
\hline & & Caucasian & 0.348 & 0.112 & 0.002 \\
\hline & & $\begin{array}{c}>\text { High school } \\
\text { education }\end{array}$ & 0.313 & 0.147 & 0.033 \\
\hline & & $\begin{array}{l}\text { Mother's age at } \\
\text { child's birth }\end{array}$ & 0.024 & 0.010 & 0.022 \\
\hline \multirow{3}{*}{$\begin{array}{l}\text { Cognitive Growth } \\
\text { Fostering }\end{array}$} & \multirow[t]{3}{*}{0.255} & Income & 0.456 & 0.118 & 0.000 \\
\hline & & Caucasian & 0.439 & 0.104 & 0.000 \\
\hline & & Married & 0.307 & 0.120 & 0.011 \\
\hline Clarity of Cues & 0.047 & Income & 0.287 & 0.117 & 0.014 \\
\hline $\begin{array}{l}\text { Response to } \\
\text { Caregiver } 1\end{array}$ & 0.038 & - & - & - & - \\
\hline $\begin{array}{l}\text { Response to } \\
\text { Caregiver } 2\end{array}$ & 0.033 & Child age & -0.662 & 0.336 & 0.049 \\
\hline
\end{tabular}

NOTE. MIMIC = multiple indicators multiple causes; $\beta=$ beta weights; $\mathrm{SE}=$ standard error 
respecification due to poor model fit, except for the CC subscale (Table 3-6).

Poor model fit reflected CFI and TLI values $<0.90$ (Brown, 2015; Hooper, Coughlan, \& Mullen, 2008). To improve model fit, a modification index $>10$ was used to respecify the model by allowing item associations within each respective subscale. Respecifying the model meant that item associations were allowed one-by-one when conducting analysis until the CFI and TLI indicated a good-fitting model. Item association varied by subscale factor, and because the $\mathrm{CC}$ subscale did not have any associated items, the fit indices before and after model modification did not change. Those subscales which were respecified are designated by an $\mathrm{R}$ following the subscale factor. RMSEA, CFI, and TLI displayed both a parsimonious and good-fitting model following respecification (Table 3-7).

Cronbach's alpha coefficients for the Mother Total score, Child Total score, and NCAT-AB Scale Total score were estimated before and after reversing identified negatively correlated items in the $\mathrm{RC}$ and $\mathrm{CC}$ subscales. Item reversal occurred in the child related subscales and subsequently, the alpha coefficients for the Child Total score and NCAT Scale Total score improved (Table 3-8). Overall, the alpha coefficients for the Mother Total and Child Total scores were lower than for the NCAT Scale Total score.

\section{Discussion}

The NCAT scale evaluates the constantly evolving interactive nature of the MCR during the first 36-months of the child's life. Although previously conducted studies have shown the NCAT scale as both a reliable and valid instrument for assessing the quality of MCI, formal examination of the psychometric properties of the NCAT scale confirming the congruence of the Barnard Model and the NCAT scale have been limited in the literature. Using the CANDLE sample of 1,121 mother-child dyads, these hypotheses were met and the results of this secondary data analysis provided support for Barnard's theoretical model of MCI while offering an opportunity for potential instrument modification and abbreviation.

In factor analysis, loadings of 0.40 are often the cut-point for determining whether an item belongs in its respective factor (Brown, 2015; Pett, Lackey, \& Sullivan 2003). Using 0.40 as a cut-point would have required removal of 20 additional items from the NCAT scale. After review, the research team felt these 20 items were essential to the clinical assessment of MCI and needed to remain in the NCAT-AB scale. Differentiating statistical versus clinical relevance in instrument development and revision requires careful consideration of the items and subscales in the context of what the instrument is intended to measure (Brown, 2015; Hooper, Coughlan, \& Mullen, 2008). From a clinical standpoint, the items contained in the NCAT subscales have helped researchers and practitioners in the early identification of interaction concerns and difficulties in the MCR. Although some of the items have consistently low rates of observed response 
Table 3-6. Model Fit Without Item Association for the CANDLE Database

\begin{tabular}{lccc}
\hline Factor & RMSEA & CFI & TLI \\
\hline Sensitivity to Cues & 0.026 & 0.806 & 0.768 \\
Response to Distress & 0.037 & 0.912 & 0.897 \\
Social-Emotional Growth Fostering & 0.035 & 0.848 & 0.821 \\
Cognitive Growth Fostering & 0.044 & 0.762 & 0.736 \\
Clarity of Cues & 0.014 & 0.994 & 0.991 \\
Response to Caregiver & 0.060 & 0.895 & 0.866 \\
\hline
\end{tabular}

NOTE. RMSEA = root mean square error of approximation; $\mathrm{CFI}=$ comparative fit index; TLI $=$ Tucker-Lewis index

Table 3-7. Final Model Fit with Item Association for the CANDLE Database

\begin{tabular}{lccc}
\hline Factor & RMSEA & CFI & TLI \\
\hline Sensitivity to Cues-R & 0.015 & 0.919 & 0.901 \\
Response to Distress-R & 0.022 & 0.970 & 0.963 \\
Social-Emotional Growth Fostering-R & 0.011 & 0.971 & 0.964 \\
Cognitive Growth Fostering-R & 0.023 & 0.938 & 0.929 \\
Clarity of Cues & 0.014 & 0.994 & 0.991 \\
Response to Caregiver-R & 0.037 & 0.961 & 0.950 \\
\hline
\end{tabular}

NOTE. $\mathrm{R}=$ respecified for model fit; RMSEA = root mean square error of approximation; $\mathrm{CFI}=$ comparative fit index; TLI = Tucker-Lewis index

Table 3-8. Cronbach's Alphas ( $\alpha$ ) for the NCAT-AB Scale Scores before and after Item Reversal in the CANDLE Database

\begin{tabular}{lcc}
\hline Scale Scores & $\boldsymbol{\alpha}$ Before Item Reversal & $\boldsymbol{\alpha}$ After Item Reversal \\
\hline Mother Total & 0.81 & 0.81 \\
Child Total & 0.21 & 0.71 \\
NCAT Scale Total & 0.78 & 0.84 \\
\hline
\end{tabular}

NOTE. NCAT-AB $=$ abbreviated version of the NCAT scale 
variability and low item-factor correlation, they are necessary for identifying high-risk mother-child dyads with the potential for low-quality interaction and may be of particular interest to some clinicians and researchers.

By using IRT, the specific characteristics of the mother and child assessed in each item of the NCAT subscales provided insight into the sensitivity of the instrument as a whole. While items ranged in difficulty, they were able to discriminate between the interactive abilities of the mothers and children. Initially, the eight negatively correlated items identified in the Response to Caregiver and Clarity of Cues subscales were thought to be reverse coded in the instrument indicating either a potential issue with the construct of the subscales or the scoring of items by the cognitive examiners. However, after review by the research team, the reverse coded items were determined to be an appropriately coded assessment of disengagement cues coming from the child. During an interaction assessment using the NCAT scale, disengagement cues such as frowning and pushing away display the child's need to break from interaction with his or her mother and are scored as a "yes" during the observation. Because these cues are disengagement, rather than engagement, they can display negative correlations despite the fact they are positive interaction indicators in the MCR. If the mother does not recognize and respond appropriately to the disengagement cues coming from the child or the child does not clearly demonstrate the cues, the interactive system and adaptive processes in the MCR can break down (Oxford \& Findlay, 2013).

The improvement in alpha coefficients supported the need to reverse specific NCAT items in the CANDLE study sample. Because the child items in the CC subscale and contingency items in the RC subscale required reverse scoring during observation, alpha scores for both the child subscale and the total instrument improved after reversing the items' correlation sign. Reversing the items did not change their use clinically but allowed for higher internal consistency reliability scores, suggesting the 57-item NCATAB scale presented in this study reliably measures the concepts embedded in the Barnard Model.

The Cronbach's alpha for the total scale was the highest score, indicating stability among the items across the subscales in the instrument. The NCAT scale manual reports alphas from the NCAST database of 0.87 for the Mother Total, 0.81 for the Child Total, and 0.87 for the NCAT Scale Total using all 73 original NCAT items (Oxford \& Findlay, 2013). The difference in alpha coefficients between the 57-item NCAT-AB scale reported in this study and the alphas reported for the 73-item full instrument in the NCAT manual may be related to the CANDLE study sample versus sample represented in the NCAST database.

The reliability and validity of any instrument should be considered in various demographic samples to support the generalizability of results. MIMC modeling considered the influence of demographics from the CANDLE sample on the NCAT scale. Results from MIMIC provided further support of the theoretical congruence between the Barnard Model and the NCAT scale. While demographic characteristics considered in this study were assessed as independent predictors, there were patterns that emerged from 
their resulting associations with the NCAT subscales. When the age of the mother was a significant predictor of her responsiveness and ability to provide social-emotional growth fostering activities, her level of education was also a significant predictor of these subscales. When marital status was a significant predictor of maternal sensitivity, socialemotional, and cognitive growth fostering ability, Caucasian race was also a significant predictor of these subscales. Associations between NCAT subscales and higher levels of household income varied in relation to other demographic predictors.

In the literature, demographic characteristics associated with the mother indicate that mothers who are older have typically attained higher levels of education, which is often associated with higher levels of income (Horodynski \& Gibbons, 2004; Noble et al., 2015). In addition, mothers who are married are thought to have increased social support and may also have a higher total household income because of two incomes in the family (Lanza et al., 2011; Patterson \& Vakili, 2014). Higher household income can offer economic stability for mothers and their children and may allow mothers to be more available and responsive to their child's needs as they provide cognitive and socialemotional growth fostering activities (Hackman \& Farah, 2009).

The implication that the Caucasian race significantly predicted maternal sensitivity and both social and cognitive growth-fostering ability despite a predominantly Black CANDLE study sample may be related to the demographic characteristics of the NCAST sample on which the NCAT scale was originally validated. Because the NCAST sample is predominantly Caucasian, consideration should be given to re-norming the NCAT scale with a more diverse sample in the future. There are cultural differences in interaction styles and environmental factors that exist beyond what demographics reveal (Sameroff, 2010; Sparrow, 2013; Tronick, 2007).

Environmental stability and supportive primary caregiving relationships act as buffers against experiences that may negatively influence or become toxic to the child's development (Garner, 2013; Horodynski \& Gibbons, 2004; Mooney-Doyle, Deatrick, Horowitz, 2015; Shonkoff, Richter, van der Gaag, \& Bhutta, 2012). Mothers who are able to perceive and accurately interpret their child's communication signals and respond appropriately, more easily engage their child in meaningful interaction using ageappropriate language and motivators. Increased sensitivity and responsiveness of the mother is not only a positive predictor of the child's social-emotional competence but also later cognition and academic achievement (Bornstein \& Tamis-LeMonda, 2010; Page et al., 2010; Raby, Roisman, Fraley, \& Simpson, 2015).

\section{Limitations}

The interactions between mothers and children enrolled in the CANDLE study were not recorded but instead each observation occurred during a scheduled clinic visit and was scored immediately following the observation. The unnatural environment of the clinic has the potential to influence the interactions embedded in the MCR as mothers may feel the need to perform as they are being observed. In addition, cognitive examiners 
were trained to the standard of the NCAST programs, however, multiple examiners were used to score observations in the CANDLE study. By using multiple examiners there is innate variation in observation which may have contributed to the different correlational patterns than have been reported with previous use of the instrument, as in the case of the child related subscales. Variation between examiners in the CANDLE study was addressed by maintaining an $85 \%$ interrater reliability with NCAT scale administration training and re-training occurring every six months throughout the data collection period.

\section{Conclusion}

Observational assessments of the interactions between mothers and children provide unique insight into the MCR. Because the cornerstone of the MCR occurs in the moment-to-moment interactions during the child's first three years of life, early identification of areas in the MCR requiring support and intervention is essential in promoting positive child outcomes (Pridham et al., 2010). The NCAT scale assesses specific qualities of the MCR that have been shown to have a profound influence on the later developmental outcomes of the child. These analyses confirmed the theoretical congruence between the Barnard Model and the NCAT scale by examining the psychometric properties of the NCAT scale through IRT, CFA, and MIMIC modeling using a community-based sample of mother-child dyads from the CANDLE study. In addition, these analyses also offer the potential for NCAT scale abbreviation, which may provide researchers and practitioners working with mothers and children during the first three years of a child's life a more concise, reliable way of measuring maternal-child interaction in community settings. 


\section{CHAPTER 4. PREDICTIVE VALIDITY OF THE NURSING CHILD ASSESSMENT TEACHING SCALE IN A COMMUNITY BASED SAMPLE OF MOTHERS AND CHILDREN FROM THE CONDITIONS AFFECTING NEUROCOGNITIVE DEVELOPMENT AND LEARNING IN EARLY CHILDHOOD STUDY}

\section{Introduction}

The first three years of a child's life are crucial to the child's long-term cognitive and linguistic development. Children are active learners interacting with the environment around them from the time they are born (Goswami, 2014). In this context, environment includes not only the child's physical home, but also available community resources and primary caregiving relationships (Belsky \& de Haan, 2011; Brooks-Gunn \& Duncan, 1997; Else-Quest, Clark, \& Tresch Owen, 2011; Hackman \& Farah, 2009). The most widely studied primary caregiving relationship in the literature surrounding early child development is the mother-child relationship (MCR). The MCR and its embedded interactive processes provide a foundation for the child's overall health and development.

Observational assessment of interactions between mothers and children has become a standard of practice in the field of early child development and has allowed researchers and practitioners to identify aspects of the MCR that are most influential on a child's developmental outcomes (Oxford \& Findlay, 2013; Pridham, Lutz, Anderson, Riesch, \& Becker, 2010). Relating specifically to cognitive and language development, research using observational assessment has shown that mothers who are more sensitive, physically affectionate, and verbally affirming in their interaction styles, positively promote the child's cognitive and linguistic processes (Banerjee \& Tamis-Lemonda, 2007; Brady-Smith et al., 2013; Eliot, 1999). How a child engages with and responds to her or his mother also influences cognitive and language development; however, the younger the child is, the more dependent they are on their mother for the provision of growth stimulating activities (Goswami, 2014; Oxford \& Findlay, 2013; Tronick, 2007). Therefore, the influence of maternal-child interaction (MCI) on a child's cognitive and language development cannot be determined until the individual characteristics of the mother and child are considered in addition to the relationship as a whole.

Two commonly used instruments for evaluating MCI and child cognition and language development are the Nursing Child Assessment Teaching Scale (NCAT) and the Bayley Scales of Infant and Toddler Development, Third Edition (Bayley-III), respectively. The NCAT scale is used to quantify observed interactions between mothers

and their children during the first 36-months (Oxford \& Findlay, 2013) and the Bayley-III is used to quantify observed behaviors typical of normal child development during the first 42-months (Bayley, 2006; Oxford \& Findlay, 2013). While the NCAT scales and Bayley-III have been used concurrently as valid and reliable measures of how MCI influences child cognition and language development, recent work evaluating the psychometric properties of the NCAT scale provided an opportunity for abbreviation of the scale that requires further investigation (Ransone et al., 2016). The full NCAT scale 
contains 73 yes/no items categorized into 6 subscales, while the abbreviated version contains 57 yes/no items categorized into 7 subscales.

Therefore, this study was conducted as a secondary analysis to determine the predictive validity of the NCAT scale by describing the influence of MCI at 12-months of child age on child cognitive and language development at 36-months using a communitybased sample of mothers and children. The full NCAT scale and abbreviated NCAT scale (NCAT-AB) were used to examine the associations within and between instruments for this study. Specifically, this study addresses the following questions:

1) What are the associations of scores within the NCAT and NCAT-AB scales at 12 months?

2) What are the associations of scores within the Bayley Scales of Infant and Toddler Development, Third Edition (Bayley-III) at 36-months?

3) What are the associations between the NCAT and NCAT-AB scores at 12-months and the Bayley-III Cognitive Scale scores at 36-months?

4) What are the associations between the NCAT and NCAT-AB scores at 12-months and the Bayley-III Language Scale scores at 36-months?

5) What are the associations between the NCAT and NCAT-AB scores at 12-months and the Bayley-III Receptive Communication subtest scores at 36-months?

6) What are the associations between the NCAT and NCAT-AB scores at 12-months and the Bayley-III Expressive Communication subtest scores at 36-months?

Hypotheses for this research apply to both the full NCAT and NCAT-AB scales. For the first two research questions, hypotheses are that: 1) the association of scores within the NCAT and NCAT-AB scales at 12-months will support the reliability of the scales by displaying positive correlations between the NCAT and NCAT-AB Scale Total and the subscale scores, and 2) the association of scores within the Bayley-III at 36months will support the reliability of the instrument by displaying positive correlations between the Bayley-III Cognitive Scale, Language Scale, Receptive Communication subtest, and Expressive Communication subtest scores. For research questions $3-6$, hypotheses are that higher NCAT and NCAT-AB scale scores at 12-months will be associated with higher Bayley-III Cognitive and Language Scale scores and with Receptive and Expressive Communication subtest scores at 36-months. These research questions were guided by the Child Health Assessment model (Figure 1-1) in addition to the Barnard model (Figure 1-2). The environment, mother, child, or any combination of the three influence the interactive system and subsequent cognitive and language outcomes of the child (Oxford \& Findlay, 2013). 


\section{Methods}

\section{Parent Study}

Data from the Conditions Affecting Neurocognitive Development and Learning in Early Childhood (CANDLE) study were used for this secondary analysis. The CANDLE study is a descriptive, longitudinal study originally designed to promote the health and well-being of children living in Shelby County, Tennessee by examining the effects of maternal prenatal activities, the early stages of the maternal-child relationship, and the child's experiences, genetic makeup, and environmental exposures on brain development during the first three years of life (The Department of Preventive Medicine UTHSC, 2014). Using convenience sampling, 1503 mothers were enrolled in the CANDLE study during their second trimester of pregnancy as a representative demographic sample of Shelby County where $52 \%$ of the population are Black, $71.5 \%$ have at least a high school education, $61 \%$ are single mothers, and $77 \%$ are between the ages of $20-35$ (U.S. Census, 2011). Similar to Shelby County, $66 \%$ of mothers enrolled in the CANDLE study are Black, $31 \%$ are Caucasian, $88 \%$ have at least a high school education, $63 \%$ are single mothers, and $82 \%$ are between the ages of 20-35 (The Department of Preventive Medicine UTHSC, 2014).

Since 2006, the mothers and children enrolled in the CANDLE study have been followed and data have been collected through observational assessments, questionnaires, and biologic specimens during clinic visits, home visits, and phone calls (Palmer et al., 2013; Völgyi et al., 2013). To assess developmental milestones at pre-identified time points, three clinic visits (CV1, CV2, CV3) were planned to coincide with approximate child ages of 12-months, 24-months, and 36-months. While data collected at any given time point provide a snapshot of the child's current developmental stage, the longitudinal design of the study contributes to the broad understanding of the many internal and external factors affecting early child development.

\section{Procedures}

Data collected from mothers and children enrolled in the CANDLE study at CV1 (approximate child age 12-months) and CV3 (approximate child age 36-months) were used for this secondary analysis. To understand how MCI during the first year correlates with the child's cognitive and language development at three years, complete data from the NCAT scale at CV1 and complete data from the Bayley-III at CV3 were requested and obtained from the primary CANDLE investigators. All analyses for this current study were conducted in $\mathrm{R}$ version 3.1.3 (R Core Team, 2015). R packages used included pysch (Revelle, 2015), ltm (Rizopoulos, 2006), lavaan (Rosseel, 2012), semTools (SemTools Contributors, 2015), Amelia (Honaker, King, \& Blackwell, 2011), and car (Fox \& Weisberg, 2011). 


\section{Measure: Maternal-Child Interaction}

The CANDLE study used the NCAT scale to quantify the interaction between mothers and their children at CV1, CV2, and CV3. The NCAT scale has been used in both community and clinically based samples and numerous intervention studies to identify and describe characteristics and interactive behaviors of mothers and children (Banerjee \& Tamis-Lemonda, 2007; Drummond, Letourneau, Neufeld, Stewart, \& Weir, 2008; Oxford \& Findlay, 2013; White-Traut et al., 2013). To appropriately use the NCAT scale, a certified observer evaluates a teaching-task between the mother and child and then scores the observed interaction. The teaching-task is an unfamiliar, developmentally challenging task chosen by the mother. For the CANDLE study, cognitive examiners were trained and certified as reliable observers to the standard of the NCAST program, maintaining $>85 \%$ correctness in their submitted coding assessments across NCAT scale data collection at CV1, CV2, and CV3. Observations in the CANDLE study were conducted in real-time with the mother, child, and cognitive examiner in the same room. For this study, the individual mother scores, combined mother-child scores, and subscale total scores for both the full NCAT scale and NCAT-AB scale were used for this secondary analysis.

\section{Measure: Child Cognitive and Language Development}

The Bayley-III was used in CANDLE at CV1, CV2, and CV3 to assess and identify behaviors typical of normal child development. The Bayley-III contains five scales organized to evaluate cognitive ability, receptive and expressive language, fine and gross motor skills, social-emotional status, and adaptive behaviors of children between 1month and 42-months of age (Bayley, 2006). The Cognitive Scale is used to assess developmental activities related to role play, information processing tasks, and counting, while the Language Scale is used to differentiate between the child's receptive and expressive abilities. Specifically, the Receptive Communication subtest assesses the child's auditory acuity and comprehension, and the Expressive Communication subtest assesses the child's ability to vocalize and gesture appropriately (Bayley, 2006).

Studies performed using the Bayley-III have consistently found accuracy in the instrument's ability to assess progression of normal cognitive and language development as well as its ability to predict developmental delay (Banerjee \& Tamis-Lemonda, 2007; Bayley, 2006; Brady-Smith et al., 2013). The Cognitive and Language Scales were chosen for administration in the CANDLE study. Similar to the NCAT scale, cognitive examiners received certification on the use of the instrument after participating in training sessions and obtained observation reliabilities $>90 \%$ (Krushkal et al., 2014).

Pearson correlations and associated probabilities were obtained for this secondary analysis using the full NCAT Scale Total, NCAT-AB Scale Total scores, and scaled Bayley-III total scores for the Cognitive Scale, Language Scale, Receptive Communication subtest, and Expressive Communication subtest. The scaled Bayley-III scores were derived from the total raw scores and reflect the average performance of a 
child relative to her or his same age group (Bayley, 2006). The sample of mothers and children with complete NCAT scale data at CV1 $(n=1,121)$ was used to identify the 946 mothers and children who had complete Bayley-III data at CV3. These 946 mother-child dyads form the study sample for this secondary analysis.

\section{Results}

\section{Full NCAT and Bayley-III Correlations}

While typical evaluation of correlation is based on numerical strength where $>$ 0.70 is strong in correlation and $<0.40$ is weak in correlation (Rosner, 2010), studies conducted using both the NCAT scale and Bayley-III instruments have commonly reported correlations between 0.25 and 0.50 as reliable and valid for predicting child outcomes (Oxford \& Findlay, 2013; Page, Wilhelm, Gamble, \& Card, 2010). Correlations between all full NCAT scale scores and Bayley-III Cognitive Scale, Language Scale, Receptive Communication subtest, and Expressive Communication subtest scores are displayed in Table 4-1. Probability values ( $p$-values) were $\leq 0.01$ for all correlations.

\section{Associations of Scores Within the Full NCAT Scale}

Scores within the full NCAT scale and Bayley-III instruments were more strongly correlated than the scores between the NCAT scale and the Bayley-III instruments. Within the NCAT scale, correlations that had p-values $\leq 0.01$ ranged from an $r$ of 0.26 between the Response to Distress subscale and the Sensitivity to Cues subscale, to an $r$ of 0.91 between the NCAT Scale Total and Contingency Total score. Within the full instrument, NCAT Scale Total score correlations for this sample of mothers and children at 12 -months were $>0.40$ and all Contingency Total score correlations were $>0.40$. Looking specifically at correlations between mother related scores, strong correlations $(r$ $>0.60$ ) were seen between the Mother Total score and the Mother Contingency Total score as well as all mother related subscale (SC, RD, SEGF, CGF) scores.

\section{Associations of Scores Within the Bayley-III}

The total scores for Bayley-III instrument (Cognitive Scale, Language Scale, Receptive Communication subtest, and Expressive Communication subtest) also displayed higher within instrument correlations (Table 4-2). All correlations within the Bayley-III had $\mathrm{p}$-values $\leq 0.01$. These correlations ranged from 0.60 between the Expressive Communication subtest and Cognitive Scale scores, to 0.94 between the Expressive Communication subtest and Language Scale scores. The associations between the child's assessed Expressive Communication and Receptive Communication 
Table 4-1. Pearson Correlations Within and Between Full NCAT Scale Scores at 12-Months and Bayley-III Scores at 36Months Using the CANDLE Database

\begin{tabular}{|c|c|c|c|c|c|c|c|c|c|c|c|}
\hline Scale Scores & MT & MCT & CT & NCAT & SC & RD & SEGF & CGF & CGT & $\mathbf{L T}$ & RT \\
\hline $\begin{array}{l}\text { Mother Contingency Total } \\
(\mathrm{MCT})\end{array}$ & 0.90 & & & & & & & & & & \\
\hline Contingency Total (CT) & 0.79 & 0.86 & & & & & & & & & \\
\hline NCAT Scale Total (NCAT) & 0.90 & 0.78 & 0.91 & & & & & & & & \\
\hline Sensitivity to Cues (SC) & 0.70 & 0.57 & 0.50 & 0.63 & & & & & & & \\
\hline Response to Distress (RD) & 0.64 & 0.65 & 0.49 & 0.49 & 0.26 & & & & & & \\
\hline $\begin{array}{l}\text { Social-Emotional Growth } \\
\text { Fostering (SEGF) }\end{array}$ & 0.80 & 0.69 & 0.65 & 0.77 & 0.49 & 0.44 & & & & & \\
\hline $\begin{array}{l}\text { Cognitive Growth Fostering } \\
\text { (CGF) }\end{array}$ & 0.84 & 0.75 & 0.69 & 0.78 & 0.47 & 0.31 & 0.53 & & & & \\
\hline Cognitive Total (CGT) & 0.24 & 0.21 & 0.19 & 0.21 & 0.14 & 0.14 & 0.18 & 0.23 & & & \\
\hline Language Total (LT) & 0.25 & 0.22 & 0.18 & 0.22 & 0.15 & 0.16 & 0.17 & 0.23 & 0.67 & & \\
\hline Receptive Total (RT) & 0.22 & 0.19 & 0.16 & 0.19 & 0.13 & 0.13 & 0.16 & 0.21 & 0.66 & 0.93 & \\
\hline Expressive Total & 0.24 & 0.21 & 0.18 & 0.21 & 0.15 & 0.16 & 0.17 & 0.22 & 0.60 & 0.94 & 0.73 \\
\hline
\end{tabular}

NOTE. MT = Mother Total; All correlations have a p-value $\leq 0.01$; MCT, CT, NCAT, SC, RD, SEGF, and CGF represent the NCAT scale and CGT, LT, RT, and Expressive Total represent the Bayley-III 
Table 4-2. Correlations Between Scores Within the Bayley-III Instrument

\begin{tabular}{lccc}
\hline Bayley-III Instrument & $\begin{array}{c}\text { Cognitive } \\
\text { Total }\end{array}$ & $\begin{array}{c}\text { Language } \\
\text { Total }\end{array}$ & $\begin{array}{c}\text { Receptive } \\
\text { Communication } \\
\text { Subtest Total }\end{array}$ \\
\hline $\begin{array}{l}\text { Language Total } \\
\text { Receptive Communication }\end{array}$ & 0.67 & 0.93 & \\
$\begin{array}{l}\text { Subtest Total } \\
\text { Expressive Communication } \\
\text { Subtest Total }\end{array}$ & 0.66 & 0.94 & 0.73 \\
\hline
\end{tabular}

NOTE. All correlations have p-value $\leq 0.01$ 
development on their overall language development at 36-months displayed the highest correlations $(0.94,0.93)$, respectively. There was also a strong relationship between the child's Cognitive Scale and Language Scale scores at the 36-month time point (0.67).

\section{Associations Between Full NCAT Scale Scores and Bayley-III Scores}

Correlations with $\mathrm{p}$-values $\leq 0.01$ between the full NCAT scale and Bayley-III scores, excluding the subscales, ranged from 0.16 between the Receptive Communication subtest total and Contingency Total to 0.25 between the Language Total and Mother Total. The Mother Total displayed the highest and most consistent correlations with all Bayley-III scores and ranged from 0.22 (Receptive Communication) to 0.25 (Language Total). The Mother Contingency Total and the NCAT Scale Total mirrored each other in their correlations with the Bayley-III scores, which varied minimally in correlational strength. The lowest correlations were seen with the Receptive Communication subtest total $(r=0.19)$ and the highest correlations were seen with the Language Total $(r=0.22)$, while the Expressive Communication subtest total and Cognitive Total each had correlations with the Mother Contingency Total and NCAT Scale Total of 0.21. The Contingency Total representing the observed back and forth interaction between the mother and child had the lowest correlational strength with the Bayley-III scores and ranged from 0.16 to 0.19 . While the correlational strength between each total score from the NCAT scale and the Bayley-III scores were similar, the consistently stronger correlations with the Mother Total indicated that at 12-months the combination of the mother's sensitivity, responsiveness, and ability to provide her child with socialemotional and cognitive growth stimulating activities was the best predictor of the child's cognitive, receptive and expressive communication, and overall language development at 36-months.

\section{NCAT-AB Scale and Bayley-III Correlations}

As with the full NCAT scale and Bayley-III correlations, the scores within the NCAT-AB scale and Bayley-III instruments were more strongly correlated than the scores between the instruments. Correlations between the NCAT-AB scale and BayleyIII instrument are displayed in Table 4-3. Abbreviated subscales are represented by a lowercase letter " $a$ ".

\section{Associations of Scores Within the NCAT-AB Scale}

Correlations with p-values $\leq 0.01$ in the NCAT-AB scale ranged from an $r$ of 0.25 between the Response to Distress (RDa) subscale and the Sensitivity to Cues ( $\mathrm{SCa}$ ) subscale, to an $r$ of 0.96 between the NCAT Scale Total (NCATa) score and Mother Total (MTa) score. Within the NCAT-AB scale, all correlations with the NCATa were > 0.60 . Strong correlations $(r>0.60)$ were seen between the MTa score and the Mother 
Table 4-3. Pearson Correlations Within and Between NCAT-AB Scale Scores at 12-Months and Bayley-III Scores at 36Months Using the CANDLE Database

\begin{tabular}{|c|c|c|c|c|c|c|c|c|c|c|c|}
\hline NCAT-AB Scale Scores & MTa & MCTa & CTa & NCATa & SCa & RDa & SEGFa & CGFa & CGT & $\mathbf{L T}$ & RT \\
\hline $\begin{array}{l}\text { Mother Contingency Total } \\
\text { (MCTa) }\end{array}$ & 0.90 & & & & & & & & & & \\
\hline Contingency Total (CTa) & 0.78 & 0.87 & & & & & & & & & \\
\hline NCAT Scale Total (NCATa) & 0.96 & 0.86 & 0.86 & & & & & & & & \\
\hline Sensitivity to Cues (SCa) & 0.70 & 0.57 & 0.48 & 0.66 & & & & & & & \\
\hline Response to Distress (RDa) & 0.64 & 0.68 & 0.53 & 0.61 & 0.25 & & & & & & \\
\hline $\begin{array}{l}\text { Social-Emotional Growth } \\
\text { Fostering (SEGFa) }\end{array}$ & 0.79 & 0.69 & 0.65 & 0.79 & 0.50 & 0.41 & & & & & \\
\hline $\begin{array}{l}\text { Cognitive Growth Fostering } \\
(\mathrm{CGFa})\end{array}$ & 0.83 & 0.71 & 0.64 & 0.79 & 0.47 & 0.31 & 0.51 & & & & \\
\hline Cognitive Total (CGT) & 0.24 & 0.22 & 0.19 & 0.22 & 0.14 & 0.14 & 0.17 & 0.23 & & & \\
\hline Language Total (LT) & 0.25 & 0.22 & 0.18 & 0.22 & 0.15 & 0.16 & 0.17 & 0.24 & 0.67 & & \\
\hline Receptive Total (RT) & 0.22 & 0.19 & 0.16 & 0.20 & 0.13 & 0.13 & 0.15 & 0.21 & 0.66 & 0.93 & \\
\hline Expressive Total & 0.24 & 0.22 & 0.18 & 0.22 & 0.15 & 0.16 & 0.16 & 0.23 & 0.60 & 0.94 & 0.73 \\
\hline
\end{tabular}

NOTE. $\mathrm{MTa}=$ Mother total abbreviated; NCAT-AB = abbreviated NCAT; All correlations have a p-value $\leq 0.01$; MTa, MCTa, CTa, NCATa, SCa, RDa, SEGFa, and CGFa represent the abbreviated NCAT scale and CGT, LT, RT, and Expressive Total represent the Bayley-III 
Contingency Total (MCTa), Contingency Total (CTa), NCATa, and all mother related subscale ( $\mathrm{SCa}, \mathrm{RDa}, \mathrm{SEGFa}, \mathrm{CGFa}$ ) scores. These mother related subscale scores were also correlated $(r>0.50)$ with the MTa and MCTa scores.

\section{Associations Between Abbreviated NCAT Scale Scores and Bayley-III Scores}

Correlations with p-value's $\leq 0.01$ between the MTa, MCTa, and NCATa scores (excluding the subscales) and Bayley-III scores ranged from 0.16 to 0.25 . The NCATa, $\mathrm{MCTa}$, and MTa scores had the highest correlations with the Cognitive, Language, Receptive Communication, and Expressive Communication Total scores. The correlations between the NCATa and Bayley-III scores ranged from 0.20 (Receptive Communication Total) to 0.22 (Language Total); the MCTa and Bayley-III score correlations ranged from 0.19 (Receptive Communication Total) to 0.22 (Language Total); and the MTa and Bayley-III score correlations ranged from 0.22 (Receptive Communication Total) to 0.25 (Language Total). The higher overall correlations between the MTa score and Bayley-III scores indicated that at 12-months the combination of the mother's sensitivity, responsiveness, and ability to provide her child with socialemotional and cognitive growth stimulating activities was the best predictor of the child's cognitive, language, receptive, and expressive development at 36-months.

\section{Comparison of Associations from the Full and NCAT-AB Scale}

When compared to the full NCAT scale, the NCAT-AB scale displayed both higher and lower correlations with the Bayley-III. Differences in these correlational strengths were small. Mother Total score correlations with the Bayley-III Cognitive Total, Language Total, and Receptive Communication subtest all decreased in the NCAT-AB scale, while the correlation with the Expressive Communication subtest increased. All $\mathrm{MCa}$ and NCATa scores increased in correlational strength with the Bayley-III when compared to the full NCAT scale. The correlation between the CTa and the Bayley-III Receptive Communication subtest remained the same as with the full NCAT, while the strength of correlations increased between the CTa and the Cognitive Total, Language Total, and Expressive Communication subtest scores.

There were also both increases and decreases in correlational strength when comparing the internal scores from the full and NCAT-AB scales. Table 4-4 displays these correlations from the Mother Total, Mother Contingency Total, Contingency Total, and subscale totals with the NCAT Scale Total score for both versions of the scale.

The largest increase in correlation from the full NCAT scale to the NCAT-AB scale occurred in the Response to Distress subscale and the only decrease in strength occurred in the Contingency Total. The Mother Total and the Contingency Total from the full scale had the highest correlations with the NCAT Scale Total, whereas the Mother Total, Mother Contingency Total, and Contingency Total from the NCAT-AB scale had the highest correlations with the NCAT Scale Total. 
Table 4-4. Full NCAT Scale Total and NCAT-AB Scale Total Correlations with Other Scale Totals and Subscale Scores

\begin{tabular}{lcc}
\hline Subscales & $\begin{array}{c}\text { Full NCAT } \\
\text { Scale Total }\end{array}$ & $\begin{array}{c}\text { NCAT-AB } \\
\text { Scale Total }\end{array}$ \\
\hline Mother Total & 0.90 & 0.96 \\
Mother Contingency Total & 0.78 & 0.86 \\
Contingency Total & 0.91 & 0.86 \\
Sensitivity to Cues & 0.63 & 0.66 \\
Response to Distress & 0.49 & 0.61 \\
Social-Emotional Growth & 0.77 & 0.79 \\
Cognitive Growth & 0.78 & 0.79 \\
\hline
\end{tabular}

NOTE. NCAT-AB $=$ abbreviated version of the NCAT scale 


\section{Discussion}

Prior to this study the predictive validity of the NCAT-AB scale had not been examined. Due to the large sample size of 946 mother-child dyads, correlational significance may have been easy to achieve. However, the correlational strength of scores within and between the full NCAT scale and Bayley-III instruments, independent of statistical significance, were consistent with correlations reported in previous studies conducted using these two instruments (Bayley, 2006; Oxford \& Findlay, 2013; Pridham et al., 2010). Correlations within the NCAT-AB scale and between the NCAT-AB scale and the Bayley-III varied in strength when compared to correlations with the full NCAT scale. Despite this variation, the hypotheses were met for this study. Based on the similarity with previously reported correlations, this study provided support for the use of the NCAT-AB scale in predicting child cognitive and language outcomes in this CANDLE sample of mothers and children.

To further the discussion of the child's cognitive and language outcomes, the internal correlations for the Bayley-III instrument were also considered in this study. The high internal correlations for the Bayley-III instrument (all > 0.50) implies that at 36months, there is a strong association between the child's cognitive and language development. While the child's cognitive and linguistic processes can be assessed as separate developmental milestones, literature suggests that they are also fostered simultaneously to varying degrees through interactions. A prime example of this simultaneous development is seen when considering expressive and receptive communication skills. Expressive communication in the first year typically consists of cooing or babbling, imitating sounds, banging on objects, and other outward gestures of feelings, while receptive communication focuses on the child's ability to comprehend and respond appropriately to what the mother says (Bayley, 2006; Cates et al., 2012; Eliot, 1999). From a cognitive standpoint where play and information processing are being evaluated, the banging of objects is a form of play and imitation of sound is a form of information processing, as are comprehension and responsiveness (Bayley, 2006). The interwoven nature of a child's cognitive and language development emphasizes the need for promoting maternal education in the selection of age-appropriate activities and use of verbal stimulation.

Highlighting the strength and similarities in correlation between the NCAT-AB scale with the Bayley-III and the correlation between the full NCAT scale with the Bayley-III is important. Previous research conducted with the NCAT scale most commonly reports the instrument total and Mother Total scores as the most reliable scores for predicting outcomes (Oxford \& Findlay, 2013). The abbreviated NCAT Scale Total score was only slightly higher in correlational strength with the Bayley-III Cognitive Total, Language Total, Expressive Communication subtest, and Receptive Communication subtest scores than the full NCAT Scale Total score. The NCAT Scale Total score considers the interactive characteristics of both the mother and the child and provides a snapshot picture of the MCR. Results from this study indicate that when using the NCAT-AB scale to assess interaction at 12-months, the combination of the mother's 
and child's characteristics is the best predictor of a child's cognitive and overall language development at 36-months.

The abbreviated Mother Total score at 12-months was also a predictor of the child's cognitive and language development at 36-months. While the full Mother Total score was more highly correlated with the Bayley-III Language Total and Receptive Communication subtest scores, the MTa score was more highly correlated with the Cognitive Total and Expressive Communication subtest scores. Overall, the correlational differences between the full and MTa scores were minimal. Therefore, using the NCATAB scale, results suggest that during the first year the combination of the mother's sensitivity, responsiveness, and ability to provide social and cognitive growth fostering activities promote the child's cognitive and overall language development at 36-months.

The NCAT-AB scale used in this study was a result of evaluating the psychometric properties of the full NCAT scale using the CANDLE sample of mothers and children (Ransone et al., 2016). Sixteen items were removed from the full NCAT scale through methods of item response theory, confirmatory factor analysis, and multiple indicators multiple causes modeling. By default, removing items from the full NCAT scale changed the total scores obtained for the NCAT-AB. The differences in total scores may have contributed to the higher and lower correlations seen within and between the full NCAT scale, NCAT-AB scale, and Bayley-III instrument. Additionally, demographic characteristics of the mothers and children from the CANDLE sample were originally considered when abbreviating the NCAT scale through multiple indicators, multiple causes modeling, but were not presented in this study. These demographic characteristics included maternal parity, age at child's birth, education, race, marital status, income and insurance status, and child age and sex.

From an early child development standpoint, this study's findings are not surprising and further support the existing body of literature. While this study looked specifically at characteristics of the mother and child identified by the NCAT scale, it is well known that available community resources, family structure, and demographic characteristics such as maternal age, education, and income influence the mother's overall interactive abilities (Drummond et al., 2008; Hackman \& Farah, 2009; Patterson $\&$ Vakili, 2014). Because the mother has a majority of the responsibility for engaging her child and fostering the achievement of developmental milestones during the first year (Cerezo, Pons-Salvador, \& Trenado, 2008; Evans \& Porter, 2009; Klass, Needlman, \& Zuckerman, 2003), a supportive environment that enables the mother's interaction attempts is important. Interactions foster varying levels of information exchange through observed, perceived, and communicated processes with both verbal and non-verbal goal directed behaviors (Oxford \& Findlay, 2013; Pridham et al., 2010; Tronick, 2007). When a mother and child interact, they are learning from and about one another, shaping their future interactions, and investing in their relationship as a whole (Beeghly \& Tronick, 2011; Feldman, 2012; Tronick, 2005). It is the relationship, upheld by its quality interactions, that influences the child's developmental outcomes. 


\section{Limitations}

The individual child scores were not considered in this study due to previously identified concerns with the NCAT scale's child subscales in the CANDLE sample. While correlations between the child related scores (Child Total, Child Contingency Total, Clarity of Cues, and Responsiveness to Caregiver) and Bayley-III were not individually considered, the give-and-take relationship existing between the mother and child was still evaluated by the Contingency Total and NCAT Scale Total scores. The collection of data for the NCAT scale and Bayley-III occurred via observation in a clinic setting. The variation in observers and the unnatural environment in which the data were collected could have contributed to the instability of the child subscales. In addition, the purpose of this study was to establish the predictive validity of the NCAT scale; however, measuring MCI concurrently at 36-months may be a better indicator of the child's cognitive and language development at 36-months.

\section{Conclusion}

The MCR provides the foundation for the child's later cognitive and language development. Because children begin their lives as active learners, their environment and experiences during the first three years of development play a critical role in determining the trajectory of their overall health and well-being (National Scientific Council on the Developing Child, 2007; Iruka, Durden, \& Kennel, 2015). This study's primary objective was determining the predictive validity of the NCAT-AB scale in this community-based sample of mothers and children. Based on the results, using the NCAT-AB scale is appropriate when evaluating interaction in the MCR at 12-months to predict the child's cognitive and language development at 36-months. Future work should extend the predictive validity of the NCAT-AB scale by evaluating its use at other time points in the MCR and determining its sensitivity to interventions in the MCR.

The ways in which mothers and children contribute to interactions in the MCR are unique and change over time. As the primary caregiver, the mother takes on the responsibility of providing her rapidly developing child with growth stimulating activities tailored to the needs of the child. Over time children begin to interact in more responsive and organized ways, but the younger the child is, the more dependent they are on their mother for stimulating cognitive and language development. Intervening in supportive ways during the first year to promote the mother's sensitivity, responsiveness, and cognitive and social-emotional growth fostering abilities may be challenging at a community level, but it is necessary for the child's overall growth and development. 


\section{CHAPTER 5. CONCLUSIONS}

\section{Overall Summary of Findings}

What researchers and clinicians know about early child development has expanded drastically over the last fifty years with advancement in technology and growth in the body of existing research. Technology advancement has allowed assessment of the developing fetus at all stages, consideration of genetic predisposition, and better understanding of the effect environment has on the child's developing brain. While these advancements have contributed to a more comprehensive picture of the developing child, the mother-child relationship (MCR) has persisted as the most complex, foundational system influencing the child's overall health and development (Alhusen, Hayat, \& Gross, 2013; Barnard, 2010; De Falco et al., 2014; Pridham et al., 2010). Within the MCR there are unique interactive processes that change over time and contribute to a deeper understanding of the mother and child as individuals, as well as the MCR as a whole. These embedded maternal-child interactions (MCI) are influenced by a variety of factors including the environment and the characteristics of both the mother and child.

Kathryn Barnard, along with her team of researchers, practitioners, and community members, understood the constantly evolving nature of the MCR and recognized the overlap between mother, child, and environment to be an important predictor of a child's later physical, emotional, social, and cognitive development (Oxford \& Findlay, 2013). They also understood that to promote positive outcomes, there needed to be regular assessments of the MCR and as a result, the Nursing Child Assessment Teaching (NCAT) scale was developed. Instruments used for observational assessment, like the NCAT scale, seek to operationalize a given concept or theory by providing quantitative ways of assessing variables of interest. To promote the reliability of an instrument and the generalizability of results, routine critical appraisal of any instrument using samples with varying characteristics is essential.

The three studies presented in Chapter 2, Chapter 3, and Chapter 4 of this dissertation provided critical appraisal of the NCAT scale by formally evaluating its psychometric properties using mothers and children from two demographically different samples, the Nursing Child Assessment Satellite Training (NCAST) and Conditions Affecting Neurocognitive Development and Learning in Early Childhood (CANDLE) databases. Results from all three studies support the continued use of the NCAT scale in evaluating MCI and contribute to the growing body of literature surrounding the MCR and early child development by discussing the influence of demographic factors on the mother and child as well as the interactions in their relationship. In addition, the results provided opportunity for NCAT scale abbreviation and validation of the abbreviation in a community-based sample of mothers and children. 


\section{Psychometric Evaluation of the Nursing Child Assessment Teaching Scale in Different Samples of Mother-Child Dyads}

Aims 1 and 2 focused on examining the psychometric properties of the NCAT scale using 1) a sample of mothers and children from the national NCAST database, and 2) a community-based sample of mothers and children from the CANDLE database. Chapter 2 specifically addressed Aim 1 by using mothers and children from the NCAST database, while Chapter 3 specifically addressed Aim 2 by using mothers and children from CANDLE database. Analyses with both databases were conducted using item response theory (IRT) and structural equation modeling approaches of confirmatory factor analysis (CFA) and multiple indicators multiple causes modeling (MIMIC).

\section{Item Response Theory}

IRT uses measurement models to evaluate and display the association between items in an instrument and the characteristics, or latent traits, of participants under investigation. The latent traits of mothers and children assessed using IRT were the NCAT subscales sensitivity to cues (SC), response to distress (RD), social-emotional growth fostering (SEGF), cognitive growth fostering (CGF), clarity of cues (CC), and response to caregiver (RC). Each of the 73 items in the NCAT scale were awarded a response rate from observational assessment of these latent traits. As discussed in Chapters 2 and 3, items on which mothers and/or children scored a "yes" greater than $97 \%$ of the time were removed from the NCAT scale because response varied less than $3 \%$ of the time. The need for variability in response to items is important from a statistical standpoint so comparisons can be made between traits of individuals in the sample. Similar items from both mother and child related subscales were removed from each database. Ultimately one more item was removed from evaluation of the instrument with the CANDLE database than with the NCAST database. Table 5-1 provides the items from each database which were removed by subscale.

Prior to removal, each item was considered from a clinical utility perspective and in the context of its contributions to its respective subscale and the NCAT scale as a whole. For example, in the full NCAT scale, items 19-21 and items 31-33 are thought to be "high-risk" items, meaning if the behavior is observed the mother and child are at high-risk for low quality interaction. This is because those items, in particular, can identify maladaptive and potentially harmful behaviors present in the MCR. If the mother is yelling, slapping, or handling her child in rough ways while being observed, there is a high likelihood those behaviors are occurring regularly in the home environment (Sparrow, 2013; Zaidman-Zait, Marshall, Young, \& Hertzman, 2014). Items 19, 21, and 32 were removed from the NCAST database, which eliminated three opportunities for observing high-risk behaviors, while items 21 and 32 were removed from the CANDLE database, which eliminated two opportunities. However, removal of these items was deemed appropriate because it meant that during observation, mothers avoided these high-risk behaviors greater than $97 \%$ of the time. 
Table 5-1. Removed Items by Subscale from the NCAT Scale for Low Variability in the NCAST and CANDLE Databases

\begin{tabular}{|c|c|c|}
\hline NCAT subscales & NCAST Database Item and Observation & CANDLE Database Item and Observation \\
\hline Sensitivity to Cues & $\begin{array}{l}1 \text { Caregiver positions child so child is safely } \\
\text { supported } \\
2 \text { Caregiver positions child so that child can } \\
\text { reach and handle teaching materials }\end{array}$ & $\begin{array}{l}1 \text { Caregiver positions child so child is safely } \\
\text { supported } \\
2 \text { Caregiver positions child so that child can reach } \\
\text { and handle teaching materials }\end{array}$ \\
\hline Response to Distress & $\begin{array}{l}19 \text { Caregiver avoids yelling at the child } \\
21 \text { Caregiver avoids slapping, hitting, or } \\
\text { spanking }\end{array}$ & 21 Caregiver avoids slapping, hitting, or spanking \\
\hline $\begin{array}{l}\text { Social-Emotional Growth } \\
\text { Fostering }\end{array}$ & $\begin{array}{l}32 \text { Caregiver avoids yelling at the child during } \\
\text { the episode }\end{array}$ & $\begin{array}{l}23 \text { Caregiver's body posture is relaxed during the } \\
\text { teaching episode }(90 \%) \\
32 \text { Caregiver avoids yelling at the child during the } \\
\text { episode }\end{array}$ \\
\hline $\begin{array}{l}\text { Cognitive Growth } \\
\text { Fostering }\end{array}$ & $\begin{array}{l}35 \text { Caregiver focuses attention and child's } \\
\text { attention on the task during most of the teaching }\end{array}$ & - \\
\hline
\end{tabular}




\section{Table 5-1. (Continued)}

\begin{tabular}{|c|c|c|}
\hline NCAT Subscales & NCAST Database Item and Observation & CANDLE Database Item and Observation \\
\hline Clarity of Cues & $\begin{array}{l}51 \text { Child is in the quiet alert state when task is } \\
\text { first presented } \\
52 \text { Child widens eyes and/or shows postural } \\
\text { attention to task situation } \\
53 \text { Child changes intensity or amount of motor } \\
\text { activity when task material is presented }\end{array}$ & $\begin{array}{l}51 \text { Child is in the quiet alert state when task is first } \\
\text { presented. } \\
52 \text { Child widens eyes and/or shows postural } \\
\text { attention to task situation } \\
53 \text { Child changes intensity or amount of motor } \\
\text { activity when task material is presented } \\
54 \text { Child's movements are clearly directed toward } \\
\text { the task or task material or away from task material } \\
\text { (not diffuse) } \\
55 \text { Child makes clearly recognizable arm } \\
\text { movements during the teaching episode (clapping, } \\
\text { reaching, waving, pounding, pointing, pushing } \\
\text { away) }\end{array}$ \\
\hline Response to Caregiver & $\begin{array}{l}56 \text { Child vocalizes while looking at the } \\
\text { task materials }\end{array}$ & $\begin{array}{l}56 \text { Child vocalizes while looking at the task } \\
\text { materials }\end{array}$ \\
\hline
\end{tabular}


Other items removed from the instrument were due to statistical collinearity issues. Specifically, one item was removed from evaluation of the NCAST database (Appendix B, item 17) and five were removed from evaluation of the CANDLE database (Appendix D, items 42, 45, 63, 65, and 66). Items retained after identifying high correlations in the respective NCAT subscales were chosen based on comparison of discriminatory strength, which meant that items which discriminated more strongly were left in the abbreviated NCAT scale (NCAT-AB). Retained items were chosen in this way because in IRT the stronger an item discriminates, the more sensitive it is in differentiating between the traits of the individuals being observed. In the case of the removed items, the traits being observed were the mother's ability to respond to the distress of her child (represented by the RD subscale), the mother's ability to provide her child with activity appropriate cognitive stimulation (represented by the CGF subscale), and the child's responsiveness to the mother (represented by the RC subscale).

IRT conducted in both databases also displayed negatively correlated items in each database. For both databases, these items were seen in the child related subscales (CC and $\mathrm{RC}$ ) and were reversed for CFA and MIMIC analyses. The reversal of these items did not alter their clinical utility or their contribution to the $\mathrm{CC}$ and $\mathrm{RC}$ subscales. However, by reversing these items, the statistical association between the items and their subscales was stronger and in the case of the CANDLE database, the Cronbach's alphas for the Child Total score and NCAT Scale Total score improved. In addition, the Response to Caregiver subscale split into two subscale factors and were renamed Response to Caregiver 1 (RC1) and Response to Caregiver 2 (RC2). Following the split, the RC1 subscale contained items of engagement where the child attempted to make eyeto-eye contact with the caregiver or vocalized and smiled in response to the caregiver. Contrastingly, the RC2 subscale contained items of disengagement where the child resisted the caregiver or displayed cues of crying, back arching, or pushing away (Oxford \& Findlay, 2013). Statistically, the split of the RC subscale allowed items with more homogenous observations of the child to be their own factor prior to CFA and MIMIC modeling. Clinically, however, it is important to note that cues of engagement and disengagement are necessary to the interactive system and adaptive processes of the MCR.

\section{Confirmatory Factor Analysis and Multiple Indicators Multiple Causes Modeling}

CFA and MIMIC modeling allow hypothesized causal processes to be structurally modeled and numerically estimated to determine how well the hypothesized model fits with the sample under investigation. For this research, the hypothesized model was the Barnard model of interaction. Therefore, CFA and MIMIC analyses conducted with the NCAST and CANDLE databases evaluated the structure and reliability of the NCAT-AB scale by determining how well the sample fit with the Barnard model. Analyses employed in Chapter 2 with the NCAST database used 62 NCAT items with 7 subscales, while analyses employed in Chapter 3 with the CANDLE database used 57 NCAT items with 7 subscales. CFA provided correlations in the NCAST and CANDLE samples between each item remaining, post-IRT removal, in the NCAT scale and each respective 
subscale. These correlations are presented in Chapter 2 using the NCAST database and Chapter 3 using the CANDLE database. In addition, negatively correlated items were identified in each database and reversed for analyses (Table 5-2). These negatively correlated items overlapped in the CC subscale between databases, but in the CANDLE database there were additional negatively correlated items in the RC subscale.

The primary purpose of the NCAT scale is to quantify the overall quality of interactions occurring in the MCR during the first 36 months of a child's life. The NCAT scale contains items which assess the mother and child's individual qualities, but also contains contingency items that identify their joint action patterns. Items removed from the NCAT scale have been discussed in this research, but from a contingency perspective, the items which were retained in the NCAT scale following IRT and CFA analyses may also be important. As a reiteration of correlational cut-points, in factor analysis 0.40 is the typical cut-point value for determining whether an item belongs in its respective factor. Those correlations $>0.40$ suggest the item should remain in the factor, while those $<0.40$ imply the item should be removed (Brown, 2015; Pett, 2003). For the NCAST database, had the 0.40 cut-point been used an additional 15 items would have been removed from the NCAT scale and for the CANDLE database an additional 20 items would have been removed. Removal of these items could have severely altered the clinical utility of the scale, so the decision was made to retain them as part of the NCAT-AB scale.

Specifically related to the contingency items, one item was removed from the NCAST database (item 17) and four items were removed from the CANDLE database (items $45,63,65$, and 66). Had the 0.40 cut-point been used for evaluating only the contingency items, 3 additional items would have been removed from the NCAST database and 8 removed from the CANDLE database. In the full NCAT scale there are 32 contingency items and all subscales except for the Clarity of Cues subscale contain three or more of these items. Thirty-one contingency items were retained in the NCAT scale in analyses with the NCAST database and 28 were retained in analyses with the CANDLE database. In both databases, more than half of the retained contingency items displayed loadings $>0.50$ with their respective subscale factor and discriminated at "high" or "very high" levels when considered from an IRT perspective. This highlights the importance of these items and emphasizes the clinical utility of their retention in the NCAT scale.

Following CFA, the influence of demographic characteristics on MCI were examined in both databases through MIMIC modeling. The NCAST database provided a predominantly Caucasian sample of married mothers who were educated beyond high school (Table 2-1), while the CANDLE database provided a predominantly Black sample of single mothers who were educated beyond high school (Table 3-2). Income and insurance variables were not available for analyses with the NCAST sample, but were used in analyses with the CANDLE sample to provide a more comprehensive picture of socio-economic status (SES). The NCAST and CANDLE samples were intentionally chosen to evaluate the psychometric properties of the NCAT scale because of their demographic differences. When evaluating any scale, heterogeneity in the samples under investigation is important for establishing the reliability of the scale. This is because "the 
Table 5-2. Negatively Correlated Items by Subscale Reverse Coded for Analyses in the NCAST and CANDLE Databases

\begin{tabular}{|c|c|c|}
\hline Subscale & $\begin{array}{l}\text { Reverse Coded Items and Observations in the } \\
\text { NCAST Database }\end{array}$ & $\begin{array}{l}\text { Reverse Coded Items and Observations in the } \\
\text { CANDLE Database }\end{array}$ \\
\hline \multirow{3}{*}{$\begin{array}{l}\text { Clarity of } \\
\text { Cues }\end{array}$} & 58 Child grimaces or frowns during the teaching episode & 58 Child grimaces or frowns during the teaching episode \\
\hline & $\begin{array}{l}59 \text { Child displays potent disengagement cues during the } \\
\text { teaching interaction }\end{array}$ & $\begin{array}{l}59 \text { Child displays potent disengagement cues during the } \\
\text { teaching interaction }\end{array}$ \\
\hline & $\begin{array}{l}60 \text { Child displays subtle disengagement cues during the } \\
\text { teaching interaction }\end{array}$ & $\begin{array}{l}60 \text { Child displays subtle disengagement cues during the } \\
\text { teaching interaction }\end{array}$ \\
\hline \multirow[t]{5}{*}{$\begin{array}{l}\text { Response to } \\
\text { Caregiver } 2\end{array}$} & & $\begin{array}{l}68 \text { When caregiver moves closer than eight inches from } \\
\text { the child's face, the child shows some subtle and/or potent } \\
\text { disengagement cues }\end{array}$ \\
\hline & & $\begin{array}{l}69 \text { Child shows subtle and/or potent disengagement cues } \\
\text { within five seconds after caregiver changes facial } \\
\text { expression or body movement }\end{array}$ \\
\hline & & $\begin{array}{l}70 \text { Child shows subtle and/or potent disengagement cues } \\
\text { within five seconds after caregiver's verbalization }\end{array}$ \\
\hline & & $\begin{array}{l}71 \text { Child shows potent and/or subtle disengagement cues } \\
\text { when the caregiver attempts to intrude physically in the } \\
\text { child's use of the task materials }\end{array}$ \\
\hline & & $\begin{array}{l}72 \text { Child physically resists or responds aggressively when } \\
\text { caregiver attempts to intrude physically in child's use of } \\
\text { the task materials }\end{array}$ \\
\hline
\end{tabular}


reliability of an instrument is a property not of the instrument but rather of the instrument when administered to certain people under certain conditions" (Polit \& Beck, 2012, p. 335). In an instrument, such as the NCAT Scale, the certain people are mothers and their children and regardless of demographics, the scale should reliably evaluate MCI.

Demographic predictors for each sample varied when considered by NCAT subscale (Table 2-4; Table 3-5). The differences between the NCAST and CANDLE databases were not compared statistically, but identified significant demographic predictors from each sample overlapped minimally when comparing results side-by-side. Table 5-3 presents the demographic predictors, by subscale, which overlapped between the NCAST and CANDLE databases.

For the SC, SEGF, and CGF subscales, Caucasian race was a common demographic predictor and for the RD and SEGF subscales the age of the mother at the time the child was born was a common demographic predictor. There were no shared demographic predictors between the child related subscales ( $\mathrm{CC}, \mathrm{RC} 1$, and $\mathrm{RC} 2)$. These findings support Hypothesis 3 from Aim 2 of this dissertation. The influence of demographic characteristics is different when looking at the results of MIMIC modeling conducted with both the NCAST and CANDLE databases. Furthermore, these findings promote the continued use of the NCAT scale in samples with varying demographic characteristics as the scale appears to be sensitive to detecting differences in MCI when considering the demographics of the sample. While there are multiple statistical methods for determining the reliability and validity of a scale, the methods of IRT, CFA, and MIMIC were chosen for this research because they allowed participant response consideration and hypothesized causal relationships to be assessed. Other measures of reliability such as test-retest reliability and interrater reliability were not used for this research due to the use of secondary data.

Initially, analyses were conducted using the same demographic characteristics for the mothers (parity, age at child's birth, education, race, and marital status) and children (age and sex) from each database. By using the same demographic predictors, the thought was that comparisons could be made more easily between results of analyses from the NCAST and CANDLE samples. However, because SES is known to influence the MCR and child developmental outcomes, the income and insurance variables were incorporated as additional demographic predictors for analyses with CANDLE. Adding income and insurance variables did not change the Caucasian race as a predictor of SC, SEGF, and CGF subscales, but did change influence of the mother's age and education on the SC and CGF subscales in addition to the influence of marital status on the RD and CC subscales.

While the mother's age and education were significant predictors of the SC and CGF subscales and the mother's marital status was a significant predictor of the RD and $\mathrm{CC}$ subscales prior to including income and insurance, they were no longer significant predictors after income and insurance consideration. Income, however, was a significant predictor in the RD, SEGF, CGF, and CC subscales. The influence of SES on the 
Table 5-3. Shared Demographic Predictors by Subscale Between the NCAST and CANDLE Databases from MIMIC Modeling

\begin{tabular}{lc}
\hline NCAT Subscale & $\begin{array}{c}\text { Shared Demographic } \\
\text { Predictor(s) }\end{array}$ \\
\hline Sensitivity to Cues & $\begin{array}{c}\text { Caucasian } \\
\text { Child age }\end{array}$ \\
Response to Distress & $\begin{array}{c}\text { Mother's age at child's birth } \\
\text { Social-Emotional Growth Fostering }\end{array}$ \\
$\begin{array}{l}\text { Caucasian } \\
\text { Mother's age at child's birth } \\
\text { Pigh School education }\end{array}$ \\
Cognitive Growth Fostering & Caucasian \\
Clarity of Cues & N/A \\
Response to Caregiver 1 & N/A \\
Response to Caregiver 2 & N/A \\
\hline
\end{tabular}


interactive processes in the MCR has been described in many studies as a predictor of maternal sensitivity, responsiveness, and parenting as well as the child's health and development (Chen, Martin, \& Matthews, 2007; Hackman \& Farah, 2009; Horodynski \& Gibbons, 2004). MIMIC modeling with the CANDLE database adds to this existing body of literature.

In each step of analysis, items were considered individually, in the context of each respective subscale, and in the context of the whole instrument. This is important because when critically appraising an instrument, the clinical use and relevance of each item and how it contributes to the instrument can be more important than the statistical results. An instrument's clinical relevance takes into account its practical use while also attempting to consider the statistical significance (Brignardello-Petersen, Carrasco-Labra, Shah, \& Azarpazhooh, 2013; Connelly, 2014). Furthermore, the critical appraisal of the NCAT scale provided an opportunity for potential instrument abbreviation, even though abbreviation of the instrument was not intended when analyses began. By abbreviating the NCAT scale, its clinical use has the potential to become easier from an administration and observation standpoint, which could promote and broaden its use. To provide further validation of the NCAT scale and explore the predictive validity of the NCAT-AB scale, an additional study was conducted.

\section{The Predictive Validity of the Full and Abbreviated Versions of the Nursing Child Assessment Teaching Scale}

Initially, Aim 3 of this dissertation was to determine the predictive validity of the NCAT scale using a community-based sample of mothers and children from the Conditions Affecting Neurocognitive Development and Learning in Early Childhood database. However, this did not account for the abbreviated version of the instrument resulting from Aims 1 and 2. While the original Aim 3 was met by Chapter 4 of this dissertation, it was taken a step further to also determine the predictive validity of the NCAT-AB scale. Specifically, Pearson correlations and associated probabilities were obtained within the NCAT and NCAT-AB scales at 12-months, within the Bayley-III at 36-months, and between the NCAT and NCAT-AB scales at 12-months and the BayleyIII Cognitive Total, Language Total, Receptive Communication subtest, and Expressive Communication subtest scores at 36-months.

\section{Abbreviation of the NCAT Scale}

The NCAT scale has reliably assessed the quality of MCI in a child's first three years of life since 1979. Abbreviation of the NCAT scale was not intended when analyses for this present research began, but was a finding worth further exploration. From a clinical perspective, shorter instruments are not only easier to administer, but also have the potential to place less burden on the patient, or in this case, the mother and child. While consideration of abbreviating or modifying an instrument through its critical 
appraisal may be appropriate, care needs to be taken to ensure the original purpose for developing the instrument goes unscathed. In the case of abbreviating the NCAT scale, this meant that it still needed to quantify the overall quality of interaction in the MCR and adequately predict the child's later development as previous studies have done.

\section{Reliability and Validation of the NCAT Scale}

Differences and similarities between the full and abbreviated versions of the NCAT scale are presented in detail in Chapter 4. Within the full NCAT and NCAT-AB at 12-months, there were strong correlations which further supported the reliability of the full instrument and provided reliability for the abbreviated instrument. Within the Bayley-III at 36-months there were also strong internal correlations (Table 4-2). All Bayley-III internal correlations from analyses with the CANDLE database were lower than what is reported in the Bayley-III technical manual, however, the largest difference in correlational strength as 0.10, which is marginal (Bayley, 2006). Although testing the reliability of the Bayley-III was not an aim of this research, the internal correlations provided from analyses with the CANDLE database support the instrument's use in assessing cognitive and language development at 36-months in this community-based sample. Additionally, the correlations from the full NCAT and NCAT-AB scale scores with the Bayley-III were consistent with other correlations in the literature (Oxford \& Findlay, 2013; Page et al., 2010), but were not as strong as typical correlational cutoffs (Brown, 2015; Rosner, 2010). These results, however, supported the validity of the full NCAT and the NCAT-AB scales. Observed interactions at 12-months assessed using either the full NCAT or the NCAT-AB predicted the child's cognitive and language development at 36-months in the CANDLE sample of mothers and children.

\section{Discussion of Limitations and Strengths}

Instrument scores from observational assessments should not be interpreted in isolation, but rather in the broader context of the subjects under investigation to be meaningful. In the CANDLE sample of mothers and children, the full NCAT scale was administered at three time points to correspond with 12-months, 24-months, and 36months of child age. The complexity of the MCR does not lend itself to a simple, onetime examination because it is constantly evolving. Repeated observation of interactions in the MCR allows clinicians and researchers to identify interaction patterns and develop interventions targeted at supporting the relationship.

For an instrument to be administered correctly, those observing must fully understand the importance of their role and be held to a standard of assessment. One of the limitations of this research was that multiple cognitive examiners were used for collecting data using the NCAT scale. While these examiners were trained to the standard of the national NCAT database and maintained at least $85 \%$ reliability in their observations, the issues emerging from this research with the child-related NCAT subscales in Chapter 3 may have been partially due to variation in observational 
assessment. Additionally, all observations using the NCAT scale for this study were from the 12-month time point and conducted in a clinic setting, which provided a single snapshot assessment of MCI in an unnatural environment. While these limitations, along with those presented in Chapter 1 regarding secondary data and convenience sampling were present, this research also had several strengths.

Interactions in the MCR are known to have a profound influence on the child's physical, emotional, social, and cognitive development. In addition to critically appraising a widely-used instrument for evaluating MCI, this research further emphasized the relationship between interaction in the MCR and the child's later cognitive and language development using a large community-based sample. Mothers and children enrolled in the CANDLE study are a sample of mother-child dyads that is demographically representative of Shelby County, Tennessee. Fewer than half of these dyads are at or above $200 \%$ of the federal poverty level and more than half of the mothers are single parents (The Urban Child Institute, 2013; U.S. Census, 2011). The demographics of the CANDLE sample contrasted those of the NCAST sample and considered the influence of income and insurance on MCI. The association between demographic characteristics and MCI described using the CANDLE sample is supported by the extensive body of literature surrounding the effects of environment on the MCR (Bronfenbrenner \& Morris, 2006; Brooks-Gunn \& Duncan, 1997; Patterson \& Vakili, 2014).

\section{Implications for Future Research}

This research provides a snapshot assessment of MCI at 12-months. From a child development standpoint, it is likely that at 24-months and 36-months these same motherchild dyads would be observed and scored differently using the NCAT scale. Future work should extend the use of the NCAT scale and explore its potential for abbreviation at varying time points in the MCR by conducting similar IRT, CFA, and MIMIC analyses. If the same items are removed from the scale at various time points for low observed response variability and high correlations, it may be possible to abbreviate the scale for future use. Because the scale is also sensitive to detecting differences in samples with varying demographic characteristics, there may be other ways of using the NCAT subscales and its embedded contingency items for assessing quality interactions in the MCR that were not explored in this research. In addition, the full NCAT scale has been used frequently to describe intervention effects in the MCR. If the NCAT scale were to be abbreviated, research would be necessary to ensure intervention effects in the MCR would continue to be readily identified.

\section{Conclusions}

Practitioners specializing in early child development have been fostering strategies for supporting healthy interactions in the MCR for decades. While issues of parenting and child outcomes are important to the general public, structured community 
support systems for mothers and other primary caregivers continue to lack effective implementation. A mother's sensitivity and responsiveness to her child and her ability to provide appropriate cognitive and social-emotional growth stimulation may not be an innate part of each MCR. In fact, it is well known that there are high-risk mothers, such as those who have low levels of education, are adolescent, have a mental illness, or are drug users, who are predisposed to negative interactions with their children (Schiffman et al., 2003). Despite these predispositions, results of studies conducted using the NCAT scale have shown that interventions aimed at supporting maternal sensitivity and responsiveness can provide mothers with nurturing parenting behaviors which may mediate environmental effect (Drummond et al., 2008; Elliott et al., 2014; Pridham et al., 2010; Schiffman et al., 2003).

A child looks for stability in the MCR to develop normally, yet the relationship, its interactive processes, and the environment change constantly. Healthy interactions in the MCR are not perfect, but rather display the mother and child's adaptive ability in their joint action patterns as they learn from and about one another (Tronick, 2005). The subscales in the NCAT scale work together to paint a picture of the MCR by focusing on attributes of the mother and child that are known to influence MCI. The on-going exchange of cues between the mother and child lay the foundation for the MCR and the child's future development (Barnard, 2010). Therefore, the emphatic proclamation that the first three years of a child's life are critical for development should not be ignored (National Scientific Council on the Developing Child, 2007; Brain Development, 2016).

Kathryn Barnard recognized the interaction among the environment, mother, and child as the overlapping and most influential component of a child's development. For this research, Barnard's model of interaction (Figure 1-2) provided the baseline model for psychometrically evaluating the NCAT scale, however, the Child Health Assessment Model (Figure 1-1) was the overall conceptual model because it addresses the influence of environment on MCI (Oxford \& Findlay, 2013). By critically appraising the NCAT scale through IRT, CFA and MIMIC analyses, this research provides support for the continued use the NCAT scale in assessing MCI in both clinically- and community-based samples, but also provides theoretical congruence for the continued use of the Barnard model. Aspects of the environment related to socio-economic status were considered through examining the influence of demographic characteristics on interactions in the MCR with both the NCAST and CANDLE samples. The abbreviation and validation of the NCAT scale, in addition to the sensitivity of the scale in detecting demographic differences were important findings from this research and may offer practitioners and researchers with a more concise yet reliable scale for assessing MCI. It also remains important that interaction in the MCR continue to be assessed in the broader context of the child's overall health and development. 


\section{LIST OF REFERENCES}

Ainsworth, M. D. (1985). Patterns of infant-mother attachments: Antecedents and effects on development. Bulletin of the New York Academy of Medicine, 61(9), 771. Retrieved from http://www.ncbi.nlm.nih.gov/pmc/articles/PMC1911899/

Alhusen, J. L., Hayat, M. J., \& Gross, D. (2013). A longitudinal study of maternal attachment and infant developmental outcomes. Archive of Women's Mental Health, 16(6), 521-529. doi:10.1007/s00737-013-0357-8

Baker, F. B. (2001). The basics of item response theory (2nd ed.). College Park, MD: ERIC Clearinghouse on Assessment and Evaluation.

Banerjee, P. N., \& Tamis-LeMonda, C. S. (2007). Infants' persistence and mothers' teaching as predictors of toddlers' cognitive development. Infant Behavior and Development, 30(3), 479-491. doi:10.1016/j.infbeh.2006.12.001

Barnard, K. E. (2010). Keys to developing early parent-child relationships. In B. M. Lester \& J. D. Sparrow (Eds.), Nurturing children and families: Building on the legacy of T. Berry Brazelton. (Kindle Edition). West Sussex, UK: Blackwell Publishing Ltd.

Barnard, K. E., \& Eyres, S. J. (1979). Child health assessment, Part 2: The first year of life. Retrieved from Health Resources Administration http://files.eric.ed.gov/fulltext/ED176864.pdf

Barnard, K. E., Hammond, M., Mitchell, S. K., Booth, C. L., Spietz, A., Snyder, C., \& Elsas, T. (1985). Caring for high-risk infants and their families. In M. Green (Ed.), The Psychosocial Aspects of the Family: Lexington Books.

Bayley, N. (2006). Bayley scales of infant and toddler development: Technical manual (Third ed.). Bloomington, MN: Pearson.

Beeghly, M., \& Tronick, E. (2011). Early resilience in the context of parent-infant relationships: A social developmental perspective. Current Problems in Pediatric and Adolescent Health Care, 41(7), 197-201. http://doi.org/10.1016/j.cppeds.2011.02.005

Belsky, J., \& de Haan, M. (2011). Annual research review: Parenting and children's brain development: The end of the beginning. Journal of Child Psychology and Psychiatry, 52(4), 409-428. doi:10.1111/j.1469-7610.2010.02281.x

Bornstein, M. H., \& Tamis-LeMonda, C. H. (2010). Parent-infant interaction. In J. G. Bremner \& T. D. Wachs (Eds.), The Wiley-Blackwell handbook of infant 
development (2nd ed., Vol. 1, pp. 458-482). West Sussex, UK: Blackwell Publishing Ltd.

Brady-Smith, C., Brooks-Gunn, J., Tamis-LeMonda, C. S., Ispa, J. M., Fuligni, A. S., Chazan-Cohen, R., \& Fine, M. A. (2013). Mother-infant interactions in early head start: A person-oriented within ethnic-group approach. Parenting: Science and Practice, 13, 27-43. doi:10.1080/15295192.2013.732430

Brazelton, T.B. (1973). Neonatal behavior assessment scale. Philadelphia: Lippincott.

Brignardello-Petersen, R., Carrasco-Labra, A., Shah, P., \& Azarpazhooh, A. (2013). A practitioner's guide to developing critical appraisal skills. The Journal of the American Dental Association, 144(7), 780-786. doi:10.14219/jada.archive.2013.0187

Bronfenbrenner, U. (1986). Ecology of family as context for human development: Research perspectives. Developmental Psychology, 22(6), 723-742.

Bronfenbrenner, U., \& Morris, P. A. (2006). The Bioecological Model of Human Development. In R. Lerner \& W. Damon (Eds.), Handbook of child psychology (Vol. 1, pp. 793-828). New York: Wiley.

Brooks-Gunn, J., \& Duncan, G. J. (1997). The effects of poverty on children. The Future of Children, 55-71. Retrieved from http://www.jstor.org/stable/1602387

Brown, T. A. (2015). Confirmatory factor analysis for applied research (2nd ed.). New York: The Guilford Press.

Cates, C. B., Dreyer, B. P., Berkule, S. B., White, L. J., Arevalo, J. A., \& Mendelsohn, A. L. (2012). Infant communication and subsequent language development in children from low-income families: The role of early cognitive stimulation. Journal of Developmental and Behavioral Pediatrics, 33(7), 577-585. doi:10.1097/DBP.0b013e318264c10f10.1097/DBP.0b013e318264c10f. $<$ p $>$

Cerezo, M. A., Pons-Salvador, G., \& Trenado, R. M. (2008). Mother-infant interaction and children's socio-emotional development with high and low-risk mothers. Infant Behavior and Development, 31(4), 578-589. doi:10.1016/j.infbeh.2008.07.010

Coffman, S., Levitt, M. J., \& Guacci-Franco, N. (1995). Infant-mother attachment: Relationships to maternal responsiveness and infant temperament. Journal of Pediatric Nursing, 10(1), 9-18.

Connelly, L. M. (2014). Statistical and clinical significance. MEDSURG Nursing, 23(2), 118-119. 
Cook, K. (2013, January). A conceptual introduction to item response theory [YouTube series]. Retrieved from https://www.youtube.com/watch?v=SrdbllMYq8M\&list=PLJNUIJnElUzDmrIPu $\underline{\mathrm{nMyF} 3 \mathrm{tTvIHb} 65 \mathrm{wNb}}$

Coyer, S. M., \& Gallo, A. M. (2005). Secondary analysis of data. Journal of Pediatric Health Care, 19(1), 60-63. doi:10.1016/j.pedhc.2004.10.003

Crittendon, P. (2016). Raising parents: Attachment, representation, and treatment (2nd ed.). New York, NY: Routledge.

De Falco, S., Emer, A., Martini, L., Rigo, P., Pruner, S., \& Venuti, P. (2014). Predictors of mother-child interaction quality and child attachment security in at-risk families. Frontiers in Psychology, 5, 1-10. doi:10.3389/fpsyg.2014.00898

Drummond, J. E., Letourneau, N., Neufeld, S. M., Stewart, M., \& Weir, A. (2008). Effectiveness of teaching an early parenting approach within a community-based support service for adolescent mothers. Research in Nursing \& Health, 31(1), 1222. doi:10.1002/nur.20235

Drummond, J. E., Weir, A. E., \& Kysela, G. M. (2002). Home visitation practice: Models, documentation, and evaluation. Public Health Nursing, 19(1), 21-29. Retrieved from http://onlinelibrary.wiley.com/doi/10.1046/j.1525$\underline{1446.2002 .19004 . x / p d f}$

Eliot, L. (1999). What's going on in there? How the brain and mind develop in the first five years of life. New York, NY: Bantum Books.

Elliott, M. R., Demianczuk, N., \& Robertson, C. M. (2014). Infants at psychosocial risk and their caregivers: Selection for early intervention - results of the pilot study. Available at SSRN 2488161. Retrieved from http://papers.ssrn.com/sol3/papers.cfm?abstract_id $=2488161$

Else-Quest, N. M., Clark, R., \& Tresch Owen, M. (2011). Stability in mother-child interactions from infancy through adolescence. Parenting, 11(4), 280-287. doi:10.1080/15295192.2011.613724

Evans, C. A., \& Porter, C. L. (2009). The emergence of mother-infant co-regulation during the first year: Links to infants' developmental status and attachment. Infant Behavior and Development (32), 147-158. doi:10.1016/j.infbeh.2008.12.005

Feldman, R. (2012). Parent-infant synchrony: A biobehavioral model of mutual influences in the formation of affiliative bonds. Monographs of the Society for Research in Child Development, 77(2), 42-51. 
Fox, J \& Weisberg, S. (2011). An R companion to applied regression (2nd ed.). Thousand Oaks CA: Sage. URL: http://socserv.socsci.mcmaster.ca/jfox/Books/Companion

Garner, A. S. (2013). Home visiting and the biology of toxic stress: Opportunities to address early childhood adversity. Pediatrics, 132(2), 65-73. doi:

10.1542/peds.2013-1021D

Goswami, U. (2014). Child psychology: A very short introduction. New York, NY: Oxford University Press.

Greenhoot, A. F., \& Dowsett, C. J. (2012). Secondary data analysis: An important tool for addressing developmental questions. Journal of Cognition and Development, 13(1), 2-18. doi:10.1080/15248372.2012.646613

Hackman, D. A., \& Farah, M. J. (2009). Socioeconomic status and the developing brain. Trends in Cognitive Sciences, 13(2), 65-73. doi:10.1016/j.tics.2008.11.003

Hair, N. L., Hanson, J. L., Wolfe, B. L., \& Pollak, S. D. (2015). Association of child poverty, brain development, and academic achievement. Journal of American Medical Association Pediatrics, 169(9), 822. doi:10.1001/jamapediatrics.2015.1475

Honaker, J., Gary King, G., \& Blackwell, M. (2011). Amelia II: A program for missing data. Journal of Statistical Software, 45(7), 1-47. URL http://www.jstatsoft.org/v45/i07/.

Hooper, D., Coughlan, J., \& Mullen, M.R. (2008). Structural equation modelling: Guidelines for determining model fit. The Electronic Journal of Business Research Methods, 6(1), 53-60.

Horodynski, M. A., \& Gibbons, C. (2004). Rural low-income mothers' interactions with their young children. Pediatric Nursing, 30(4), 299-306.

Huang, K.-Y., O’Brien Caughy, M., Genevro, J. L., \& Miller, T. L. (2005). Maternal knowledge of child development and quality of parenting among White, AfricanAmerican and Hispanic mothers. Journal of Applied Developmental Psychology, 26(2), 149-170. http://doi.org/10.1016/j.appdev.2004.12.001

Huttenlocher, P. (2002). Neural plasticity: The effects of the environment on the development of the cerebral cortex. London: Harvard University Press.

Iruka, I. U., Durden, T., \& Kennel, P. (2015). Changing faces: Parenting, culture, and child learning and development. Zero to Three, 35(4), 10.

Klass, P. E., Needlman, R., \& Zuckerman, B. (2003). The developing brain and early learning. Archives of Disease in Childhood, 88(8), 651-654. 
Kline, R. B. (2012). Assumptions in structural equation modeling. In R. Hoyle (Ed.), Handbook of structural equation modeling (pp. 111-125). New York: Guilford Press.

Kochanska, G. (2002). Mutually responsive orientation between mothers and their young children: A context for the early development of conscience. Current Directions in Psychological Science, 11(6), 191-195. Retrieved from http://cdp.sagepub.com/content/11/6/191.short

Kochanska, G., \& Kim, S. (2013). Difficult temperament moderates links between maternal responsiveness and children's compliance and behavior problems in low-income families: Temperament, parenting, socioemotional outcomes. Journal of Child Psychology and Psychiatry, 54(3), 323-332. http://doi.org/10.1111/jcpp.12002

Krushkal, J., Murphy, L. E., Palmer, F. B., Graff, J. C., Sutter, T. R., Mozhui, K., . . Adkins, R. A. (2014). Epigenetic analysis of neurocognitive development at 1 year of age in a community-based pregnancy cohort. Behavior Genetics, 44, 113 125. doi:10.1007/s10519-014-9641-2

Lanza, S. T., Rhoades, B. L., Greenberg, M. T., Cox, M., \& Family Life Project Key, I. (2011). Modeling multiple risks during infancy to predict quality of the caregiving environment: contributions of a person-centered approach. Infant Behavior and Development, 34(3), 390-406. doi:10.1016/j.infbeh.2011.02.002

Lavelli, M., \& Fogel, A. (2013). Interdyad differences in early mother-infant face-to-face communication: Real-time dynamics and developmental pathways. Developmental Psychology, 49(12), 2257-2271. doi:10.1037/a0032268

Lei, P.W., \& Wu, Q. (2007). Introduction to structural equation modeling: Issues and practical considerations. Instructional Topics in Educational Measurement, 33-43.

Lester, B. M. (2010). Transforming the research landscape. In B. M. Lester \& J. D. Sparrow (Eds.), Nurturing children and their families: Building on the legacy of T. Berry Brazelton (Kindle Edition). West Sussex, UK: Blackwell Publishing Ltd.

Luby, J., Belden, A., Botteron, K., Marrus, N., Harms, M. P., Babb, C., ... Barch, D. (2013). The effects of poverty on childhood brain development: The mediating effect of caregiving and stressful life events. Journal of American Medical Association Pediatrics, 167(12), 1135-1142. http://doi.org/10.1001/jamapediatrics.2013.3139

Lugo-Gil, J., \& Tamis-LeMonda, C. S. (2008). Family resources and parenting quality: Links to children's cognitive development across the first 3 years. Child Development, 79(4), 1065-1085. 
Lupien, S. J., King, S., Meaney, M. J., \& McEwen, B. S. (2000). Child's stress hormone levels correlate with mother's socioeconomic status and depressive state.

Biological Psychiatry, 48(10), 976-980. Retrieved from http://www.sciencedirect.com/science/article/pii/S0006322300009653

Lynn, M. R. (2015). Instrumentation: Development, testing, and revision. Chapel Hill, NC: University of North Carolina.

Mazzeschi, C., Pazzagli, C., Radi, G., Raspa, V., \& Buratta, L. (2015). Antecedents of maternal parenting stress: The role of attachment style, prenatal attachment, and dyadic adjustment in first-time mothers. Frontiers in Psychology, 6, 1-9 doi:10.3389/fpsyg.2015.01443

Monk, C., Spicer, J., \& Champagne, F. A. (2012). Linking prenatal maternal adversity to developmental outcomes in infants: The role of epigenetic pathways.

Development and Psychopathology, 24(04), 1361-1376.

doi:10.1017/S0954579412000764

Mooney-Doyle, K., Deatrick, J.A., \& Horowitz, J.A. (2015). Tasks and communication as an avenue to enhance parenting of children birth -5 years: An integrative review. Journal of Pediatric Nursing, 30(1), 184 - 207. doi:

10.1016/j.pedn.2014.03.002

Moore, G. A., Hill-Soderlund, A. L., Propper, C. B., Calkins, S. D., Mills-Koonce, W. R., \& Cox, M. J. (2009). Mother-infant vagal regulation in the face-to-face still-face paradigm is moderated by maternal sensitivity. Child Development, 80(1), 209223. Retrieved from http://onlinelibrary.wiley.com/doi/10.1111/j.1467$\underline{8624.2008 .01255 . \mathrm{x} / \mathrm{pdf}}$

Murray, L. (2014). The psychology of babies: How relationships support development from birth to two. London: Constable \& Robinson Ltd.

National Scientific Council on the Developing Child. (2004). Young children develop in an environment of relationships: Working Paper No. 1. Retrieved from http://www.developingchild.net

National Scientific Council on the Development Child. (2014). Excessive stress disrupts the architecture of the developing brain: Working paper No. 3. Retrieved from http://www.developingchild.net

National Scientific Council on the Developing Child (2007). The timing and quality of early experiences combine to shape brain architecture: Working paper no. 5. Retrieved from http://www.developingchild.net 
National Scientific Council on the Developing Child (2010). Early experiences can alter gene expression and affect long-term development: Working paper no. 10. Retrieved from http://www.developingchild.net

Noble, K. G., Houston, S. M., Brito, N. H., Bartsch, H., Kan, E., Kuperman, J. M., . . . Sowell, E. R. (2015). Family income, parental education and brain structure in children and adolescents. Nature Neuroscience, 18(5), 773-778. doi:10.1038/nn.3983

Nuttall, A. K., Valentino, K., \& Borkowski, J. G. (2012). Maternal history of parentification, maternal warm responsiveness, and children's externalizing behavior. Journal of Family Psychology, 26(5), 767-75. doi.org/10.1037/a0029470

Oberklaid, F., Baird, G., Blair, M., Melhuish, E., \& Hall, D. (2013). Children's health and development: Approaches to early identification and intervention. Archives of Disease in Childhood, 98(12), 1008-1011. doi.org/10.1136/archdischild-2013$\underline{304091}$

Oxford, M. L., \& Findlay, D. M. (2013). NCAST caregiver/parent-child interaction teaching manual. University of Washington, School of Nursing, Seattle: NCAST Programs.

Page, M., Wilhelm, M. S., Gamble, W. C., \& Card, N. A. (2010). A comparison of maternal sensitivity and verbal stimulation as unique predictors of infant socialemotional and cognitive development. Infant Behavior and Development, 33(1), 101-110. doi.org/10.1016/j.infbeh.2009.12.001

Palmer, F. B., Anand, K. J. S., Graff, J. C., Murphy, L. E., Qu, Y., Völgyi, E., ... Tylavsky, F. A. (2013). Early adversity, socioemotional development, and stress in urban 1-year-old children. The Journal of Pediatrics, 163(6), 1733-1739.e1731. doi:10.1016/j.jpeds.2013.08.030

Patterson, J. E., \& Vakili, S. (2014). Relationships, environment, and the brain: How emerging research is changing what we know about the impact of families on human development. Family Process, 53(1), 22-32. doi:10.1111/famp.12057

Pett, M.A, Lackey, N.R., \& Sullivan, J.J. (2003). Making sense of factor analysis: The use of factor analysis for instrument development in health care research. Thousand Oaks, California: Sage Publications.

Polit, D. F., \& Beck, C. T. (2012). Nursing research: Generating and assessing evidence for nursing practice (9th ed.). Philadelphia, PA: Lippincott Williams \& Wilkins.

Pridham, K. A., Lutz, K. F., Anderson, L. S., Riesch, S. K., \& Becker, P. T. (2010). Furthering the understanding of parent-child relationships: A nursing scholarship 
review series. Part 3: Interaction and the parent-child relationship - assessment and intervention studies. Journal for Specialists in Pediatric Nursing, 15(1), 3361. doi:10.1111/j.1744-6155.2009.00216.x

Raby, K. L., Roisman, G. I., Fraley, R. C., \& Simpson, J. A. (2015). The enduring predictive significance of early maternal sensitivity: Social and academic competence through age 32 years. Child Development, 86(3), 695-708. http://doi.org/10.1111/cdev.12325

Ransone, S. H., Graff, J. C., Oxford, M. L., Wicks, M. N., Archbold, K., \& Bush, A. J. (2016). Psychometrics of the nursing child assessment teaching (NCAT) scale in a community based sample. Manuscript in preparation, The University of Tennessee Health Science Center, Memphis, Tennessee.

R Core Team (2015). R: A language and environment for statistical computing. $\mathrm{R}$ Foundation for Statistical Computing, Vienna, Austria. URL http://www.Rproject.org/

Revelle, W. (2015). Psych: Procedures for personality and psychological research. Northwestern University, Evanston, Illinois, USA, http://CRAN.Rproject.org $/$ package $=$ psych. Version $=1.5 .8$.

Rhoades, B. L., Greenberg, M. T., Lanza, S. T., \& Blair, C. (2011). Demographic and familial predictors of early executive function development: Contribution of a person-centered perspective. Journal of Experimental Child Psychology, 108(3), 638-662. doi:10.1016/j.jecp.2010.08.004

Rizopoulos, D. (2006). ltm: An R package for latent variable modelling and item response theory analyses. Journal of Statistical Software, 17(5), 1-25. URL http://www.jstatsoft.org/v17/i05/

Rosner, B. (2010). Fundamentals of biostatistics (Seventh ed.). United States: Brooks/Cole Cengage Learning.

Rosseel, Y. (2012). Lavaan: An R package for structural equation modeling. Journal of Statistical Software, 48(2), 1-36. URL http://www.jstatsoft.org/v48/i02/.

Salisbury, A., Yanni, P., Lagasse, L., \& Lester, B. (2005). Maternal-fetal psychobiology: A very early look at emotional development. In J. Nadal \& D. Muir (Eds.), Emotional development (pp. 95-125). New York, NY: Oxford University Press Inc.

Sameroff, A. (2010). A unified theory of development: A dialectic integration of nature and nurture. Child Development, 81(1), 6-22. 
SemTools Contributors. (2015). SemTools: Useful tools for structural equation modeling. $\mathrm{R}$ package version 0.4-10. Retrieved from http://cran.rproject.org/package $=$ semTools

Schiffman, R. F., Omar, M. A., \& McKelvey, L. M. (2003). Mother-infant interaction in low income families. MCN: The American Journal of Maternal/Child Nursing, 28(4), 246-251.

Schlomer, G. L., Bauman, S. and Card, N. A. (2010). Best practices for missing data management in counseling psychology. Journal of Counseling Psychology, 57(1), $1-10$.

Shin, H., Park, Y.-J., Ryu, H., \& Seomun, G.-A. (2008). Maternal sensitivity: A concept analysis. Journal of Advanced Nursing, 64(3), 304-314. http://doi.org/10.1111/j.1365-2648.2008.04814.x

Shonkoff, J. P., Richter, L., van der Gaag, J., \& Bhutta, Z. A. (2012). An integrated scientific framework for child survival and early childhood development. Pediatrics, 129(2), e460-472. doi:10.1542/peds.2011-0366

Sparrow, J. (2013). Newborn behavior, parent-infant interaction, and developmental change processes: Research roots of developmental, relational, and systemstheory-based practice. Journal of Child and Adolescent Psychiatric Nursing, 26(3), 180-185. doi:10.1111/jcap.12047

The Department of Preventive Medicine. (2014). The CANDLE study. The University of Tennessee Health Sciences Center. Retrieved from http://candlestudy.com/research/research

The Urban Child Institute. (2013). Data book: The state of children in Memphis and Shelby County. Retrieved from http://www.urbanchildinstitute.org/resources/publications/

Tronick, E. Z. (1998). Dyadically expanded states of consciousness and the process of therapeutic change. Infant Mental Health Journal, 19(3), 290-299.

Tronick, E. Z. (2001). Emotional connections and dyadic consciousness in infant-mother and patient-therapist interactions: Commentary on paper by Frank M. Lachmann. Psychoanalytic Dialogues, 11(2), 187-194.

Tronick, E. Z. (2005). Why is connection with others so critical? The formation of dyadic states of consciousness and the expansion of individuals' states of consciousness: Coherence governed selection and the co-creation of meaning out of the messy meaning making. In J. Nadal \& D. Muir (Eds.), Emotional development (pp. 293315). New York, NY: Oxford University Press Inc. 
Tronick, E. Z. (2007). The role of culture in brain organization, child development, and parenting. In The neurobehavioral and social-emotional development of infants and children (Kindle). W.W. Norton \& Company Ltd.

Tronick, E. Z. (2010). Infants and mothers. In B. M. Lester \& J. D. Sparrow (Eds.), Nurturing children and families: Building on the legacy of T. Berry Brazelton. (Kindle Edition.). West Sussex, UK: Blackwell Publishing Ltd.

United States Census Bureau. (2011). American Community Survey. Retrieved from www.census.gov.

Van Puyvelde, M., Loots, G., Vinck, B., De Coster, L., Matthijs, L., Mouvet, K., \& Pattyn, N. (2013). The interplay between tonal synchrony and social engagement in mother-infant interaction. Infancy, 18(5), 849-872. Retrieved from http://www.scopus.com/inward/record.url?eid=2-s2.0$\underline{84882267608 \& \text { partnerID }=40 \& \mathrm{md} 5=0 \mathrm{a} 73 \mathrm{ecf} 8111 \mathrm{efda} 8 \mathrm{ce} 075 \mathrm{~d} 1021 \text { feedaa }}$

Völgyi, E., Carroll, K., Hare, M., Ringwald-Smith, K., Piyathilake, C., Yoo, W., \& Tylavsky, F. (2013). Dietary patterns in pregnancy and effects on nutrient intake in the mid-south: The conditions affecting neurocognitive development and learning in early childhood (CANDLE) study. Nutrients, 5(5), 1511-1530. doi:10.3390/nu5051511

Wachs, T. D., \& Bates, J. E. (2010). Temperment. In J. G. Bremner \& T. D. Wachs (Eds.), The Wiley-Blackwell handbook of infant development (2nd ed., Vol. 1, pp. 592-622). West Sussex, UK: Blackwell Publishing Ltd.

White-Traut, R., Norr, K. F., Fabiyi, C., Rankin, K. M., Li, Z., \& Liu, L. (2013). Motherinfant interaction improves with a developmental intervention for mother-preterm infant dyads. Infant Behavior and Development, 36(4), 694-706. http://doi.org/10.1016/j.infbeh.2013.07.004

Zaidman-Zait, A., Marshall, S. K., Young, R. A., \& Hertzman, C. (2014). Beyond compliance: Mother-child joint action during a "do" task. Journal of Child and Family Studies, 23(6), 1034-1049. doi:10.1007/s10826-013-9760-z

Brain Development. (2016). In ZERO TO THREE: National Center for Infants, Toddlers, and Families. Retrieved from https://www.zerotothree.org/early-learning/braindevelopment 


\section{APPENDIX A. TWO-PARAMETER ITEM RESPONSE THEORY DIFFICULTY AND DISCRIMINATION BY SUBSCALE FOR THE NURSING CHILD ASSESSMENT SATELLITE TRAINING DATABASE}

Table A-1. NCAST Sensitivity to Cues Subscale

\begin{tabular}{lcccc}
\hline Item & $\begin{array}{c}\text { Difficulty } \\
\text { Label }\end{array}$ & Difficulty & Discrimination & $\begin{array}{c}\text { Discrimination } \\
\text { Label }\end{array}$ \\
\hline 3 & & -1.98 & 3.07 & Very High \\
4 & -1.39 & 2.77 & Very High \\
5 & Hardest & -0.88 & 0.76 & Moderate \\
6 & & -1.66 & 0.63 & Low \\
7 & & -2.53 & 1.33 & Moderate \\
8 & & -1.38 & 1.17 & Moderate \\
9 & & -2.49 & 0.60 & Low \\
10 & & -2.75 & 0.59 & Low \\
11 & & -3.05 & 0.85 & Moderate \\
\hline
\end{tabular}

Table A-2. NCAST Response to Distress Subscale

\begin{tabular}{lcccc}
\hline Item & $\begin{array}{c}\text { Difficulty } \\
\text { Label }\end{array}$ & Difficulty & Discrimination & $\begin{array}{c}\text { Discrimination } \\
\text { Label }\end{array}$ \\
\hline 12 & & -1.69 & 2.08 & Very High \\
13 & -1.43 & 6.08 & Very High \\
14 & & -1.93 & 3.25 & Very High \\
15 & & -2.33 & 1.89 & Very High \\
16 & Hardest & -1.20 & 3.52 & Very High \\
18 & & -2.31 & 2.07 & Very High \\
20 & & -2.21 & 2.54 & Very High \\
22 & Easiest & -2.39 & 2.26 & Very High \\
\hline
\end{tabular}


Table A-3. NCAST Social Emotional Growth Fostering Subscale

\begin{tabular}{llccc}
\hline Item & $\begin{array}{c}\text { Difficulty } \\
\text { Label }\end{array}$ & Difficulty & Discrimination & $\begin{array}{c}\text { Discrimination } \\
\text { Label }\end{array}$ \\
\hline 23 & & -4.36 & 0.83 & Moderate \\
24 & & -1.04 & 0.37 & Low \\
25 & & -1.94 & 2.26 & Very High \\
26 & Hardest question & -0.62 & 0.93 & Moderate \\
27 & & -1.23 & 2.33 & Very High \\
28 & & -0.74 & 2.13 & Very High \\
29 & & -1.11 & 2.34 & Very High \\
30 & & -5.00 & 0.52 & Low \\
31 & & -4.44 & 0.65 & Moderate \\
33 & Easiest question & -5.08 & 0.54 & Moderate \\
\hline
\end{tabular}

Table A-4. NCAST Cognitive Growth Fostering Subscale

\begin{tabular}{lcccc}
\hline Item & $\begin{array}{c}\text { Difficulty } \\
\text { Label }\end{array}$ & Difficulty & Discrimination & $\begin{array}{c}\text { Discrimination } \\
\text { Label }\end{array}$ \\
\hline 34 & Easiest & -29.24 & 0.05 & Very Low \\
36 & & -1.81 & 1.20 & Moderate \\
37 & & -2.03 & 0.89 & Moderate \\
38 & Hardest & 0.25 & 1.32 & Moderate \\
39 & & -1.04 & 1.90 & Very High \\
40 & & -0.46 & 1.86 & Very High \\
41 & & -0.43 & 1.50 & High \\
42 & & -1.19 & 1.71 & Very High \\
43 & & -2.73 & 0.96 & Moderate \\
44 & & -0.82 & 1.78 & Very High \\
45 & & -1.58 & 1.46 & High \\
46 & & -1.42 & 1.33 & Moderate \\
47 & & -1.63 & 2.07 & Very High \\
48 & & -0.62 & 2.79 & Very High \\
49 & & -0.75 & 0.65 & Low \\
50 & & -5.98 & 0.35 & Low \\
\hline
\end{tabular}


Table A-5. NCAST Clarity of Cues Subscale

\begin{tabular}{lcccc}
\hline Item & $\begin{array}{c}\text { Difficulty } \\
\text { Label }\end{array}$ & Difficulty & Discrimination & $\begin{array}{c}\text { Discrimination } \\
\text { Label }\end{array}$ \\
\hline 54 & & -3.62 & 1.01 & Moderate \\
55 & Easiest & -8.00 & 0.39 & Low \\
57 & & -7.76 & 0.21 & Very Low \\
58 & & -0.22 & 1.61 & High \\
59 & Hardest & -0.08 & 2.70 & Very High \\
60 & & 0.56 & 3.62 & Very High \\
\hline
\end{tabular}

Table A-6. NCAST Response to Caregiver 1

\begin{tabular}{lcccc}
\hline Item & $\begin{array}{c}\text { Difficulty } \\
\text { Label }\end{array}$ & Difficulty & Discrimination & $\begin{array}{c}\text { Discrimination } \\
\text { Label }\end{array}$ \\
\hline 61 & Easiest & -1.79 & 1.60 & High \\
62 & & -0.69 & 2.09 & Very High \\
63 & -0.73 & 2.29 & Very High \\
64 & & -0.76 & 1.73 & Very High \\
65 & & -0.72 & 1.76 & Very High \\
66 & & -0.59 & 6.24 & Very High \\
67 & Hardest & -0.48 & 5.00 & Very High \\
\hline
\end{tabular}

Table A-7. NCAST Response to Caregiver 2

\begin{tabular}{lcccc}
\hline Item & $\begin{array}{c}\text { Difficulty } \\
\text { Label }\end{array}$ & Difficulty & Discrimination & $\begin{array}{c}\text { Discrimination } \\
\text { Label }\end{array}$ \\
\hline 68 & Hardest & 0.88 & 1.45 & High \\
69 & & 0.13 & 3.86 & Very High \\
70 & & 0.06 & 3.59 & Very High \\
71 & Easiest & -0.02 & 2.63 & Very High \\
72 & & 0.37 & 1.84 & Very High \\
73 & & 0.24 & 1.16 & Moderate \\
\hline
\end{tabular}




\section{APPENDIX B. REMOVED NURSING CHILD ASSESSMENT TEACHING SCALE ITEMS BY SUBSCALE FROM ANALYSIS WITH THE NURSING CHILD ASSESSMENT SATELLITE TRAINING DATABASE}

\begin{tabular}{|c|c|c|}
\hline Subscale & Item & Observation \\
\hline \multirow[t]{2}{*}{ Sensitivity to Cues } & 1 & CG positions child so child is safely supported. \\
\hline & 2 & $\begin{array}{l}\text { CG positions child so that child can reach and handle } \\
\text { teaching materials. }\end{array}$ \\
\hline \multirow[t]{3}{*}{$\begin{array}{l}\text { Response to } \\
\text { Distress }\end{array}$} & 17 & $\begin{array}{l}\text { CG diverts the child's attention by playing games, } \\
\text { introduces new toy. }\end{array}$ \\
\hline & 19 & CG avoids yelling at the child. \\
\hline & 21 & CG avoids slapping, hitting, or spanking. \\
\hline $\begin{array}{l}\text { Social-Emotional } \\
\text { Growth Fostering }\end{array}$ & 32 & CG avoids yelling at the child during the episode. \\
\hline $\begin{array}{l}\text { Cognitive Growth } \\
\text { Fostering }\end{array}$ & 35 & $\begin{array}{l}\text { CG focuses attention and child's attention on the task } \\
\text { during most of the teaching }(85 \%) \text {. }\end{array}$ \\
\hline \multirow[t]{4}{*}{ Clarity of Cues } & 51 & $\begin{array}{l}\text { Child is in the quiet alert state when task is first } \\
\text { presented. }\end{array}$ \\
\hline & 52 & $\begin{array}{l}\text { Child widens eyes and/or shows postural attention to task } \\
\text { situation. }\end{array}$ \\
\hline & 53 & $\begin{array}{l}\text { Child changes intensity or amount of motor activity when } \\
\text { task material is presented. }\end{array}$ \\
\hline & 56 & Child vocalizes while looking at the task materials \\
\hline
\end{tabular}

NOTE. $C G=$ Caregiver. The Nursing Child Assessment Teaching Scale Instrument. Oxford, M. L., \& Findlay, D. M. (2013). NCAST caregiver/parent-child interaction teaching manual. University of Washington, School of Nursing, Seattle: NCAST Programs. 


\section{APPENDIX C. TWO-PARAMETER ITEM RESPONSE THEORY DIFFICULTY AND DISCRIMINATION BY SUBSCALE FOR THE NURSING CHILD ASSESSMENT SATELLITE TRAINING DATABASE}

Table C-1. CANDLE Sensitivity to Cues Subscale

\begin{tabular}{lcccc}
\hline Item & $\begin{array}{c}\text { Difficulty } \\
\text { Label }\end{array}$ & Difficulty & Discrimination & $\begin{array}{c}\text { Discrimination } \\
\text { Label }\end{array}$ \\
\hline 3 & & -2.05 & 2.44 & Very High \\
4 & -2.00 & 1.61 & High \\
5 & Hardest & 0.46 & 0.79 & Moderate \\
6 & & -0.34 & 0.63 & Low \\
7 & & -2.42 & 1.17 & Moderate \\
8 & & -0.37 & 0.65 & Moderate \\
9 & & -1.57 & 0.51 & Low \\
10 & Easiest & -6.57 & 0.42 & Low \\
11 & & -2.52 & 0.42 & Low \\
\hline
\end{tabular}

Table C-2. CANDLE Response to Distress Subscale

\begin{tabular}{lcccc}
\hline Item & $\begin{array}{c}\text { Difficulty } \\
\text { Label }\end{array}$ & Difficulty & Discrimination & $\begin{array}{c}\text { Discrimination } \\
\text { Label }\end{array}$ \\
\hline 12 & & -1.72 & 0.97 & Moderate \\
13 & -0.89 & 3.04 & Very High \\
14 & & -1.33 & 3.53 & Very High \\
15 & Easiest & -4.27 & 0.80 & Moderate \\
16 & & -0.57 & 2.22 & Very High \\
17 & Hardest & 0.33 & 1.56 & High \\
18 & & -2.34 & 1.27 & Moderate \\
19 & & -2.45 & 2.01 & Very High \\
20 & & -2.13 & 2.18 & Very High \\
22 & & -2.88 & 1.48 & High \\
\hline
\end{tabular}


Table C-3. CANDLE Social Emotional Growth Fostering Subscale

\begin{tabular}{lcccc}
\hline Item & $\begin{array}{c}\text { Difficulty } \\
\text { Label }\end{array}$ & Difficulty & Discrimination & $\begin{array}{c}\text { Discrimination } \\
\text { Label }\end{array}$ \\
\hline 24 & & 0.06 & 0.42 & Low \\
25 & & -1.38 & 3.07 & Very High \\
26 & & -0.36 & 1.27 & Moderate \\
27 & & -1.45 & 2.67 & Very High \\
28 & & 0.28 & 1.57 & High \\
29 & Hardest & 0.45 & 0.92 & Moderate \\
30 & Easiest & -5.45 & 0.47 & Low \\
31 & & -3.96 & 0.77 & Moderate \\
33 & & -3.10 & 0.71 & Moderate \\
\hline
\end{tabular}

Table C-4. CANDLE Cognitive Growth Fostering Subscale

\begin{tabular}{lcccc}
\hline Item & $\begin{array}{c}\text { Difficulty } \\
\text { Label }\end{array}$ & Difficulty & Discrimination & $\begin{array}{c}\text { Discrimination } \\
\text { Label }\end{array}$ \\
\hline 34 & & -6.37 & 0.44 & Low \\
35 & & -3.65 & 1.01 & Moderate \\
36 & & -1.08 & 0.75 & Moderate \\
37 & -1.93 & 0.56 & Low \\
38 & & 1.47 & 1.51 & High \\
39 & & -0.79 & 1.29 & Moderate \\
40 & & -0.50 & 1.05 & Moderate \\
41 & & 0.23 & 0.82 & Moderate \\
43 & & -1.52 & 0.72 & Moderate \\
44 & & -0.03 & 1.73 & Very High \\
46 & & -2.66 & 0.93 & Moderate \\
47 & & -1.86 & 2.90 & Very High \\
48 & & -0.72 & 1.77 & Very High \\
49 & Hardest & 1.89 & 0.65 & Moderate \\
50 & Easiest & -10.20 & 0.13 & Very Low \\
\hline
\end{tabular}


Table C-5. CANDLE Clarity of Cues Subscale

\begin{tabular}{lcccc}
\hline Item & $\begin{array}{c}\text { Difficulty } \\
\text { Label }\end{array}$ & Difficulty & Discrimination & $\begin{array}{c}\text { Discrimination } \\
\text { Label }\end{array}$ \\
\hline 57 & Easiest & -3.47 & 0.48 & Low \\
58 & & 0.50 & 2.24 & Very High \\
59 & & 0.79 & 4.86 & Very High \\
60 & Hardest & 1.75 & 3.49 & Very High \\
\hline
\end{tabular}

Table C-6. CANDLE Response to Caregiver 1

\begin{tabular}{lcccc}
\hline Item & $\begin{array}{c}\text { Difficulty } \\
\text { Label }\end{array}$ & Difficulty & Discrimination & $\begin{array}{c}\text { Discrimination } \\
\text { Label }\end{array}$ \\
\hline 61 & Easiest & -1.36 & 3.48 & Very High \\
62 & & -0.40 & 2.76 & Very High \\
64 & & -3.41 & 0.77 & Moderate \\
67 & Hardest & -1.01 & 1.12 & Moderate \\
\hline
\end{tabular}

Table C-7. CANDLE Response to Caregiver 2

\begin{tabular}{lcccc}
\hline Item & $\begin{array}{c}\text { Difficulty } \\
\text { Label }\end{array}$ & Difficulty & Discrimination & $\begin{array}{c}\text { Discrimination } \\
\text { Label }\end{array}$ \\
\hline 68 & & 0.34 & 1.21 & Moderate \\
69 & Easiest & -1.58 & 1.92 & Very High \\
70 & Easiest & -1.58 & 2.11 & Very High \\
71 & & -0.15 & 2.59 & Very High \\
72 & Hardest & 0.65 & 3.78 & Very High \\
73 & & -1.26 & 0.67 & Moderate \\
\hline
\end{tabular}




\section{APPENDIX D. TWO-PARAMETER ITEM RESPONSE THEORY DIFFICULTY AND DISCRIMINATION BY SUBSCALE FOR THE NURSING CHILD ASSESSMENT SATELLITE TRAINING DATABASE}

\begin{tabular}{|c|c|c|}
\hline Subscale & Item & Observation \\
\hline \multirow[t]{2}{*}{ Sensitivity to Cues } & 1 & CG positions child so child is safely supported. \\
\hline & 2 & $\begin{array}{l}\text { CG positions child so that child can reach and } \\
\text { handle teaching materials. }\end{array}$ \\
\hline Response to Distress & 21 & CG avoids slapping, hitting, or spanking. \\
\hline \multirow[t]{2}{*}{$\begin{array}{l}\text { Social-Emotional } \\
\text { Growth Fostering }\end{array}$} & 23 & $\begin{array}{l}\text { CG's body posture is relaxed during the teaching } \\
\text { episode }(90 \%) \text {. }\end{array}$ \\
\hline & 32 & CG avoids yelling at the child during the episode. \\
\hline \multirow[t]{2}{*}{$\begin{array}{l}\text { Cognitive Growth } \\
\text { Fostering }\end{array}$} & 42 & $\begin{array}{l}\text { CG uses both verbal description and modeling } \\
\text { simultaneously in teaching any part of the task. }\end{array}$ \\
\hline & 45 & $\begin{array}{l}\text { CG smiles and/or nods at the child after child } \\
\text { performs better or more successfully than the last } \\
\text { attempt. }\end{array}$ \\
\hline \multirow[t]{6}{*}{ Clarity of Cues } & 51 & $\begin{array}{l}\text { Child is in the quiet alert state when task is first } \\
\text { presented. }\end{array}$ \\
\hline & 52 & $\begin{array}{l}\text { Child widens eyes and/or shows postural attention } \\
\text { to task situation. }\end{array}$ \\
\hline & 53 & $\begin{array}{l}\text { Child changes intensity or amount of motor activity } \\
\text { when task material is presented. }\end{array}$ \\
\hline & 54 & $\begin{array}{l}\text { Child's movements are clearly directed toward the } \\
\text { task or task material or away from the task material } \\
\text { (not diffuse). }\end{array}$ \\
\hline & 55 & $\begin{array}{l}\text { Child makes clearly recognizable arm movements } \\
\text { during the teaching episode (clapping, reaching, }\end{array}$ \\
\hline & 56 & $\begin{array}{l}\text { waving, pounding, pointing, pushing away). } \\
\text { Child vocalizes while looking at the task material. }\end{array}$ \\
\hline \multirow[t]{3}{*}{ Response to $\mathrm{CG}$} & 63 & $\begin{array}{l}\text { The child looks at the CG's face or eyes when CG } \\
\text { attempts to establish eye-to-eye contact. }\end{array}$ \\
\hline & 65 & $\begin{array}{l}\text { Child vocalizes or babbles within five seconds after } \\
\text { CG's gesturing, touching, } \\
\text { or changing of facial expression. }\end{array}$ \\
\hline & 66 & $\begin{array}{l}\text { Child smiles at CG within five seconds after CG's } \\
\text { verbalization. }\end{array}$ \\
\hline
\end{tabular}

NOTE. $\mathrm{CG}=$ Caregiver. The Nursing Child Assessment Teaching Scale Instrument. Oxford, M. L., \& Findlay, D. M. (2013). NCAST caregiver/parent-child interaction teaching manual. University of Washington, School of Nursing, Seattle: NCAST Programs. 


\section{VITA}

Samantha Helen Ransone, born 1986, received a Bachelor's of Science in Nursing degree from the University of Memphis in 2007. After seven years as a staff nurse in the pediatric intensive care unit (PICU), she became an extracorporeal life support coordinator and her curiosity led her to pursue a doctorate. Samantha's ten years of experience within the nursing profession includes working with the most critically ill neonatal and pediatric patients, promoting family-centered care, participating in multiple hospital councils, teaching undergraduate students during clinical rotations, and working with an interdisciplinary team in quality improvement and research relating to extracorporeal support devices.

Samantha has presented her research at local and national conferences, including Pediatric Research Day at Le Bonheur Children's Hospital, the Extracorporeal Life Support Organization's Annual Conference, and the Zero to Three National Teaching Institute. She will be presenting her work on early mobilization in pediatric critical care as a podium presentation in the upcoming 2017 American Association of Critical Care Nurses National Teaching Institute. Samantha has been nominated twice as nurse of the year and was named one of the top eleven nurses in Shelby and Fayette County, Tennessee in 2014. She holds multiple professional memberships including the Southern Nurses Research Society, the Extracorporeal Life Support Organization, the Society of Pediatric Nurses, and the American Association of Critical Care Nurses.

Samantha will receive her Doctor of Philosophy degree in Nursing Science in May of 2017. Her dissertation research focused on the influence of interactions in the maternal-child relationship during the first twelve months of life and child cognitive and language development at thirty-six months. Her dissertation research has already begun to influence her work in critical care as she continues to promote family-centered care and the interactions between parents and their critically ill children on extracorporeal life support devices. 